\title{
Vasodilators for women undergoing fertility treatment (Review)
}

Gutarra-Vilchez RB, Bonfill Cosp X, Glujovsky D, Viteri-García A, Runzer-Colmenares FM, Martinez-Zapata MJ

Gutarra-Vilchez RB, Bonfill Cosp X, Glujovsky D, Viteri-García A, Runzer-Colmenares FM, Martinez-Zapata MJ. Vasodilators for women undergoing fertility treatment.

Cochrane Database of Systematic Reviews 2018, Issue 10. Art. No.: CD010001.

DOI: 10.1002/14651858.CD010001.pub3.

www.cochranelibrary.com 
TABLE OF CONTENTS

HEADER 1

ABSTRACT

PLAIN LANGUAGE SUMMARY

SUMMARY OF FINDINGS

BACKGROUND

OBJECTIVES

METHODS

Figure 1.

Figure 2.

Figure 3.

RESULTS

Figure 4.

Figure 5.

Figure 6.

DISCUSSION

AUTHORS' CONCLUSIONS

ACKNOWLEDGEMENTS

REFERENCES

CHARACTERISTICS OF STUDIES

DATA AND ANALYSES

Analysis 1.1. Comparison 1 Vasodilator vs placebo or no treatment, Outcome 1 Live birth.

Analysis 1.2. Comparison 1 Vasodilator vs placebo or no treatment, Outcome 2 Vasodilator side effects.

Analysis 1.3. Comparison 1 Vasodilator vs placebo or no treatment, Outcome 3 Specific vasodilator side effects.

Analysis 1.4. Comparison 1 Vasodilator vs placebo or no treatment, Outcome 4 Clinical pregnancy.

Analysis 1.5. Comparison 1 Vasodilator vs placebo or no treatment, Outcome 5 Thickened endometrium.

Analysis 1.6. Comparison 1 Vasodilator vs placebo or no treatment, Outcome 6 Other adverse effects.

APPENDICES

WHAT'S NEW

CONTRIBUTIONS OF AUTHORS

DECLARATIONS OF INTEREST

SOURCES OF SUPPORT

DIFFERENCES BETWEEN PROTOCOL AND REVIEW

INDEX TERMS 
[Intervention Review]

\section{Vasodilators for women undergoing fertility treatment}

Rosa B Gutarra-Vilchez ${ }^{1}$, Xavier Bonfill Cosp², Demián Glujovsky³ ${ }^{3}$, Andres Viteri-García ${ }^{4}$, Fernando M. Runzer-Colmenares 5 , Maria José Martinez-Zapata2,6

1Faculty of Human Medicine, San Martin de Porres University, Lima, Peru. 2Iberoamerican Cochrane Centre, Biomedical Research Institute Sant Pau (IIB Sant Pau), CIBER Epidemiología y Salud Pública (CIBERESP), Barcelona, Spain. ${ }^{3}$ Reproductive Medicine, CEGYR (Centro de Estudios en Genética y Reproducción), Buenos Aires, Argentina. ${ }^{4}$ Cochrane Ecuador. Centro de Investigación en Salud Pública y Epidemiología Clínica (CISPEC). Facultad de Ciencias de la Salud Eugenio Espejo, Universidad Tecnológica Equinoccial, Quito, Ecuador. ${ }^{5}$ Research Institute, Faculty of Medicine, Universidad de San Martín de Porres, Lima, Peru. ${ }^{6}$ Cochrane Ecuador. Center for Research in Public Health and Clinical Epidemiology (CISPEC). Eugenio Espejo School of Health Sciences, Equinoccial Technological University, Quito, Ecuador

Contact address: Rosa B Gutarra-Vilchez, Faculty of Human Medicine, San Martin de Porres University, Alameda del Corregidor $N^{\circ} 1531$, Urb. Los Sirius, Etapa III, La Molina, Lima, Peru. dragutarra2@gmail.com.

Editorial group: Cochrane Gynaecology and Fertility Group.

Publication status and date: New search for studies and content updated (no change to conclusions), published in Issue 10, 2018.

Citation: Gutarra-Vilchez RB, Bonfill Cosp X, Glujovsky D, Viteri-García A, Runzer-Colmenares FM, Martinez-Zapata MJ. Vasodilators for women undergoing fertility treatment. Cochrane Database of Systematic Reviews 2018, Issue 10. Art. No.: CD010001. DOI: 10.1002/14651858.CD010001.pub3.

Copyright @ 2018 The Cochrane Collaboration. Published by John Wiley \& Sons, Ltd.

\section{A B S T R A C T}

\section{Background}

The rate of successful pregnancies brought to term has barely increased since the first assisted reproductive technology (ART) technique became available. Vasodilators have been proposed to increase endometrial receptivity, thicken the endometrium, and favour uterine relaxation, all of which could improve uterine receptivity and enhance the chances for successful assisted pregnancy.

\section{Objectives}

To evaluate the effectiveness and safety of vasodilators in women undergoing fertility treatment.

\section{Search methods}

We searched the following electronic databases, trial registers, and websites: the Cochrane Gynaecology and Fertility Group (CGF) Specialised Register of controlled trials, the Cochrane Central Register of of Controlled Trials, via the Cochrane Register of Studies Online (CRSO), MEDLINE, Embase, PsycINFO, the Cumulative Index to Nursing and Allied Health Literature (CINAHL), Web of Knowledge, the Open System for Information on Grey Literature in Europe (OpenSIGLE), the Latin American and Caribbean Health Science Information Database (LILACS), clinical trial registries, and the reference lists of relevant articles. We conducted the search in October 2017 and applied no language restrictions.

\section{Selection criteria}

Randomised controlled trials (RCTs) comparing vasodilators alone or in combination with other treatments versus placebo or no treatment or versus other agents in women undergoing fertility treatment.

\section{Data collection and analysis}

Four review authors independently selected studies, assessed risk of bias, extracted data, and calculated risk ratios (RRs). We combined study data using a fixed-effect model and assessed evidence quality using Grades of Recommendation, Assessment, Development and Evaluation Working Group (GRADE) methods. Our primary outcomes were live birth or ongoing pregnancy and vasodilator side effects. Secondary outcomes included clinical pregnancy, endometrial thickness, multiple pregnancy, miscarriage, and ectopic pregnancy. 


\section{Main results}

We included 15 studies with a total of 1326 women. All included studies compared a vasodilator versus placebo or no treatment. We judged most of these studies as having unclear risk of bias. Overall, the quality of evidence was low to moderate for most outcomes. The main limitations were imprecision due to low numbers of events and participants and risk of bias due to unclear methods of randomisation.

Vasodilators probably make little or no difference in rates of live birth compared with placebo or no treatment (RR $1.18,95 \%$ confidence interval (CI) 0.83 to 1.69; three RCTs; $N=350 ; I^{2}=0 \%$; moderate-quality evidence) but probably increase overall rates of side effects including headache and tachycardia (RR $2.35,95 \% \mathrm{Cl} 1.51$ to 3.66 ; four RCTs; $\mathrm{N}=418 ; \mathrm{I}^{2}=0 \%$; moderate-quality evidence). Evidence suggests that if 236 per 1000 women achieve live birth with placebo or no treatment, then between 196 and 398 per 1000 will do so with the use of vasodilators.

Compared with placebo or no treatment, vasodilators may slightly improve clinical pregnancy rates (RR $1.45,95 \% \mathrm{Cl} 1.19$ to $1.77 ; 11 \mathrm{RCTs}$; $\mathrm{N}=1054 ; \mathrm{I}^{2}=6 \%$; low-quality evidence). Vasodilators probably make little or no difference in rates of multiple gestation (RR $1.15,95 \% \mathrm{Cl}$ 0.55 to 2.42 ; three RCTs; $N=370 ; I^{2}=0 \%$; low-quality evidence), miscarriage (RR $0.83,95 \%$ Cl 0.37 to 1.86 ; three RCTs; $N=350 ; I^{2}=0 \% ;$ lowquality evidence), or ectopic pregnancy (RR $1.48,95 \% \mathrm{Cl} 0.25$ to 8.69 ; two RCTs; $\mathrm{N}=250 ; \mathrm{I}^{2}=5 \%$; low-quality evidence). All studies found benefit for endometrial thickening, but reported effects varied $\left(\mathrm{I}^{2}=92 \%\right)$ and ranged from a mean difference of $0.80 \mathrm{higher}(95 \% \mathrm{Cl} 0.18$ to $1.42)$ to 3.57 higher $(95 \% \mathrm{Cl} 3.01$ to 4.13$)$ with very low-quality evidence, so we are uncertain how to interpret these results.

\section{Authors' conclusions}

Evidence was insufficient to show whether vasodilators increase the live birth rate in women undergoing fertility treatment. However, low-quality evidence suggests that vasodilators may slightly increase clinical pregnancy rates. Moderate-quality evidence shows that vasodilators increase overall side effects in comparison with placebo or no treatment. Adequately powered studies are needed so that each treatment can be evaluated more accurately.

\section{PLAIN LANGUAGE SUMMARY}

\section{Vasodilators for women undergoing fertility treatment}

\section{Review question}

Researchers at Cochrane reviewed available evidence on the effects of vasodilators (drugs used to widen blood vessels) in women undergoing fertility treatment.

\section{Background}

For women undergoing fertility treatment for different causes, interventions aimed at improving the receptivity of the uterus are of utmost importance. Many different drugs have been evaluated, with the aim of increasing rates of implantation and live birth. These include vasodilating agents, which are used to dilate blood vessels to improve endometrial receptivity, thicken the endometrium, and favour uterine relaxation, among other effects.

\section{Study characteristics}

We found 15 randomised controlled trials (a type of experiment in which people are randomly allocated to one or more treatment groups) that compared the use of vasodilators versus placebo or no treatment in a total of 1326 women undergoing fertility treatment. The evidence is current to October 2017.

\section{Key results}

Only three of the included studies reported live birth rates. Overall, vasodilators probably make little or no difference in rates of live birth. Moderate-quality evidence shows that vasodilators probably increase overall rates of side effects (including headache and tachycardia (faster than normal heartbeat)) in comparison with placebo or no treatment. However, low-quality evidence suggests that vasodilators may increase the chance of becoming pregnant.

\section{Quality of the evidence}

The evidence is of low to moderate quality. More research is needed (one study is ongoing and will be incorporated into this review in a subsequent update). 


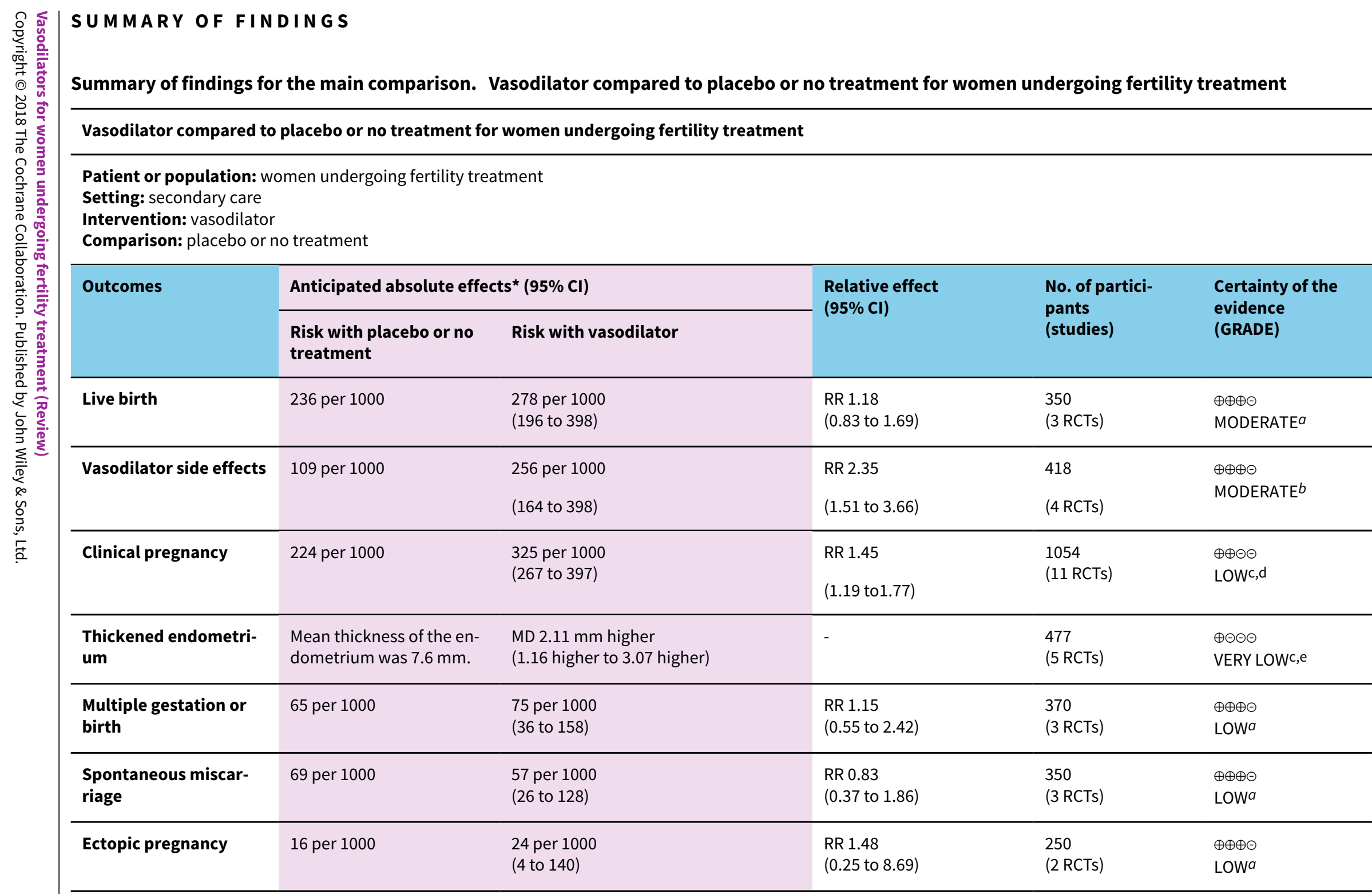

${ }^{\star}$ The risk in the intervention group (and its $95 \%$ confidence interval) is based on the assumed risk in the comparison group and the relative effect of the intervention (and its $95 \% \mathrm{Cl})$.

$\mathrm{Cl}$ : confidence interval; MD: mean difference; RCT: randomised controlled trial; RR: risk ratio. 


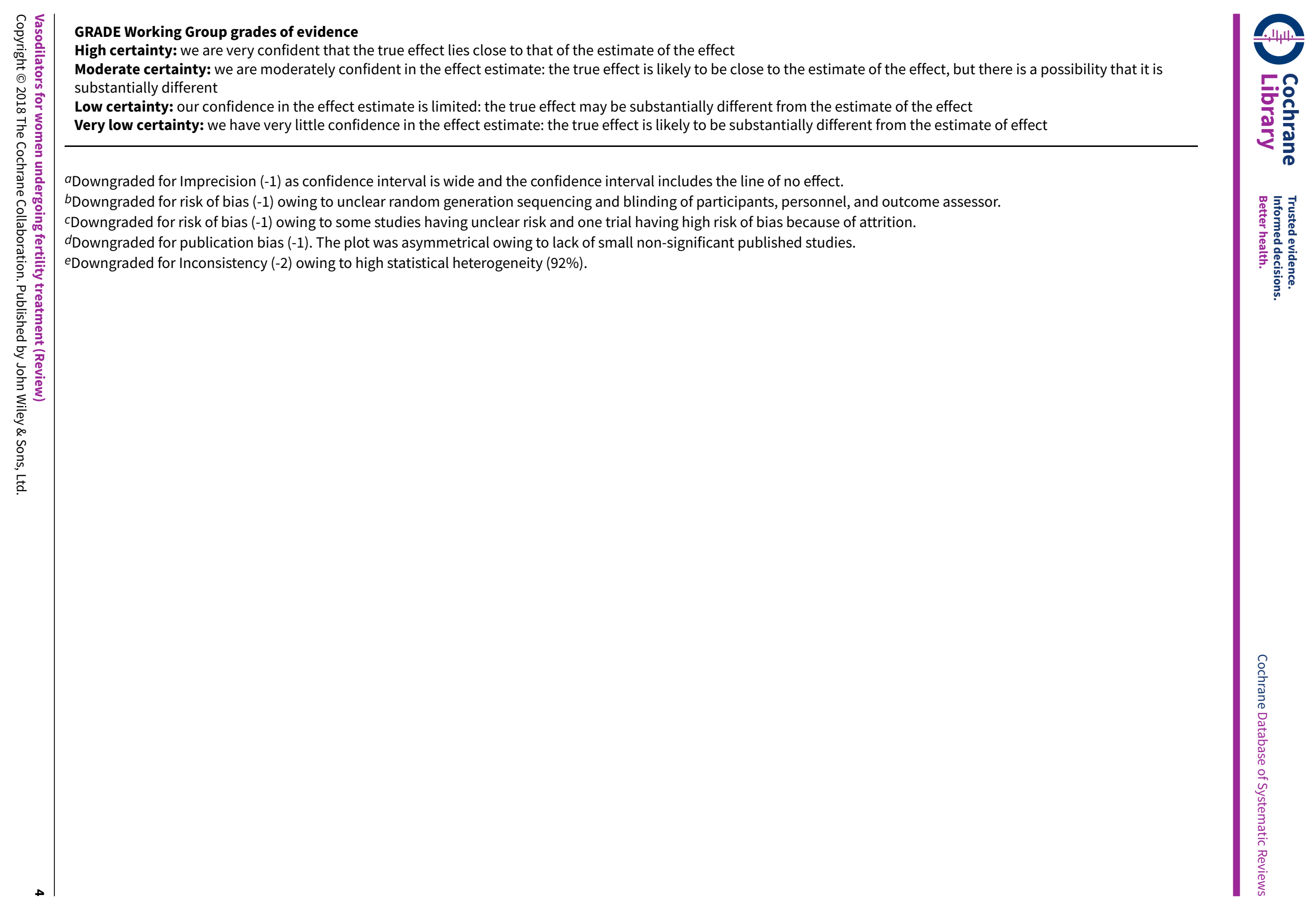




\section{B A C K G R O U N D}

\section{Description of the condition}

Between $0.2 \%$ and $4.7 \%$ of babies born in developed countries are conceived through techniques of assisted reproductive technology (ART) (Bouillon 2013; Sunderam 2012; Sunderam 2017). A total of $1,144,858$ babies were reported to have been born worldwide in 2008, 2009, and 2010 (Dyer 2016). Worldwide, ART practices are characterised by outcome differences between regions. By 2012-2013, fresh cycle live birth rates were highest in the United States (29\%) and lowest in Japan (5\%) (Kushnir 2017). In the 17 European countries that report the number of ART procedures, practitioners performed 374,177 ART cycles in a population of 310 million (1175 cycles per million). In these countries, the clinical pregnancy rates for in vitro fertilisation (IVF) per aspiration and per transfer were $29.6 \%$ and $34.5 \%$, respectively. Those for intracytoplasmic sperm injection (ICSI) were $27.8 \%$ and $32.9 \%$ (European IVF-Monitoring Consortium (EIM) 2017). Statistics have been very similar in recent years (de Mouzon 2012; ESHIRE 2016; Ferraretti 2012; Ferraretti 2013; Sullivan 2013).

According to the World Health Organization, medically assisted reproduction is defined as reproduction brought about through ovulation induction, controlled ovarian stimulation, ovulation triggering, insemination, and ART techniques (Zegers-Hochschild 2009; Zegers-Hochschild 2017). ART refers to "all treatments or procedures that include the in vitro handling of both human oocytes and sperm or of embryos for the purpose of establishing a pregnancy. This includes, but is not limited to, in vitro fertilization and embryo transfer, gamete intrafallopian transfer, zygote intrafallopian transfer, tubal embryo transfer, gamete and embryo cryopreservation, oocyte and embryo donation, and gestational surrogacy" (Zegers-Hochschild 2009; Zegers-Hochschild 2017). The success of assisted reproduction varies depending on several factors, such as maternal age (Marinakis 2011; Schmidt 2012; Yavas 2017), maternal weight (Cai 2017; Kawwass 2016; Pinborg 2011), the number of embryos transferred (Martin 2017; McLernon 2010), the use of gonadotrophins (Maheshwari 2011; Mochtar 2017; Pouwer 2015), inadequate endometrial thickness (Baradwan 2018; Oron 2018), uterine contractions (Chung 2017; Chung 2016), and others.

A thin endometrium (measured at $<8 \mathrm{~mm}$ by ultrasound scan) has a negative impact on the success of assisted reproduction (Check 2011; Eftekhar 2017); live births are possible despite thin endometria, but the pregnancy rate among these women is poor (Dix 2010; Kasius 2014). Investigators have expressed a marked interest in studying the role that the endometrium plays in the success of assisted reproduction (Casper 2011; Senturk 2008; Weiss 2017).

Uterine contractions influence embryo implantation, possibly through mechanical displacement of the embryo. Decreases in pregnancy rates and implantation rates were noted as the frequency of uterine contractions increased. Approaches aimed at inhibiting uterine contractions could improve pregnancy rates for assisted reproduction (Aguilar 2010; Bulletti 2006; Chung 2017; Fanchin 2001; Fanchin 2009; Lesny 1998; Ng 2014).

\section{Description of the intervention}

Different vasodilating agents have been proposed to thicken the endometrium and to favour uterine relaxation. Agents used in assisted reproduction include sildenafil, glyceryl trinitrate (GTN), nifedipine, amlodipine, pentoxifylline, and isosorbide monohydrate (Abdel 2017; Aleyasin 2009; Alieva 2012; Azmy 2016; Das 2009; Dehghani Firouzabadi 2013; El-Berry 2010; Fahmy 2015; Farzi 2005; Kim 2010; Magdi Ammar 2017; Mahran 2016; Mostafa 2003; Ohl 2002; Shaker 1993). Sildenafil (Viagra) is a phosphodiesterase-5-specific inhibitor that increases the vasodilatory effects of nitric oxide on vascular smooth muscle by preventing the degradation of cyclic guanosine monophosphate (cGMP). Studies report that vaginally administered sildenafil could lead to improvement in uterine blood flow (Fetih 2017; Sher 2002; Takasaki 2010;). Nitric oxide donors such as isosorbide monohydrate and GTN are used in assisted reproduction. Glyceryl trinitrate is also used medically as a vasodilator; in 2002 it was discovered that these effects occur because GTN is converted inside the body to nitric oxide by mitochondrial aldehyde dehydrogenase. Glyceryl trinitrate, which is available in the form of tablets, sprays, and patches, is used in assisted reproduction in an effort to improve pregnancy rates (Chen 2005). Acharya 2009 and Letur-Konirsch 2003 used pentoxifylline plus vitamin E in women undergoing assisted reproduction. Reports have described successful conception and pregnancy with nifedipine given at doses of $30 \mathrm{mg} / \mathrm{d}$ after secondary infertility (Wilson 1990).

\section{How the intervention might work}

Endometrial thickness varies with vascularity of the endometrium and the sub-endometrium, regardless of the concentration of oestradiol or progesterone (Raine-Fenning 2004). It is well known that some vasodilators, such as vaginal sildenafil citrate, can produce selective endometrial vasodilation: this occurred in two women with Asherman's syndrome (a condition characterised by the presence of adhesions or fibrosis, or both, within the uterine cavity). "These women achieved pregnancy in the first treatment cycle with vaginal sildenafil citrate" (Zinger 2006). Vasodilators also increase radial artery flow, improving the quality of the endometrium in women with a thin endometrium (Takasaki 2010). It has been observed in animal studies that sildenafil plays a role in both implantation and decidualisation (cellular changes in the endometrium in preparation for implantation of the embryo caused by the effects of progesterone) by affecting $\beta(3)$ integrins (which are cell membrane proteins) and vascular endothelial growth factor (VEGF) expression during the implantation period (Biyiksiz 2011).

In addition, we know that markers of endometrial receptivity are reduced during stimulated cycles compared with natural cycles (Chen 2008; Evans 2012; Revel 2012), and that vasodilators have an effect on amelioration of endometrial receptivity when used in combination with an ovarian hyperstimulation protocol (Biyiksiz 2011). A limited number of studies have reported enhanced endometrial development and increased implantation rates after administration of vasodilators (Sher 2002; Takasaki 2010; Zinger 2006). Glyceryl trinitrate at very low doses showed a significant inhibitory effect on human myometrium in vitro (Orth 2011; Wetzka 2001). Pentoxifylline may be beneficial in reducing hydrogen peroxide-induced embryo damage and improving outcomes of in vitro fertilisation (Zhang 2004). It also appears to improve the pregnancy rate among patients with a thin endometrium when combined with vitamin E (Acharya 2009; Lédée-Bataille 2002; Letur-Könirsch 2002). Nimodipine, which is a vasodilator calcium channel blocker, may prevent or delay the luteinising 
hormone (LH) surge during controlled ovarian stimulation cycles when clomiphene citrate is used in sub-fertile patients undergoing assisted reproduction by intrauterine insemination (Penzias 2012).

\section{Why it is important to do this review}

Several randomised controlled trials (RCTs) have studied the efficacy of different treatments (gonadotrophin-releasing hormone $(\mathrm{GnRH})$ agonist, progesterone, aspirin, steroids, human chorionic gonadotrophin (hCG), vitamin E, cytokines, and vasodilators) in endometrial preparation for women undergoing assisted reproduction (Aleyasin 2009; Eftekhar 2017; Gelbaya 2005; Glujovsky 2010; Kim 2010; Lensen 2016; Ohl 2002; Shaker 1993; Torres 2005). However, evidence is insufficient to allow investigators to endorse a particular protocol for endometrial preparation.

Researchers have only partially studied the effects of vasodilators on endometrial preparation in fertility treatment. Their role in implantation, decidualisation, and uterine relaxation, among other events, has not been evaluated. A previous systematic review assessed different treatments for endometrial preparation for embryo transfer but excluded the comparison of vasodilators versus other treatments (Glujovsky 2010). Instead, the effectiveness of these treatments remains unproven, and this could potentially increase incrementally costs or side effects involved in assisted reproduction. Studies are needed to identify and assess the efficacy and safety of vasodilators used with or without other agents, or compared with placebo or other agents, in women undergoing fertility treatment.

\section{OB JECTIVES}

To evaluate the effectiveness and safety of vasodilators in women undergoing fertility treatment.

\section{METHODS}

\section{Criteria for considering studies for this review}

\section{Types of studies}

We included randomised controlled trials (RCTs).

- We excluded cross-over trials, as the design is not valid in this context.

\section{Types of participants}

We considered women undergoing fertility treatment, regardless of the thickness of the endometrium. We applied no restrictions on age or comorbidities.

For the purposes of this review, fertility treatment means medically assisted reproduction, such as ovulation induction; controlled ovarian stimulation; ovulation triggering; assisted reproductive technology procedures; and intrauterine, intracervical, and intravaginal insemination with the semen of husband, partner, or donor (Zegers-Hochschild 2009; Zegers-Hochschild 2017).

\section{Types of interventions}

We planned to include vasodilators (nifedipine, nimodipine, pentoxifylline, nitric oxide donors such as GTN and isosorbide mononitrate, and sildenafil, among others) administered via any route, with or without other agents (oestrogen or tocopherol vitamin E) compared with placebo or no treatment or any other active intervention (progesterone, oestrogen, or other).

\section{Types of outcome measures}

\section{Primary outcomes}

1. Live birth or ongoing pregnancy

2. Vasodilator side effects: hypotension, headache, tachycardia, or other effects related to vasodilators, as defined by primary study authors

\section{Secondary outcomes}

1. Clinical pregnancy

2. Thickened endometrium (reported as dichotomous or continuous data)

3. Other adverse events: multiple gestation or birth, spontaneous miscarriage, ectopic pregnancy

\section{Definitions of terms}

Terms were defined as follows.

1. Live birth: the complete expulsion or extraction from a woman of a product of fertilisation after 22 completed weeks' gestation, which, after such separation, breathes or shows any other evidence of life, such as heartbeat, umbilical cord pulsation, or definitive movement of voluntary muscles, irrespective of whether the umbilical cord has been cut or the placenta is attached. A birth weight of 500 grams or more can be used if gestational age is unknown. 'Live birth' refers to the individual newborn, for example, a twin delivery represents two live births (Zegers-Hochschild 2017).

a. Ongoing pregnancy is defined as evidence of a gestational sac with foetal heart motion at 12 weeks, confirmed by ultrasound.

2. Clinical pregnancy: a pregnancy diagnosed by ultrasonographic visualisation of one or more gestational sacs or definitive clinical signs of pregnancy. In addition to intrauterine pregnancy, this includes a clinically documented ectopic pregnancy (Zegers-Hochschild 2017).

3. Thickened endometrium: an endometrium that measures 8 $\mathrm{mm}$ or greater, as determined by ultrasound scan.

4. Multiple gestation or birth: a pregnancy that involves more than one embryo or fetus (Zegers-Hochschild 2017).

5. Spontaneous abortion or miscarriage: the spontaneous loss of an intrauterine pregnancy before 22 completed weeks' gestation (Zegers-Hochschild 2017).

6. Ectopic pregnancy: a pregnancy outside the uterine cavity diagnosed by ultrasound, surgical visualisation, or histopathology (Zegers-Hochschild 2017).

\section{Search methods for identification of studies}

We searched for all published and unpublished RCTs of vasodilators in fertility treatment, without language restriction and in consultation with the Cochrane Gynaecology and Fertility Group (CGFG) Information Specialist.

\section{Electronic searches}

For this update, we searched the following databases, trial registers, and websites in October 2017. 
1. Cochrane Gynaecology and Fertility Group (CGFG) Specialised Register of Controlled Trials; PROCITE platform (searched 24 October 2017) (Appendix 1).

2. Cochrane Central Register of Controlled Trials, via the Cochrane Register of Studies Online (CRSO Web platform) (searched 24 October 2017) (Appendix 2).

3. MEDLINE: Epub Ahead of Print, In-Process \& Other Non-Indexed Citations, Ovid (searched from 1946 to 24 October 2017) (Appendix 3).

4. Embase: Ovid (searched from 1980 to 24 October 2017) (Appendix 4).

5. PsycINFO: Ovid (searched from 1806 to 24 October 2017) (Appendix 5).

6. Cumulative Index to Nursing and Allied Health Literature (CINAHL) EBSCO platform (searched from 1982 to 24 October 2017) (Appendix 6).

7. Other electronic sources of trials, including:

a. clinical trial registries for ongoing and registered trials, including:

i. http://www.clinicaltrials.gov (a service of the US National Institutes of Health); and

ii. http://www.who.int/trialsearch/Default.aspx (World Health Organization International Trials Registry Platform search portal).

8. Latin American Caribbean Health Sciences Literature (LILACS) and other Spanish/Portuguese language databases (searched 24 October 2017), including:

a. those found in the Virtual Health Library Regional Portal (VHL), at http://bvsalud.org/portal/?lang=en .

9. The Cochrane Library, at http://www.cochrane.org/index.htm.
10.Conference abstracts in the Web of Knowledge, at http:// wokinfo.com/.

11.OpenSigle for Grey Literature from Europe, at http:// opensigle.inist.fr/.

12.PubMed and Google Scholar (for recent trials not yet indexed in the major databases)

\section{Searching other resources}

We reviewed the reference lists of articles retrieved by the aforementioned search. We contacted experts in the field to request additional data. We handsearched conference abstracts of the International Federation of Gynaecology and Obstetrics (FIGO) World Congress from 1985, 1988, 1991, 1994, 1997, 2000, 2003, 2006, 2009,2012 , and 2015, and we checked the references of relevant identified systematic reviews.

\section{Data collection and analysis}

\section{Selection of studies}

We performed the pertinent statistical analysis in accordance with the guidelines for statistical analysis developed by Cochrane. Review authors (RG or DG and MJM or AV) independently examined titles and abstracts retrieved through the search and determined whether studies met review inclusion criteria. For studies with potential or unclear eligibility, we obtained the full text of the article for independent assessment. If needed, we contacted study investigators to clarify study eligibility. We resolved disagreements by discussion and consensus with a third review author (DG or XB). We documented the selection process in a PRISMA (Preferred Reporting Items for Systematic Reviews and Meta-Analyses) flow chart (Figure 1). 
Figure 1. Flow of information through different phases of the systematic review.

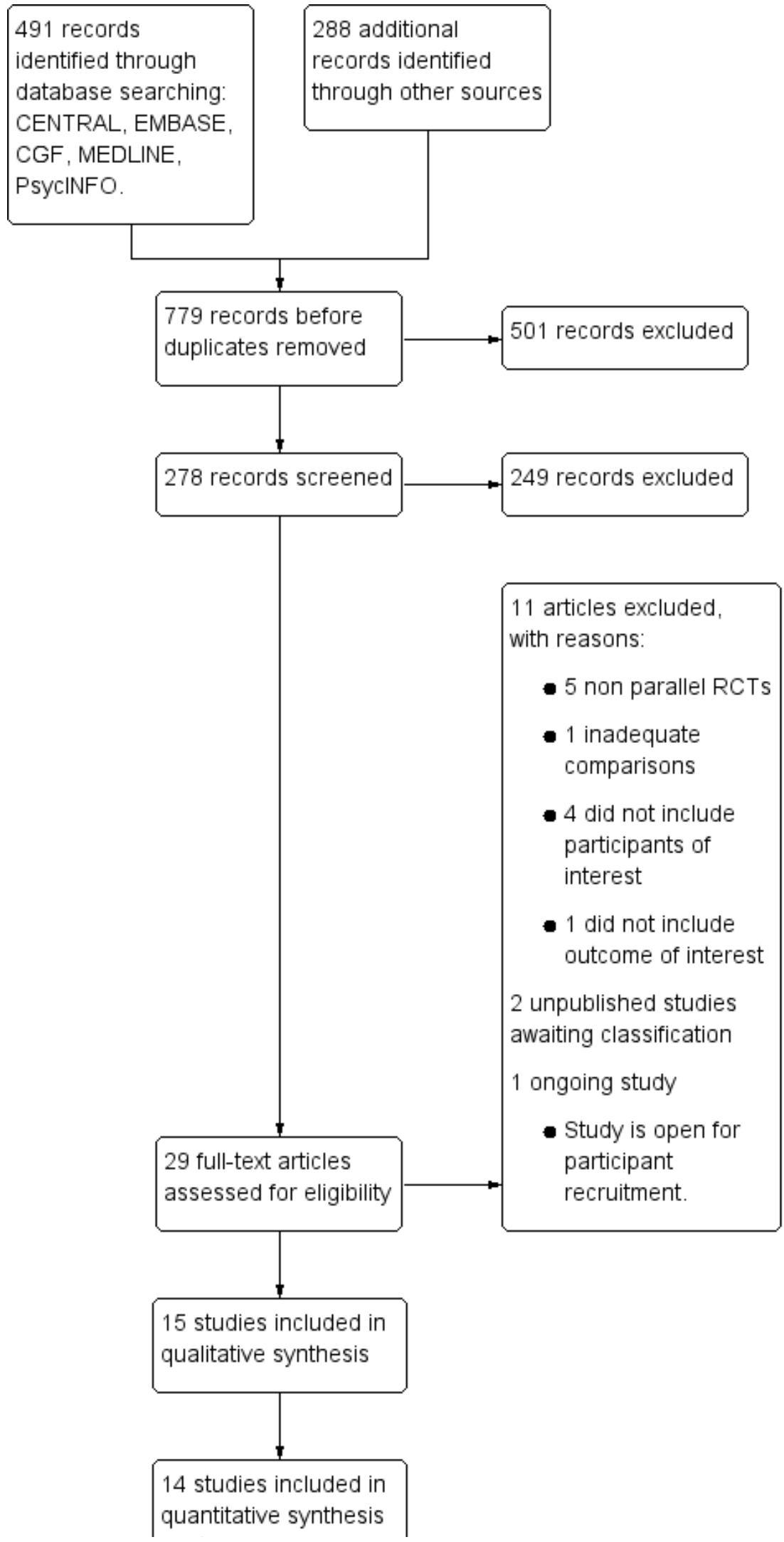


Figure 1. (Continued)

$$
\begin{aligned}
& \text { quantitative synthesis } \\
& \text { (meta-analysis) } \\
& \text { including } 5 \text { added at } \\
& \text { this update }
\end{aligned}
$$

\section{Data extraction and management}

Review authors (RG or FR and MJM or AV) independently extracted data from eligible studies using a data extraction form designed and pilot-tested by the review authors. We resolved disagreements by discussion and consensus with a third review author (DG or XB). Data extracted included study characteristics, methods, and outcome data. When a study had multiple publications, we used the main trial report for reference purposes and derived additional details from secondary papers. We contacted the original study authors if we needed further information. For multi-arm studies, we excluded data from arms that did not meet review eligibility criteria.

\section{Assessment of risk of bias in included studies}

Review authors (RG or FR and MJM or AV) independently assessed the included studies for risk of bias using Cochrane's 'Risk of bias' assessment tool (Higgins 2011). We assessed allocation (random sequence generation and allocation concealment), blinding of participants and personnel, incomplete outcome data, selective reporting, and other biases. We resolved disagreements by discussion and consensus with a third review author. We fully described all judgements and presented conclusions in the 'Risk of bias' table (Figure 2; Figure 3), which we incorporated into our interpretation of review findings by performing sensitivity analyses (see below).

We assessed whether evidence suggested within-trial selective reporting, including failure to report obvious outcomes or insufficient reporting of outcomes. We searched published protocols to compare outcomes versus those of the corresponding published studies. When a study failed to report live births but did report interim outcomes such as pregnancy, we undertook an informal assessment to determine whether interim values (e.g. clinical pregnancy) were similar to those reported in studies that also reported live births.

\section{Figure 2. Risk of bias graph: review authors' judgements about each risk of bias item presented as percentages across all included studies.}

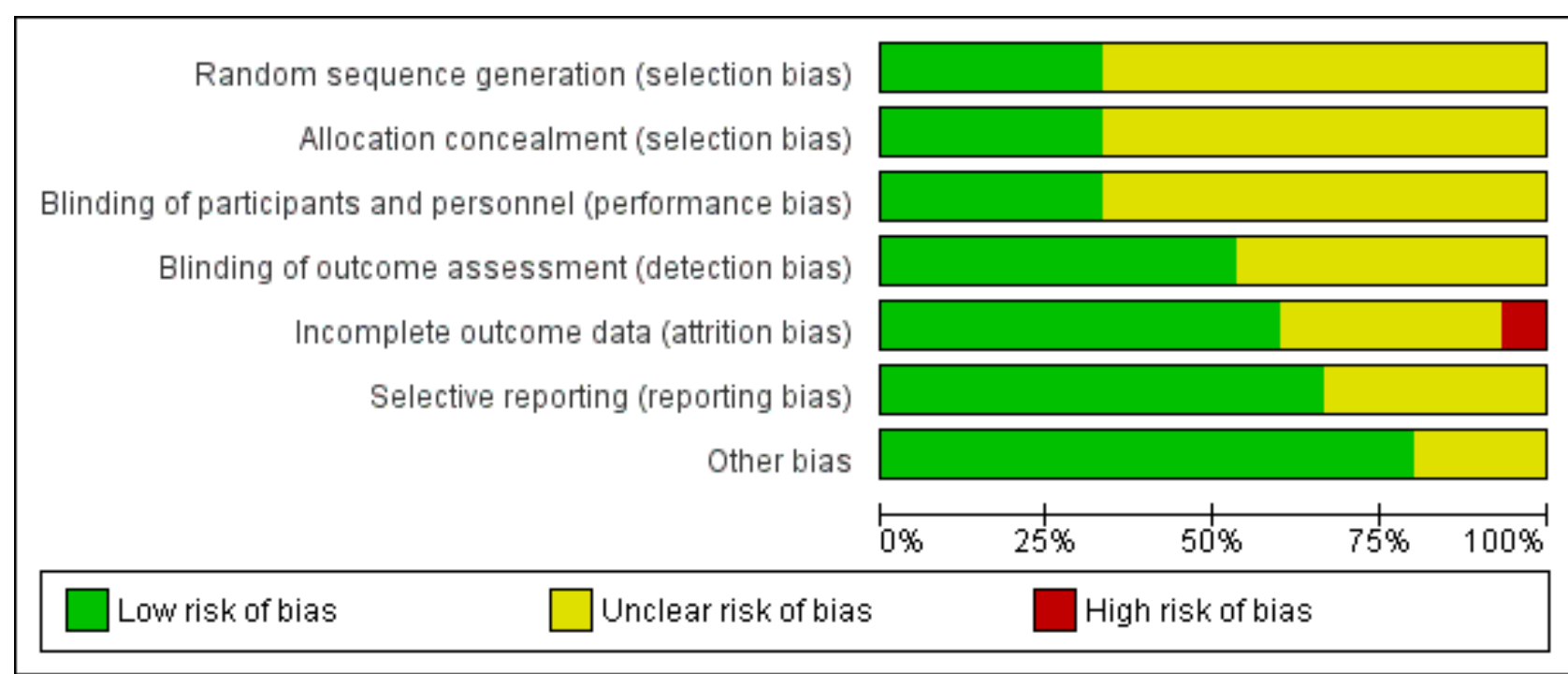


Figure 3. Risk of bias summary: review authors' judgements about each risk of bias item for each included study.

\begin{tabular}{|c|c|c|c|c|c|c|c|}
\hline & 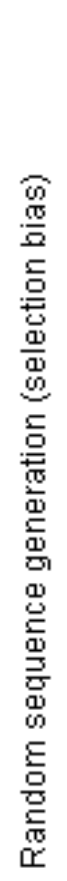 & 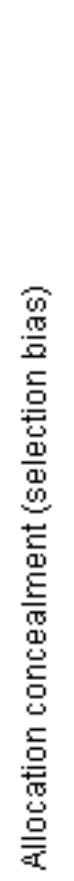 & 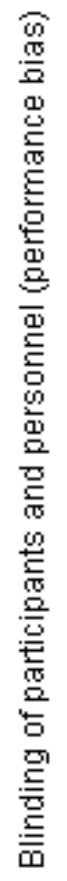 & 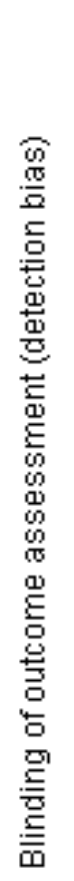 & 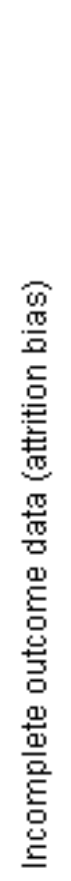 & 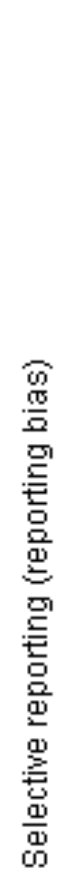 & 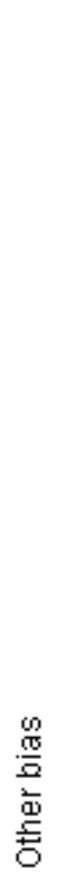 \\
\hline Abdel 2017 & + & + & 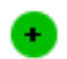 & + & + & + & + \\
\hline Aleyasin 2009 & 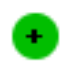 & $\odot$ & $\odot$ & $\odot$ & 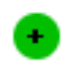 & 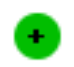 & $\odot$ \\
\hline Alieva 2012 & $?$ & $?$ & $?$ & $?$ & $?$ & $?$ & $?$ \\
\hline Azmy 2016 & $?$ & $?$ & $?$ & $?$ & $?$ & + & $?$ \\
\hline Das 2009 & $?$ & $?$ & $?$ & + & $\oplus$ & $?$ & $\oplus$ \\
\hline Dehghani Firouzabadi 2013 & 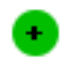 & $?$ & $?$ & + & + & + & $\oplus$ \\
\hline El-Berry 2010 & $?$ & $?$ & $?$ & + & $?$ & $?$ & $\oplus$ \\
\hline Fahmy 2015 & $?$ & + & $?$ & $?$ & + & + & $\oplus$ \\
\hline Farzi 2005 & $?$ & $?$ & + & + & $\oplus$ & $\oplus$ & $\oplus$ \\
\hline Kim 2010 & $?$ & $?$ & $?$ & + & + & $?$ & $\oplus$ \\
\hline Magdi Ammar 2017 & + & $?$ & $?$ & $?$ & - & + & + \\
\hline Mahran 2016 & $?$ & + & $?$ & $?$ & $?$ & + & + \\
\hline Mostafa 2003 & $?$ & $?$ & $?$ & $?$ & $?$ & $?$ & $?$ \\
\hline Ohl 2002 & $\oplus$ & + & + & + & + & + & $\oplus$ \\
\hline Shaker 1993 & $?$ & $?$ & + & $?$ & + & + & + \\
\hline
\end{tabular}




\section{Measures of treatment effect}

For dichotomous data (e.g. live births), we calculated risk ratios (RRs) using the numbers of events in control and intervention groups of each study. We presented $95 \%$ confidence intervals $(\mathrm{Cls})$ for all outcomes. When data were not available to calculate RRs, we used the most detailed available numerical data that could be used to complete similar analyses (e.g. test statistics, P value). We compared the magnitude and direction of effect reported by studies against the way in which they are presented in the review, while taking account of legitimate differences. For continuous data, we calculated the mean difference (MD) with $95 \% \mathrm{Cl}$.

\section{Unit of analysis issues}

We conducted all analyses per woman randomly assigned. When data did not allow valid analyses (e.g. "per cycle" data), we contacted study authors to request "per woman" data. If available data could not be analysed, we planned to summarise the data briefly in an additional table without meta-analysis. We counted multiple live births (e.g. twins, triplets) as a single live birth event.

\section{Dealing with missing data}

We analysed data on an intention-to-treat basis. We attempted to obtain missing data from the original researchers. We asked trial authors via email or telephone to provide further details. We planned to impute individual values for missing data for any of the primary outcomes, but no study with data for primary outcomes presented important attrition bias.

\section{Assessment of heterogeneity}

We determined whether clinical and methodological characteristics of included studies were sufficiently similar for meta-analysis to provide a clinically meaningful summary. We assessed statistical heterogeneity by using the $\mathrm{I}^{2}$ statistical measure. We considered an $\mathrm{I}^{2}$ value greater than $50 \%$ to show evidence of substantial heterogeneity (Higgins 2003). When we detected substantial heterogeneity, we explored possible explanations via corresponding analyses. We took statistical heterogeneity into account when interpreting the results.

\section{Assessment of reporting biases}

If all eligible studies were not retrieved, the review may be biased. The review authors have tried to minimise the potential impact of publication and other reporting biases by ensuring a comprehensive search for eligible studies and by remaining alert to data duplication. If more studies had been included in an analysis, we would have used a funnel plot to explore the possibility of smallstudy effects (i.e. the tendency for estimates of the intervention effect to be more beneficial in smaller studies).

\section{Data synthesis}

When we judged studies to be sufficiently similar, we combined data using a fixed-effect model for the following comparisons.
1. Vasodilator (with or without an additional intervention) versus placebo or no treatment.

a. Glyceryl trinitrate (GTN).

b. Isosorbide mononitrate (ISMN or IMN).

c. Sildenafil.

d. Amlodipine.

e. Tadalafil.

f. Pentoxifylline (PTX) and vitamin E.

g. Sildenafil and oestradiol.

2. Vasodilator (with or without an additional intervention) versus active intervention.

a. Stratified by type of vasodilator.

\section{Subgroup analysis and investigation of heterogeneity}

If data had been available, we would have conducted subgroup analyses to examine separate evidence within the following subgroups.

1. Studies in women with thin endometrium $(<8 \mathrm{~mm})$ undergoing fertility treatment.

2. Studies in women with normal endometrial thickness undergoing fertility treatment.

3. Studies including different routes of administration.

4. Studies with and without co-interventions.

We also performed a post hoc subgroup analysis to evaluate studies that used only vasodilators versus no co-intervention (vitamin E, oestrogen).

\section{Sensitivity analysis}

We conducted sensitivity analyses for the primary outcomes to determine whether conclusions were robust enough to withstand arbitrary decisions regarding eligibility and analysis of included studies.

These analyses required consideration of whether the review conclusions would have differed if we had adopted a randomeffects model.

\section{Overall quality of the body of evidence - 'Summary of findings' table}

We prepared a 'Summary of findings' table using GRADEpro and Cochrane methods (GRADEpro GDT 2014; Higgins 2011). This table presents overall quality of the body of evidence for the review outcomes live birth or ongoing pregnancy, vasodilator side effects, clinical pregnancy, thickened endometrium, multiple gestation, spontaneous miscarriage, and ectopic pregnancy for the main review comparison (vasodilator vs placebo or no treatment). We assessed the quality of evidence using GRADE criteria: risk of bias, consistency of effect, imprecision, indirectness, and publication bias. Two review authors (MJM and AV) working independently judged evidence quality (high, moderate, low, or very low) and resolved disagreements by discussion. We justified, documented, and incorporated judgements into reporting of results for each outcome. 


\section{RESULTS}

\section{Description of studies}

\section{Results of the search}

Through the search, we retrieved 779 articles. A total of 29 studies were potentially eligible, and we retrieved those full texts. Fifteen studies met the inclusion criteria of this review (Abdel 2017; Aleyasin 2009; Alieva 2012; Azmy 2016; Das 2009; Dehghani Firouzabadi 2013; El-Berry 2010; Fahmy 2015; Farzi 2005; Kim 2010; Magdi Ammar 2017; Mahran 2016; Mostafa 2003; Ohl 2002; Shaker 1993). We excluded 11 studies (Alborzi 2007; Ataalla 2016; Balasch 1997; Check 2004; Creus 2008; Kamencic 2008; Malinova 2013; Raine-Fenning 2009; Rosen 1987; Sher 2000; Shin 2002); two studies are awaiting classification (Casper 2013; Penzias 2012); and one study is ongoing (NCT02072291).

For further information, see the following tables: Characteristics of included studies; Characteristics of excluded studies; Characteristics of studies awaiting classification; and Characteristics of ongoing studies.

See Figure 1 (PRISMA study screening and selection flow chart) for details of this process.

\section{Included studies}

\section{Study design and setting}

We included in this review 15 randomised controlled trials (RCTs) with a parallel design (Abdel 2017; Aleyasin 2009; Alieva 2012; Azmy 2016; Das 2009; Dehghani Firouzabadi 2013; El-Berry 2010; Fahmy 2015; Farzi 2005; Kim 2010; Magdi Ammar 2017; Mahran 2016; Mostafa 2003; Ohl 2002; Shaker 1993). Publication dates for the included studies ranged from 1993 to 2017. Most studies were conducted at hospital clinics for infertility.

\section{Participants}

We included in this review 15 studies with a total of 1326 women.

The studies included 690 women in the intervention groups and 636 in the control groups. Mean participant age was $31.50( \pm 4.92)$ years. Four trials included women with a 'poor prognosis' (i.e. infertile women with a thin endometrium or an antecedent of poor endometrial response, or with a history of two or more previous implantation failures) (Das 2009; Dehghani Firouzabadi 2013; Kim 2010; Ohl 2002). Eleven trials included women with a 'good prognosis' (i.e. women without a previous history of failure of zygote intrafallopian transfer (ZIFT) or in vitro fertilisation (IVF), or women with unexplained infertility, or women with infertility and with regular menstrual cycles, or women who had received a diagnosis of polycystic ovarian syndrome) (Abdel 2017; Aleyasin 2009; Alieva 2012; Azmy 2016; El-Berry 2010; Fahmy 2015; Farzi 2005; Magdi Ammar 2017; Mahran 2016; Mostafa 2003; Shaker 1993). Eight of the 15 studies were performed in women undergoing ART (Aleyasin 2009; Alieva 2012; Dehghani Firouzabadi 2013; Farzi 2005; Kim 2010; Mostafa 2003; Ohl 2002; Shaker 1993), one was performed in women undergoing artificial insemination (Das 2009), and six involved ovulation induction (Abdel 2017; Azmy 2016; ElBerry 2010; Fahmy 2015; Magdi Ammar 2017; Mahran 2016).

\section{Interventions}

Vasodilators used in these studies included pentoxifylline $400 \mathrm{mg}$ twice daily + tocopherol vitamin E $400 \mathrm{mg}$ twice daily 2 cycles before starting ZIFT cycle until the $\beta$-hCG became positive or the cycle was cancelled (Aleyasin 2009); nitric oxide donors (isosorbide mononitrate (ISMN)) $20 \mathrm{mg}$ vaginally until diagnosis of ovulation and pregnancy (El-Berry 2010); isosorbide mononitrate (IMN) $10 \mathrm{mg}$ vaginal tablets from cycle day 5 to 9 (Abdel 2017); $10 \mathrm{mg}$ isosorbide mononitrate (ISMN) tablets applied vaginally from day 2 to day 15 of the cycle or $20 \mathrm{mg}$ ISMN tablets applied vaginally from day 2 to day 15 of the cycle (Mahran 2016); glyceryl trinitrate (GTN) 0.4 $\mathrm{mg}$ oral dose 15 minutes before fresh ET (Farzi 2005); sildenafil citrate tablets $(50 \mathrm{mg}$ ) daily (from first day of cycle until day progesterone was started) (Dehghani Firouzabadi 2013); sildenafil $25 \mathrm{mg}$ vaginally 4 times a day from day 5 of cycle until day of hCG administration (Das 2009); sildenafil citrate $25 \mathrm{mg}$ orally 3 times/d from seventh to 11th day of cycle (Fahmy 2015); amlodipine (Azmy 2016); tadalafil oral $5 \mathrm{mg} / \mathrm{d}$ for 7 days (from fourth day until 10th day of the cycle) (Magdi Ammar 2017); vaginal sildenafil $25 \mathrm{mg} / \mathrm{d}+$ oral oestradiol valerate $4 \mathrm{mg} / \mathrm{d}$ from day of embryo transfer until pregnancy test (11 days) (Kim 2010); 5 mg glyceryl trinitrate (GTN) patch applied once daily, beginning the morning of the day before transfer, just after transvaginal ultrasonography and colour doppler were performed (Ohl 2002); 2 sublingual spray emissions of GTN $400 \mathrm{\mu g} / \mathrm{spray}$ (Shaker 1993); sildenafil citrate in the IVF cycle (Alieva 2012); and glyceryl trinitrate skin patches $5 \mathrm{mg}$ daily for 2 weeks (Mostafa 2003).

1. Thirteen of 15 studies compared vasodilator alone versus placebo or no treatment (Abdel 2017; Alieva 2012; Azmy 2016; Das 2009; Dehghani Firouzabadi 2013; El-Berry 2010; Fahmy 2015; Farzi 2005; Magdi Ammar 2017; Mahran 2016; Mostafa 2003; Ohl 2002; Shaker 1993).

2. Two of 15 studies compared vasodilator plus another agent versus placebo or no treatment (Aleyasin 2009; Kim 2010).

\section{Outcomes}

Researchers reported the following outcomes.

1. Three of 15 studies reported live births (Aleyasin 2009; Farzi 2005; Ohl 2002).

2. Four of 15 studies reported side effects (Fahmy 2015; Mahran 2016; Ohl 2002; Shaker 1993).

3. Eight of 15 studies reported clinical pregnancy (Aleyasin 2009; Dehghani Firouzabadi 2013; Fahmy 2015; Farzi 2005; Kim 2010; Magdi Ammar 2017; Mostafa 2003; Ohl 2002). However, four studies reported biochemical pregnancy (Abdel 2017; Das 2009; El-Berry 2010; Mahran 2016), and three studies did not report the method used to diagnose pregnancy (Alieva 2012; Azmy 2016; Shaker 1993). We did not include in analyses studies reporting biochemical pregnancy.

4. Four of 15 studies reported other adverse events (Aleyasin 2009; Alieva 2012; Farzi 2005; Ohl 2002). In one study, reproductive loss in the control group looks unusually high (20\%), but the adverse event was not defined (Alieva 2012).

No study provided data on the number of participants with thickened endometrium. Only two studies mentioned that all women had a thin endometrium before treatment (Das 2009; Kim 2010). However, five studies reported a mean difference in 
thickened endometrium (Abdel 2017; Azmy 2016; Das 2009; Magdi Ammar 2017; Mahran 2016).

\section{Excluded studies}

We excluded 11 studies from the review for the following reasons.

1. Five of 11 studies were not parallel RCTs (Ataalla 2016; Check 2004; Raine-Fenning 2009; Sher 2000; Shin 2002).

2. Four of 11 studies did not include participants of interest for this review (Alborzi 2007; Balasch 1997; Creus 2008; Kamencic 2008).

3. One of 11 studies did not include comparisons of interest for this review (Rosen 1987).

4. One of 11 studies did not include outcomes of interest for this review (Malinova 2013).

In addition, two studies are awaiting classification (Casper 2013; Penzias 2012), and one study is ongoing (NCT02072291).

\section{Risk of bias in included studies}

In Figure 2 and Figure 3, we have shown and summarised the judgements of review authors regarding each risk of bias item for each included study.

\section{Allocation}

\section{Random sequence generation}

Five studies had low risk of selection bias related to sequence generation (Abdel 2017; Aleyasin 2009; Dehghani Firouzabadi 2013; Magdi Ammar 2017; Ohl 2002). The other 10 studies did not describe the method of randomisation, and we ranked them as having unclear risk of bias (Alieva 2012; Azmy 2016; Das 2009; El-Berry 2010; Fahmy 2015; Farzi 2005; Kim 2010; Mahran 2016; Mostafa 2003; Shaker 1993).

\section{Allocation concealment}

Five studies had low risk of bias related to allocation concealment (Abdel 2017; Aleyasin 2009; Fahmy 2015; Mahran 2016; Ohl 2002). The other 10 studies did not describe the method used to conceal the sequence, and we ranked them as having unclear risk of bias (Alieva 2012; Azmy 2016; Das 2009; Dehghani Firouzabadi 2013; ElBerry 2010; Farzi 2005; Kim 2010; Magdi Ammar 2017; Mostafa 2003; Shaker 1993).

\section{Blinding}

Five of 15 studies had low risk of performance bias (Abdel 2017; Aleyasin 2009; Farzi 2005; Ohl 2002; Shaker 1993). Four of these were double-blind and used placebo as a control (Abdel 2017; Farz 2005; Ohl 2002; Shaker 1993), and one was single-blind (surgeons who conducted the operations were blinded) (Aleyasin 2009). Three studies did not provide a description of blinding (Alieva 2012; Magdi Ammar 2017; Mostafa 2003).

Eight of 15 studies had low risk of detection bias (Abdel 2017; Aleyasin 2009; Das 2009; Dehghani Firouzabadi 2013; El-Berry 2010; Farzi 2005; Kim 2010; Ohl 2002). Seven of 15 studies did not mention blinding, and we judged them as having unclear risk of detection bias (Alieva 2012; Azmy 2016; Fahmy 2015; Magdi Ammar 2017; Mahran 2016; Mostafa 2003; Shaker 1993). Blinding was not considered as likely to influence the outcome of live birth or clinical pregnancy. The same was not true for adverse events, for which lack of blinding could potentially affect findings.

\section{Incomplete outcome data}

Nine of 15 studies analysed all or most (>95\%) of the women randomly assigned and had low risk of attrition bias (Abdel 2017; Aleyasin 2009; Das 2009; Dehghani Firouzabadi 2013; Fahmy 2015; Farzi 2005; Kim 2010; Ohl 2002; Shaker 1993). Only one study used the number of cycles instead of the number of participants in analysis (El-Berry 2010), and four studies did not describe attrition (Alieva 2012; Azmy 2016; Mahran 2016; Mostafa 2003). These studies had unclear risk of attrition bias. One of 15 studies was at high risk of attrition bias (Magdi Ammar 2017).

\section{Selective reporting}

Ten of 15 studies reported outcomes that were clearly prespecified in the methods section, and we classified them as having low risk of selective reporting bias (Abdel 2017; Aleyasin 2009; Azmy 2016; Dehghani Firouzabadi 2013; Fahmy 2015; Farzi 2005; Kim 2010; Magdi Ammar 2017; Ohl 2002; Shaker 1993). Four of these studies reported primary outcomes (Aleyasin 2009; Farzi 2005; Ohl 2002; Shaker 1993): three studies reported live birth (Aleyasin 2009; Farzi 2005; Ohl 2002), and four reported adverse effects (Fahmy 2015; Mahran 2016; Ohl 2002; Shaker 1993). However, the protocol was available for only one study (Dehghani Firouzabadi 2013).

\section{Other potential sources of bias}

Twelve of 15 studies reported baseline balance between groups in terms of age and duration of infertility (Abdel 2017; Aleyasin 2009; Das 2009; Dehghani Firouzabadi 2013; El-Berry 2010; Fahmy 2015; Farzi 2005; Kim 2010; Magdi Ammar 2017; Mahran 2016; Ohl 2002; Shaker 1993). In addition, four studies reported baseline comparability regarding type of infertility, cause of infertility, and body mass index. We classified these studies as having low risk of bias. We identified no other potential sources of bias. However, three studies did not report baseline features, and we judged them to have unclear risk of detection bias (Alieva 2012; Azmy 2016; Mostafa 2003).

\section{Effects of interventions}

See: Summary of findings for the main comparison Vasodilator compared to placebo or no treatment for women undergoing fertility treatment

\section{Vasodilator (with or without an additional intervention) versus placebo or no treatment}

Primary outcomes

1.1. Live birth or ongoing pregnancy

(Analysis 1.1; Figure 4) 
Figure 4. Forest plot of comparison: 1 Vasodilator vs placebo or no treatment, outcome: 1.1 Live birth.

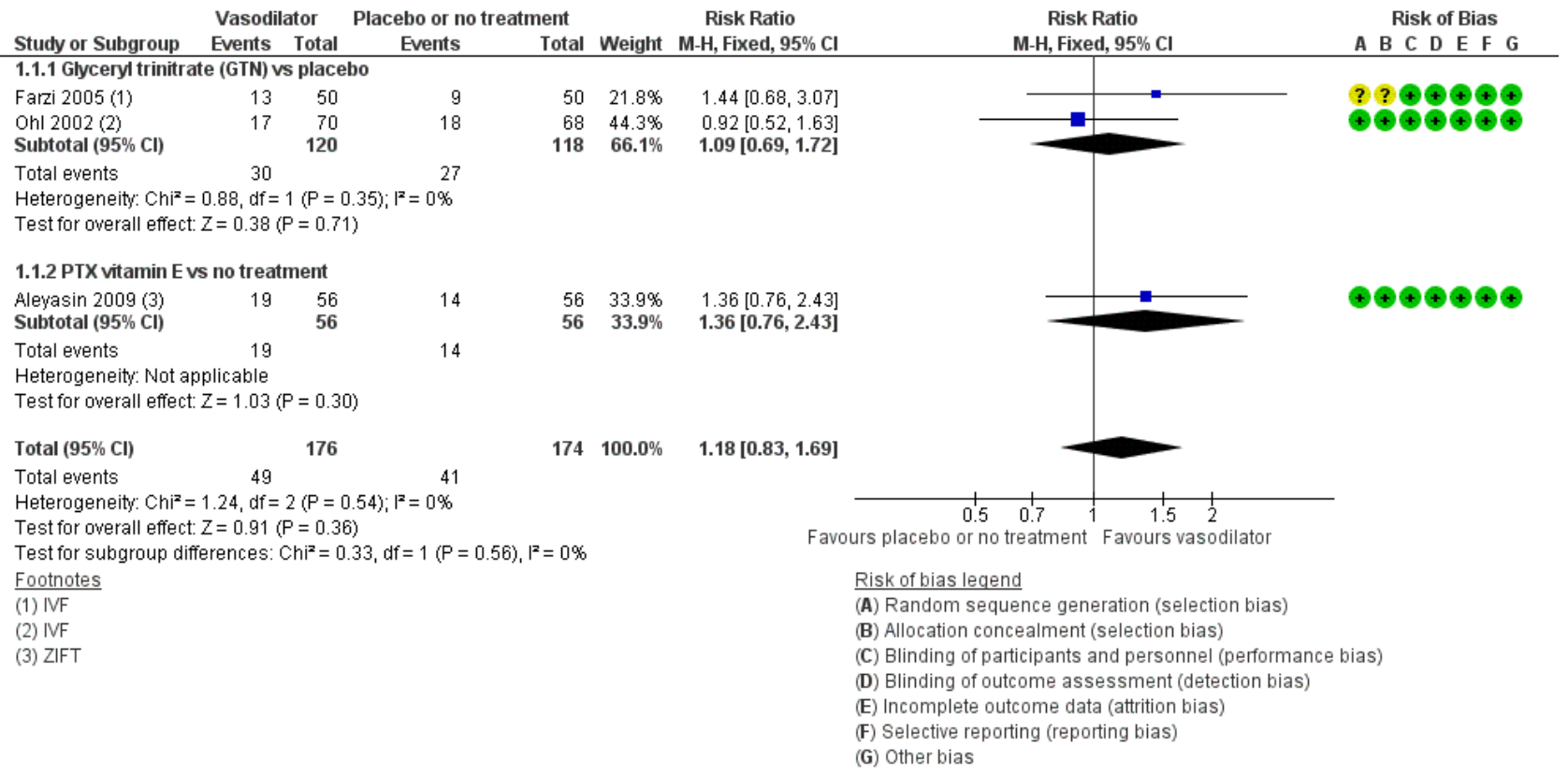

Three studies reported this outcome. All reported live births.

1. Comparison of glyceryl trinitrate (GTN) versus placebo (Farzi 2005; Ohl 2002).

2. Comparison of pentoxifylline + tocopherol vitamin $E$ versus no treatment (Aleyasin 2009).

Vasodilators (given alone or with another agent) probably make little or no difference in rates of "live birth or ongoing pregnancy" compared with placebo or no treatment (RR $1.18,95 \% \mathrm{Cl}$ 0.83 to 1.69 ; three RCTs; $N=350 ; I^{2}=0 \%$; moderate-quality evidence; Analysis 1.1; Figure 4; Summary of findings for the main comparison). Limiting the analysis to studies of vasodilators given without a co-intervention did not substantially change the main finding (RR 1.09, 95\% Cl 0.69 to 1.72 ; two RCTs; $\mathrm{N}=238 ; \mathrm{I}^{2}=0 \%$; moderate-quality evidence).

We stratified the analysis by type of vasodilator. The test for subgroup differences shows no evidence of differences between subgroups for this outcome $\left(\mathrm{Chi}^{2}=0.33, \mathrm{df}=1(\mathrm{P}=0.56), \mathrm{I}^{2}=0 \%\right)$.

Sensitivity analyses based on a random-effects model did not change the evidence (RR $1.18,95 \% \mathrm{Cl} 0.83$ to 1.69 ; three RCTs; $\mathrm{N}=$ $350 ; 1^{2}=0 \%$; moderate-quality evidence).

\subsection{Vasodilator side effects}

(Analysis 1.2: Figure 5) 
Figure 5. Forest plot of comparison: 1 Vasodilator vs placebo or no treatment, outcome: 1.2 Vasodilator side effects.

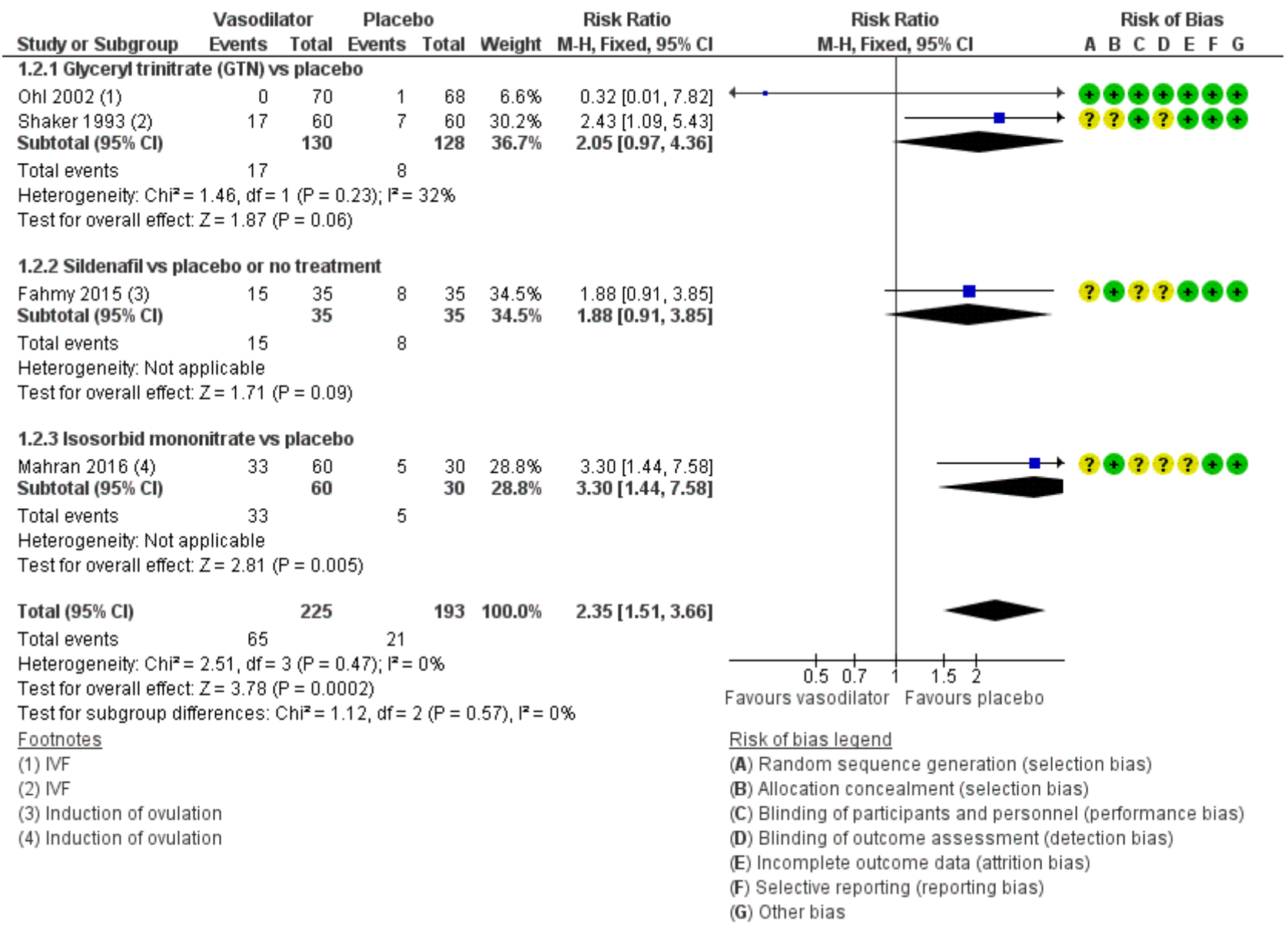

Four studies reported the number of vasodilator side effects by group. Two assessed glyceryl trinitrate (GTN) versus placebo (Ohl 2002; Shaker 1993), one sildenafil versus placebo (Fahmy 2015), and another isosorbide mononitrate (ISMN) versus no treatment (Mahran 2016).

The vasodilator group most commonly reported the following adverse events (AEs): hypotension, headache, tachycardia, dizziness, hot flushes, nervousness, insomnia, constipation, and a feeling of weakness.

Vasodilators (alone or with another agent) probably increase side effects compared with placebo or no treatment (RR $2.35,95 \% \mathrm{Cl}$ 1.51 to 3.66 ; four RCTs; $N=418 ; I^{2}=0 \%$; moderate-quality evidence).

We stratified the analysis by type of vasodilator. The test for subgroup differences shows no evidence of differences between subgroups for this outcome $\left(\mathrm{Chi}^{2}=1.12, \mathrm{df}=2(\mathrm{P}=0.57), \mathrm{I}^{2}=0 \%\right)$.

\subsection{Specific vasodilator side effects}

Two studies reported specific vasodilator side effects. One compared sildenafil versus placebo (Fahmy 2015), and another isosorbide mononitrate (ISMN) versus no treatment (Mahran 2016). Vasodilators may increase headache (RR 4.12, $95 \% \mathrm{CI} 1.87$ to 9.06; two RCTs; $N=160 ; I^{2}=7 \%$; low-quality evidence) and tachycardia (RR 3.83, 95\% Cl 1.25 to 11.75 ; one RCT; $\mathrm{N}=90$; low-quality evidence). Evidence was insufficient to show whether groups had differences in hypotension (RR $1.11,95 \% \mathrm{Cl} 0.58$ to 2.14 ; one RCT; N = 90; low-quality evidence), dizziness (RR $1.57,95 \% \mathrm{Cl} 0.76$ to 3.26 ; one RCT; N = 90; low-quality evidence), or hot flushes (RR 2.40, 95\% $\mathrm{Cl} 0.96$ to 5.99; two RCTs; $\mathrm{N}=160 ; \mathrm{I}^{2}=7 \%$; low-quality evidence).

\section{Secondary outcomes}

\subsection{Clinical pregnancy}

(Analysis 1.4; Figure 6) 
Figure 6. Forest plot of comparison: 1 Vasodilator vs placebo or no treatment, outcome: 1.4 Clinical pregnancy.

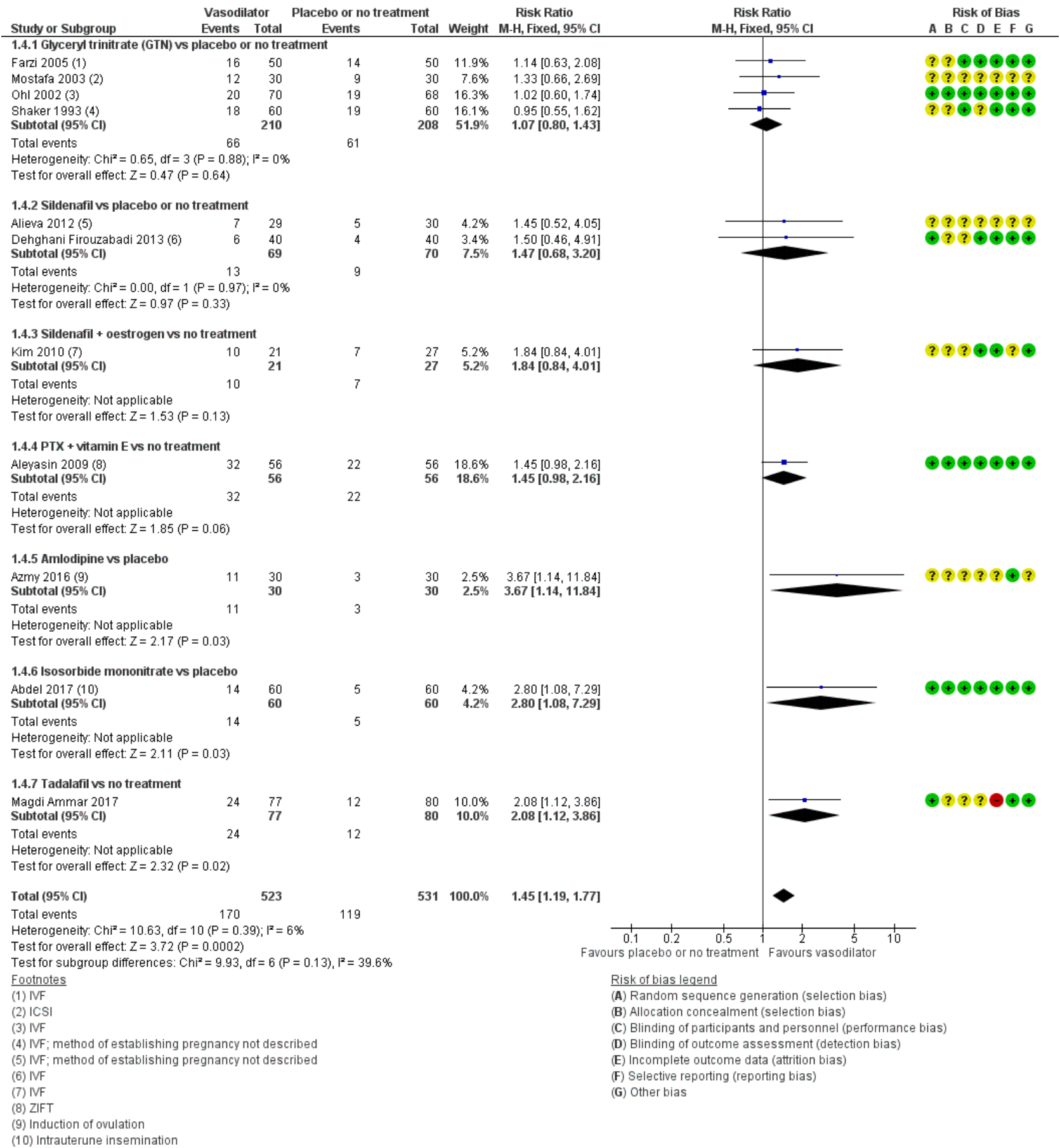

Fifteen studies reported clinical pregnancy. However, four studies reported biochemical pregnancy, and we did not include them in the analysis (Das 2009; El-Berry 2010; Fahmy 2015; Mahran 2016). Two studies did not report the method used to diagnose pregnancy (Alieva 2012; Shaker 1993). We included them in the analyses and noted this limitation in the footnotes. We analysed 11 studies (Abdel 2017; Aleyasin 2009; Alieva 2012; Azmy 2016; Dehghani Firouzabadi 2013; Farzi 2005; Kim 2010; Magdi Ammar 2017; Mostafa 2003; Ohl 2002; Shaker 1993).
1. Farzi 2005,Mostafa 2003,Ohl 2002, and Shaker 1993 compared glyceryl trinitrate (GTN) versus placebo or no treatment.

2. Alieva 2012 and Dehghani Firouzabadi 2013 compared sildenafil versus no treatment or placebo.

3. Kim 2010 compared sildenafil plus oestrogen versus no treatment.

4. Aleyasin 2009 compared pentoxifylline (PTX) + tocopherol vitamin E versus no treatment. 
5. Abdel 2017 compared isosorbide mononitrate (IMN or ISMN) versus placebo or no treatment.

6. Azmy 2016 compared amlodipine versus placebo.

7. Magdi Ammar 2017 compared tadalafil versus placebo.

Vasodilators (alone or with another agent) may slightly improve clinical pregnancy compared with placebo or no treatment (RR $1.45,95 \% \mathrm{Cl} 1.19$ to $1.77 ; 11$ RCTs; $\mathrm{N}=1054 ; \mathrm{I}^{2}=6 \%$; lowquality evidence; Analysis 1.4; Figure 6; Summary of findings for the main comparison). Limiting the analysis to studies of vasodilators without a co-intervention (vitamin $\mathrm{E}$, oestrogen) did not substantially change the main findings (RR $1.43,95 \% \mathrm{Cl} 1.13$ to 2.20; 11 RCTs; $\mathrm{N}=1054 ; I^{2}=21 \%$; moderate-quality evidence).

We stratified the analysis by type of vasodilator. The test for subgroup differences did not clearly suggest any differences between subgroups for this outcome $\left(\mathrm{Chi}^{2}=9.93, \mathrm{df}=6(\mathrm{P}=0.13)\right.$, $\left.\mathrm{I}^{2}=39 \%\right)$.

\subsection{Thickened endometrium}

Five studies reported thickened endometrium. Two assessed isosorbide mononitrate (IMN or ISMN) (Abdel 2017; Mahran 2016), one amlodipine (Azmy 2016), one sildenafil (Das 2009), and one tadalafil (Magdi Ammar 2017); researchers compared these agents versus placebo or no treatment. The effects shown in each study varied $\left(I^{2}=92 \%\right)$ and ranged from a mean difference of 0.80 higher (95\% $\mathrm{Cl} 0.18$ to 1.42 ) to 3.57 higher ( $95 \% \mathrm{Cl} 3.01$ to 4.13 ). We are uncertain whether vasodilators improved thickened endometrium, as we have assessed the quality of the evidence as very low. We downgraded the quality of evidence because of high risk of bias and inconsistency (Analysis 1.5; Summary of findings for the main comparison).

\subsection{Other adverse events}

\subsubsection{Multiple gestation or birth}

Three studies reported this outcome.

1. Ohl 2002 compared glyceryl trinitrate (GTN) versus placebo.

2. Aleyasin 2009 compared pentoxifylline + tocopherol vitamin $E$ versus no treatment.

3. Abdel 2017 compared isosorbide mononitrate (IMN) versus placebo.

Vasodilators probably make little or no difference in rates of multiple gestation or birth compared with placebo or no treatment (RR 1.15, 95\% Cl 0.55 to 2.42; three RCTs; $\mathrm{N}=370 ; \mathrm{I}^{2}=0 \%$; moderatequality evidence) (Analysis 1.6; Summary of findings for the main comparison).

\subsubsection{Spontaneous miscarriage}

Four studies reported this outcome.

1. Farzi 2005 and Ohl 2002 compared glyceryl trinitrate (GTN) versus placebo.

2. Aleyasin 2009 compared pentoxifylline + tocopherol vitamin $E$ versus no treatment.

3. Alieva 2012 compared sildenafil versus no treatment.

In one study, the miscarriage rate in the control group looked unusually high (Alieva 2012). So, we analysed only three studies (Aleyasin 2009; Farzi 2005; Ohl 2002). Vasodilators probably make little or no difference in spontaneous abortion/miscarriage rates compared with placebo or no treatment (RR $0.83,95 \% \mathrm{Cl} 0.37$ to 1.86; three RCTs; $N=350 ; I^{2}=0 \%$; moderate-quality evidence).

\subsubsection{Ectopic pregnancy}

Two studies reported this outcome.

1. Ohl 2002 compared glyceryl trinitrate (GTN) versus placebo.

2. Aleyasin 2009 compared pentoxifylline + tocopherol vitamin $E$ versus no treatment.

Vasodilators probably make little or no difference in ectopic pregnancy rates compared with placebo or no treatment (RR 1.48, $95 \% \mathrm{Cl} 0.25$ to 8.69 ; two RCTs; $N=250 ;\left.\right|^{2}=5 \%$; moderatequality evidence; Analysis 1.6; Summary of findings for the main comparison).

\section{Subgroup analyses}

We did not conduct some analyses initially proposed as stratified because we found no suitable studies.

As none of the included studies provided data on the number of women with endometrium measured as greater or less than 8 $\mathrm{mm}$, we could not perform planned subgroup analyses. Only two studies mentioned that all women had a thin endometrium before interventions were provided (Das 2009; Kim 2010).

\section{Sensitivity analysis}

Results of analysis did not change substantially when we excluded studies of vasodilators combined with another drug (vitamin $\mathrm{E}$, oestrogen), or when we applied a random-effects model.

\section{ISC USSION}

\section{Summary of main results}

Results of this systematic review suggest that moderate-quality evidence is insufficient to show that vasodilators improve the live birth rate among women undergoing fertility treatment. However, treatment with vasodilators was associated with an increased overall rate of side effects compared with placebo or no treatment. Analysis of specific side effects revealed that headache and tachycardia were increased.

Low-quality evidence suggests that vasodilators alone or in combination with other treatments (vitamin E, oestradiol) increased clinical pregnancy rates compared with placebo or no treatment. When we excluded studies of vasodilators combined with other medications, we noted that vasodilators alone had similar effects on clinical pregnancy rates.

Last, we found no clear evidence to suggest differences between groups for other adverse effects such as multiple gestation or birth, spontaneous abortion/miscarriage, and ectopic pregnancy; few relevant data were available.

\section{Overall completeness and applicability of evidence}

All studies reported pregnancy as an outcome. However, for women and for clinicians, live birth rate and side effects are the most important outcomes of fertility treatment. As only three studies and four studies reported these outcomes, respectively, this review might not address the main concerns surrounding fertility 
treatment. This, in turn, serves as evidence that more studies are needed to assess these important outcomes. No studies compared active interventions.

Age restrictions for women specified in the inclusion and exclusion criteria of studies were similar across 11 included studies. However, some trials included women with a 'bad prognosis' (i.e. infertile women with a thin endometrium or with a history of two or more previous implantation failures), and other trials included women with a 'good prognosis' (i.e. women without a previous history of failure of zygote intrafallopian transfer (ZIFT) or in vitro fertilisation (IVF)). Even though we found no evidence of statistical heterogeneity in main outcomes among trials, we could not rule out the effects of clinical heterogeneity on study results.

All studies compared the intervention versus placebo or no treatment, so a limitation of this review is that we found no headto-head studies comparing two different vasodilators.

\section{Quality of the evidence}

Overall, the quality of evidence was low to moderate for most comparisons. The main limitations were imprecision due to low numbers of events and participants, and risk of bias due to unclear methods of randomisation and concealment of allocation, blinding, incomplete outcome data, and selective reporting. We could not assess risk of publication bias because of the small number of identified studies.

We rated evidence for live birth and vasodilator side effects as moderate quality, with imprecision as the main limitation. Evidence for clinical pregnancy, multiple gestation, miscarriage and ectopic pregnancy, and vasodilator side effects was of low quality, with low precision and unexplained heterogeneity. Evidence for the thickened endometrium was of very low quality, and low precision and high heterogeneity are evident (Summary of findings for the main comparison).

Risk of selection bias was unclear in 10 studies. Concealment of allocation was adequate, and five trials explicitly described this. Five studies were placebo-controlled but did not specify the use of blinding. Other studies were not blinded or failed to mention blinding. However, as most assessed outcomes were not subjective, lack of blinding did not imply an increase in risk of bias. Nine studies were analysed via intention-to-treat, five studies had unclear risk of attrition bias, and one study had high risk of attrition bias. Risk of selective reporting was unclear in some studies. Live birth rate was reported in a minority of cases, and only four studies reported adverse events as an outcome.

\section{Potential biases in the review process}

The process of identifying all potentially eligible studies for inclusion in this review was thorough and meticulous, even yielding three studies published only in abstract form. We contacted the authors of these works, but only one of them replied (Das 2009). Regarding all other procedures related to this review, we used the updated version of the Cochrane Handbook for Systematic Reviews of Interventions, and, as far as possible, we adhered to methods specified in the protocol, so potential biases could be limited. Also, it was not possible to evaluate potential biases in all studies for lack of data. We considered these studies to have unclear risk of bias. We contacted the authors of these studies, but only two of them replied (Farzi 2005; Kim 2010).

\section{Agreements and disagreements with other studies or reviews}

We have not reviewed other reviews in women undergoing assisted fertility treatment with vasodilators. However, we identified relevant studies in women undergoing assisted fertility treatment (Fetih 2017; Sher 2000; Sher 2002; Takasaki 2010). In a selfcontrolled clinical trial, clinical pregnancy rate increased with sildenafil vaginal gel, but the numbers were small (Fetih 2017). Likewise, one of the most important observational studies was a cohort study examining the effect of vaginal sildenafil on the outcome of in vitro fertilisation after multiple IVF failures attributed to poor endometrial development; this study reported high ongoing pregnancy rates (Sher 2002).

\section{AUTHORS' CONCLUSIONS}

\section{Implications for practice}

Evidence was insufficient to show whether vasodilators increase the live birth rate in women undergoing fertility treatment. However, low-quality evidence suggests that vasodilators may slightly increase clinical pregnancy rates. Moderate-quality evidence shows that vasodilators increase some side effects, such as headache and tachycardia, in comparison with placebo or no treatment. Adequately powered studies are needed, so that researchers can evaluate each treatment more accurately.

\section{Implications for research}

Although this review suggests that vasodilators increase clinical pregnancy rates compared with placebo or no treatment, future studies on vasodilators should report live birth rates, side effects, and other important outcomes to enable consumers and healthcare providers to make well-informed decisions on the best treatment options. Based on the results of this review, we provide the following recommendations.

1. Randomised controlled trials with larger sample sizes are needed to evaluate whether any vasodilator is associated with an increase in live birth rate or pregnancy rate.

2. Future research should help to determine the optimal route of administration and dosage of different vasodilators.

3. Future research probably should focus mainly on tadalafil or amlodipine or "isosorbide mononitrate" and should include assessment of the optimal route of administration and the optimal dosage.

4. Future research should evaluate relevant outcomes such as live births and side effects.

5. Future research should investigate whether women with a thin endometrium may benefit from medication.

6. Improved descriptions of methods and adherence to CONSORT (Consolidated Standards of Reporting Trials) recommendations are needed for all randomised controlled trials.

7. Future researchers should perform comparisons of one active treatment versus another. 


\section{A C K N OWLEDGEMENTS}

To the Cochrane Gynaecology and Fertility Group, especially Marian Showell, who devised the search strategy and contributed to identification of some studies. To Daniel Comande, librarian, who contributed to the search by identifying some studies. To Marta Roque, who advised on and supervised the methods and the analysis. To Hector Pardo, who helped in editing the final version of the manuscript.

To trial authors, who kindly answered our questions regarding their studies.
RG was a PhD candidate at the Paediatrics, Obstetrics and Gynaecology, Preventive Medicine and Public Health Department at the Universitat Autònoma de Barcelona, Spain.

AV is a MSc candidate in the Official Master's Degree in Applied Clinical Research in Health Sciences programme at Universitat Autònoma de Barcelona, Spain.

The authors of the 2018 update thank Vicente Benites for his contributions to this review, and Drs. Andrea Coscia and Gerard Urrútia for their contributions to the previous version of this review. 


\section{R E F E R E N C E S}

\section{References to studies included in this review}

\section{Abdel 2017 \{published data only\}}

Abdel Razik M, El-Berry S, El-Nezamy A, Saad A, Abdel Wahab A. Nitric oxide donors increase the pregnancy rate in patients with unexplained infertility undergoing clomiphene citrate stimulation and intrauterine insemination: a randomized controlled pilot study. Gynecological Endocrinology 2017;33(3):199-202.

\section{Aleyasin 2009 \{published data only\}}

Aleyasin A, Aghahosseini M, Mohseni M, Mahdavi A. Effects of pentoxifylline and vitamin $E$ on pregnancy rate in infertile women treated by ZIFT: a randomized clinical trial. Iranian Journal of Reproductive Medicine 2009;7(4):175-9.

\section{Alieva 2012 \{published and unpublished data\}}

Alieva K, Kulakova E, Ipatova M, Smolnikova S, Kalinina E. Efficiency of recovery physiotherapy and sildenafil citrate in complex preparation of endometrium in women with disorders in uterine hemodynamics undergoing IVF. Human Reproduction 2012;27(Suppl 2):P-276.

\section{Azmy 2016 \{published data only\}}

Azmy O, El Faham D, Taha T, Bibars M, Salama S, Abbassy A. Amlodipine effect on pre-ovulatory follicle blood flow among women with polycystic ovarian syndrome: randomised controlled trial. British Journal of Obstetrics and Gynaecology 2016;123(Suppl 2):227.

\section{Das 2009 \{published data only\}}

Das V, Agarwal A, Pandey A, Jain V, Agarwal S, Ara A. Evaluation of role of sildenafil in improving IUI success rates. International Journal of Gynecology \& Obstetrics. 2009; Vol. 107S2 S413-S729, issue Poster presentations.

\section{Dehghani Firouzabadi 2013 \{published data only\}}

Dehghani Firouzabadi R, Davar R, Hojjat F, Mahdavi M. Effect of sildenafil citrate on endometrial preparation and outcome of frozen-thawed embryo transfer cycles: a randomized clinical trial. Iranian Journal of Reproductive Medicine 2013;11(2):151-8.

\section{El-Berry 2010 \{published data only\}}

El-Berry S, Razik MA. Nitric oxide donors increase pregnancy rate in clomiphene citrate treated polycystic ovary infertile patients. Middle East Fertility Society Journal 2010;15:106-9.

\section{Fahmy 2015 \{published data only\}}

Fahmy AA, El Sokkary M, Sayed S. The value of oral sildenafil in the treatment of female infertility: a randomized clinical trial. Life Science Journal 2015;12(4):78-82.

\section{Farzi 2005 \{published data only\}}

Farzi F, Mehrafza M, Mirmansouri A, Oudi M, Hoseeini A. Administration of NTG before embryo transfer does not increase pregnancy rate. Iranian Journal of Reproductive Medicine 2005;3(2):95-100.
Kim 2010 \{published data only\}

Kim KR, Lee HS, Ryu HE, Park CY, Min SH, Park C, et al. Efficacy of luteal supplementation of vaginal sildenafil and oral estrogen on pregnancy rate following IVF-ET in women with a history of thin endometria: a pilot study. Journal of Women's Medicine 2010;3(4):155-8.

\section{Magdi Ammar 2017 \{published data only\}}

Magdi Ammar I, Ahmed Salem M. Effect of oral tadalafil on endometrial thickness in patients receiving clomiphene citrate for ovulation induction. Middle East Fertility Society Journal 2017;https://doi.org/10.1016/j.mefs.2017.09.001:1-5.

\section{Mahran 2016 \{published data only\}}

Mahran A, Abdelmeged A, Shawki A, Moheyelden A, Mohamed A. Nitric oxide donors improve the ovulation and pregnancy rates in anovulatory women with polycystic ovary syndrome treated with clomiphene citrate: an RCT. International Journal of Reproductive Biomedicine 2016;14(1):9-14.

\section{Mostafa 2003 \{published and unpublished data\}}

Mostafa R, Motawe B. Nitric oxide donors and uterine artery Doppler blood flow: a step for optimizing uterine receptivity and implantation in ICSI. Abstracts of the 19th Annual Meeting of the ESHRE, Madrid, Spain of the European Society of Human Reproduction and Embryology. 2003; Vol. 1:138.

Ohl 2002 \{published data only\}

Ohl J, Bettahar Lebugle K, Rongieres C, Avril C. Nitric oxide donors and in-vitro fertilization. Human Reproduction 2001;16(Suppl 1):22.

* Ohl J, Lefebvre-Maunoury C, Wittemer C, Nisand G, Laurent MC, Hoffmann P. Nitric oxide donors for patients undergoing IVF. A prospective, double-blind, randomized, placebo-controlled trial. Human Reproduction 2002;17(10):2615-30.

\section{Shaker 1993 \{published data only\}}

Shaker A, Fleming R, Jamieson ME, Yates RWS, Coutts JRT. Assessments of embryo transfer after in-vitro fertilization: effects of glyceryl trinitrate. Human Reproduction 1993;8(9):1426-8.

\section{References to studies excluded from this review}

\section{Alborzi 2007 \{published data only\}}

Alborzi S, Ghotbi S, Parsanezhad ME, Dehbashi S, Alborzi S, Alborzi M. Pentoxifylline therapy after laparoscopic surgery for different stages of endometriosis: a prospective, double-blind, randomized, placebo-controlled study. Journal of Minimally Invasive Gynecology 2007; Vol. 14, issue 1:54-8.

\section{Ataalla 2016 \{published data only\}}

Ataalla WM, Elhamid T, Elhalwagy AE. Adjuvant sildenafil therapy in poor responders undergoing in vitro fertilization: a prospective, randomized, double-blind, placebo-controlled trial. Middle East Fertility Society Journal 2016;21(3):175-9. 
Balasch 1997 \{published data only\}

Balasch J, Creus M, Fabregues F, Carmona F, Martinez-Roman S, Manau $D$, et al. Pentoxifylline versus placebo in the treatment of infertility associated with minimal or mild endometriosis: a pilot randomized clinical trial. Human Reproduction 1997; Vol. 12 , issue 9:2046-50.

\section{Check 2004 \{published data only\}}

Check JH, Graziano V, Lee G, Nazari A, Choe JK, Dietterich C. Neither sildenafil nor vaginal estradiol improves endometrial thickness in women with thin endometria after taking oral estradiol in graduating dosages. Clinical \& Experimental Obstetrics \& Gynecology 2004; Vol. 31, issue 2:99-102.

\section{Creus 2008 \{published data only\}}

Creus M, Fabregues F, Carmona F, del Pino M, Manau D, Balasch J. Combined laparoscopic surgery and pentoxifylline therapy for treatment of endometriosis-associated infertility: a preliminary trial. Human Reproduction 2008; Vol. 23, issue 8:1910-6.

\section{Kamencic 2008 \{published data only\}}

Kamencic $\mathrm{H}$, Thiel JA. Pentoxifylline after conservative surgery for endometriosis: a randomized, controlled trial. Journal of Minimally Invasive Gynecology 2008;15(1):62-6. [PUBMED: 18262146]

\section{Malinova 2013 \{published data only\}}

Malinova M, Abouyta T, Krasteva M. [The effect of vaginal sildenafil citrate on uterine blood flow and endometrium in the infertile women]. Akusherstvo Ginekologiia 2013;52(Suppl 1):26-30.

\section{Raine-Fenning 2009 \{published data only\}}

Raine-Fenning NJ, Campbell BK, Clewes JS, Kendall NR, Johnson IR. Viagra increases endometrial and sub-endometrial blood flow but not endometrial volume or thickness. Human Reproduction 2009; Vol. 24(Suppl 1):i201, Abstract No P-505; Poster.

\section{Rosen 1987 \{published data only\}}

Rosen MA, Roizen MF, Eger El 2d, Glass RH, Martin M, Dandekar PV, et al. The effect of nitrous oxide on in vitro fertilization success rate. Anesthesiology 1987; Vol. 67, issue 1:42-4.

\section{Sher 2000 \{published data only\}}

Sher G, Fisch JD. Vaginal sildenafil (Viagra): a preliminary report of a novel method to improve uterine artery blood flow and endometrial development in patients undergoing IVF. Human Reproduction 2000;15(4):806-9.

\section{Shin 2002 \{published data only\}}

Hwang J, Chang H, Lee J, Choi H, Cho P, Cho P, et al. Use of vaginal sildenafil and estradiol valerate to improve endometrial receptivity for the patients with thin endometrium in IVF-ET. 17th World Congress of Fertility and Sterility, Melbourme, 25-30 November. 2001.

* Shin SY, Kim DW, Shin JH, Hong SY, Park W, Cho BG, et al. Effectiveness of estradiol and sildenafil supplement therapy in IVF. ET patients with thin endometrium. Korean Society of Obstetrics and Gynecology 2002;45:642-50.

\section{References to studies awaiting assessment}

\section{Casper 2013 \{published and unpublished data\}}

Casper R, Bentov Y. Use of a calcium channel blocker to prevent premature luteinizing hormone surges in infertility patients (nimodipine). US National Institutes of Health. ClinicalTrials.gov Identifier: NCT01551368.

\section{Penzias 2012 \{published and unpublished data\}}

Penzias AS, Nguyen KH. Nimodipine to prevent LH surge during ovulation induction: blinded placebo-controlled RCT (NIMO) [Using nimodipine, a calcium channel blocker, to prevent LH surge in women undergoing controlled ovarian stimulation and intrauterine insemination: a double-blinded, randomized controlled study]. US National Institutes of Health. ClinicalTrials.gov Identifier: NCT01672801.

\section{References to ongoing studies}

NCT02072291 \{published and unpublished data\}

NCT02072291. The influence of nifedipine treatment on uterine contractility during frozen embryo transfer. [Nifedipine treatment on uterine contractility in IVF]. https:// clinicaltrials.gov/ct2/show/NCT02072291 (first received 26 February 2014).

\section{Additional references}

\section{Acharya 2009}

Acharya S, Yasmin E, Balen AH. The use of a combination of pentoxifylline and tocopherol in women with a thin endometrium undergoing assisted conception therapies - a report of 20 cases. Human Fertility 2009;12(4):198-203. [PUBMED: 19938908]

\section{Aguilar 2010}

Aguilar HN, Mitchell BF. Physiological pathways and molecular mechanisms regulating uterine contractility. Human Reproduction 2010;16(6):725-44. [PUBMED: 20551073]

\section{Baradwan 2018}

Baradwan S, Shafi D, Baradwan A, Bashir MS, Al-Jaroudi D. The effect of endometrial thickness on pregnancy outcome in patients with Asherman's syndrome post-hysteroscopic adhesiolysis. International Journal of Women's Health 2018;10:77-82.

\section{Biyiksiz 2011}

Biyiksiz PC, Filiz S, Vural B. Is sildenafil citrate affect endometrial receptivity? An immunohistochemical study. Gynecological Endocrinology 2011;27(10):767-74. [PUBMED: 21190420]

\section{Bouillon 2013}

Bouillon C, Fauque P. [Follow-up of children conceived by assisted reproductive technologies] [Devenir des enfants issus des techniques d'assistance medicale a la procreation.]. 
Archives of Pediatrics (Organe Officiel de la Societe Francaise de Pediatrie) 2013;20(5):575-9. [PUBMED: 23545282]

\section{Bulletti 2006}

Bulletti C, de Ziegler D. Uterine contractility and embryo implantation. Current Opinion in Obstetrics \& Gynecology 2006;18(4):473-84. [PUBMED: 16794431]

\section{Cai 2017}

Cai J, Liu L, Zhang J, Qiu H, Jiang X, Li P, et al. Low body mass index compromises live birth rate in fresh transfer in vitro fertilization cycles: a retrospective study in a Chinese population. Fertility and Sterility 2017;107(2):422-9.e2.

\section{Casper 2011}

Casper RF. It's time to pay attention to the endometrium. Fertility and Sterility 2011;96(3):519-21. [PUBMED: 21880272]

\section{Check 2011}

Check JH. The importance of sonographic endometrial parameters in influencing success following embryo transfer in the modern era and therapeutic options - part 1: the importance of late proliferative phase endometrial thickness. Clinical and Experimental Obstetrics and Gynecology 2011; Vol. 38, issue 3:197-200. [PUBMED: 21995142]

\section{Chen 2005}

Chen Z, Foster MW, Zhang J, Mao L, Rockman HA, Kawamoto T, et al. An essential role for mitochondrial aldehyde dehydrogenase in nitroglycerin bioactivation. Proceedings of the National Academy of Sciences of the United States of America 2005;102(34):12159-64. [PUBMED: 16103363]

\section{Chen 2008}

Chen QJ, Sun XX, Li L, Gao XH, Gemzell-Danielsson K, Cheng LN. Effects of ovarian stimulation on endometrial integrin beta3 and leukemia inhibitory factor expression in the peri-implantation phase. Fertility and Sterility 2008;89(Suppl 5):1357-63. [PUBMED: 17681328]

\section{Chung 2016}

Chung $\mathrm{CH}$, Wong AW, Chan CP, Saravelos SH, Kong GW, Cheung LP, et al. The changing pattern of uterine contractions before and after fresh embryo transfer and its relation to clinical outcome. Reprod Biomed Online 2017;34(3):240-247.

\section{Chung 2017}

Chung $\mathrm{CH}$, Wong AW, Chan CP, Saravelos $\mathrm{SH}$, Kong GW, Cheung $\mathrm{LP}$, et al. The changing pattern of uterine contractions before and after fresh embryo transfer and its relation to clinical outcome. Reproductive BioMedicine Online 2017;34(3):240-7.

\section{de Mouzon 2012}

de Mouzon J, Goossens V, Bhattacharya S, Castilla JA, Ferraretti AP, Korsak V, et al. Assisted reproductive technology in Europe, 2007: results generated from European registers by ESHRE. Human Reproduction 2012;27(4):954-66. [PUBMED: 22343707]

\section{Dix 2010}

Dix E, Check JH. Successful pregnancies following embryo transfer despite very thin late proliferative endometrium. Clinical and Experimental Obstetrics and Gynecology 2010;37(1):15-6. [PUBMED: 20420271]

\section{Dyer 2016}

Dyer S, Chambers GM, de Mouzon J, Nygren KG, ZegersHochschild F, Mansour R, et al. International Committee for Monitoring Assisted Reproductive Technologies World Report: Assisted Reproductive Technology 2008, 2009 and 2010. Human Reproduction 2016;31(7):1588-609.

\section{Eftekhar 2017}

Eftekhar M, Tabibnejad N, Alsadat Tabatabaie A. The thin endometrium in assisted reproductive technology: an ongoing challenge. Middle East Fertility Society Journal 2017;https:// doi.org/10.1016/j.mefs.2017.12.006:1-7.

\section{ESHIRE 2016}

European IVF-Monitoring Consortium (EIM), European Society of Human Reproduction and Embryology (ESHRE), Kupka MS, D'Hooghe T, Ferraretti AP, de Mouzon J, Erb K, Castilla JA, et al. Assisted reproductive technology in Europe, 2011: results generated from European registers by ESHRE. Human Reproduction 2016;31(2):233-48.

\section{European IVF-Monitoring Consortium (EIM) 2017}

European IVF-Monitoring Consortium (EIM), European Society of Human Reproduction and Embryology (ESHRE), CalhazJorge C, De Geyter C, Kupka MS, de Mouzon J, et al. Assisted reproductive technology in Europe, 2013: results generated from European registers by ESHRE. Human Reproduction 2017;32(10):1957-73.

\section{Evans 2012}

Evans J, Hannan NJ, Hincks C, Rombauts LJ, Salamonsen LA. Defective soil for a fertile seed? Altered endometrial development is detrimental to pregnancy success. Public Library of Science One 2012;7(12):e53098. [PUBMED: 23300868]

\section{Fanchin 2001}

Fanchin R. Assessing uterine receptivity in 2001: ultrasonographic glances at the new millennium. Annals of the New York Academy of Sciences 2001;943:185-202. [PUBMED: 11594540]

\section{Fanchin 2009}

Fanchin R, Ayoubi JM. Uterine dynamics: impact on the human reproduction process. Reproductive BioMedicine Online 2009;18(Suppl 2):57-62. [PUBMED: 19406033]

\section{Ferraretti 2012}

Ferraretti AP, Goossens V, de Mouzon J, Bhattacharya S, Castilla JA, Korsak V, et al. Assisted reproductive technology in Europe, 2008: results generated from European registers by ESHRE. Human Reproduction 2012;27(9):2571-84. [PUBMED: 22786779] 


\section{Ferraretti 2013}

Ferraretti AP, Goossens V, Kupka M, Bhattacharya S, de Mouzon J, Castilla JA, et al. Assisted reproductive technology in Europe, 2009: results generated from European registers by ESHRE. Human Reproduction 2013;28(9):2318-31. [PUBMED: 23842560]

\section{Fetih 2017}

Fetih AN, Habib DM, Abdelaal II, Hussein M, Fetih GN, Othman ER. Adding sildenafil vaginal gel to clomiphene citrate in infertile women with prior clomiphene citrate failure due to thin endometrium: a prospective self-controlled clinical trial. Facts, Views \& Vision in ObGyn 2017;9(1):21-27.

\section{Gelbaya 2005}

Gelbaya TA, Kyrgiou M, Li TC, Stern C, Nardo LG. Low-dose aspirin for in vitro fertilization: a systematic review and metaanalysis. Human Reproduction 2007;13(4):357-64.

\section{Glujovsky 2010}

Glujovsky D, Pesce R, Fiszbajn G, Sueldo C, Hart RJ, Ciapponi A. Endometrial preparation for women undergoing embryo transfer with frozen embryos or embryos derived from donor oocytes. Cochrane Database of Systematic Reviews 2010;1:CD006359. [PUBMED: 20091592]

\section{GRADEpro GDT 2014}

GRADEpro GDT. GRADE software for Summary of Findings tables, Health Technology Assessment and Guidelines. https:// gradepro.org/.

\section{Higgins 2003}

Higgins JP, Thompson SG, Deeks JJ, Altman DG. Measuring inconsistency in meta-analyses. BMJ 2003;327(7414):557-60. [PUBMED: 12958120]

\section{Higgins 2011}

Higgins JPT, Deeks JJ. Chapter 7. Selecting studies and collecting data. Cochrane Handbook for Systematic Reviews of Interventions. Version 5.1.0 (updated March 2011). http:// www.cochrane-handbook.org.

\section{Kasius 2014}

Kasius A, Smit JG, Torrance HL, Eijkemans MJ, Mol BW, Opmeer BC, et al. Endometrial thickness and pregnancy rates after IVF: a systematic review and meta-analysis. Human Reproduction 2014;20(4):530-41.

\section{Kawwass 2016}

Kawwass JF, Kulkarni AD, Hipp HS, Crawford S, Kissin DM, Jamieson DJ. Extremities of body mass index and their association with pregnancy outcomes in women undergoing in vitro fertilization in the United States. Fertility and Sterility. 2016;106(7):1742-50.

\section{Kushnir 2017}

Kushnir VA, Barad DH, Albertini DF, Darmon SK, Gleicher N. Systematic review of worldwide trends in assisted reproductive technology 2004-2013. Reproductive Biology and Endocrinology 2017;15(1):6

\section{Lensen 2016}

Lensen SF, Manders M, Nastri CO, Gibreel A, Martins WP, Templer GE, et al. Endometrial injury for pregnancy following sexual intercourse or intrauterine insemination. Cochrane Database of Systematic Reviews 2016;14(6):CD011424.

\section{Lesny 1998}

Lesny P, Killick SR, Tetlow RL, Robinson J, Maguiness SD. Uterine junctional zone contractions during assisted reproduction cycles. Human Reproduction Update 1998;4(4):440-5. [PUBMED: 9825859]

\section{Letur-Konirsch 2003}

Letur-Konirsch H, Delanian S. Successful pregnancies after combined pentoxifylline-tocopherol treatment in women with premature ovarian failure who are resistant to hormone replacement therapy. Fertility and Sterility 2003;9:439-41.

\section{Letur-Könirsch 2002}

Letur-Könirsch H, Guis F, Delanian S. Uterine restoration by radiation sequelae regression with combined pentoxifyllinetocopherol: a phase II study. Fertility and Sterility 2002;77:1219-26.

\section{Lédée-Bataille 2002}

Lédée-Bataille N, Olivennes F, Lefaix J-L, Chaouat G, Frydman R, Delanian S. Combined treatment by pentoxifylline and tocopherol for recipient women with a thin endometrium enrolled in an oocyte donation programme. Human Reproduction 2002;17:1249-53.

\section{Maheshwari 2011}

Maheshwari A, Gibreel A, Siristatidis CS, Bhattacharya S. Gonadotrophin-releasing hormone agonist protocols for pituitary suppression in assisted reproduction. Cochrane Database of Systematic Reviews (online) 2011;8:CD006919. [PUBMED: 21833958]

\section{Marinakis 2011}

Marinakis G, Nikolaou D. What is the role of assisted reproduction technology in the management of age-related infertility?. Human Fertility 2011;14(1):8-15. [PUBMED: 21329469]

\section{Martin 2017}

Martin AS, Chang J, Zhang Y, Kawwass JF, Boulet SL, McKane P, et al. Perinatal outcomes among singletons after assisted reproductive technology with single-embryo or double-embryo transfer versus no assisted reproductive technology. Fertility and Sterility 2017;107(4):954-60.

\section{McLernon 2010}

McLernon DJ, Harrild K, Bergh C, Davies MJ, de Neubourg D, Dumoulin JC, et al. Clinical effectiveness of elective single versus double embryo transfer: meta-analysis of individual patient data from randomised trials. BMJ 2010;341:c6945. [PUBMED: 21177530]

\section{Mochtar 2017}

Mochtar MH, Danhof NA, Ayeleke RO, Van der Veen F, van Wely M. Recombinant luteinizing hormone ( $\mathrm{rLH})$ 
and recombinant follicle stimulating hormone $(\mathrm{rFSH})$ for ovarian stimulation in IVF/ICSI cycles. Cochrane Database of Systematic Reviews 2017;5:CD005070:doi: 10.1002/14651858.CD005070.pub3.

\section{Ng 2014}

$\mathrm{Ng} \mathrm{EH}$, Li RH, Chen L, Lan VT, Tuong HM, Quan S. A randomized double blind comparison of atosiban in patients undergoing IVF treatment. Human Reproduction 2014;29(12):2687-94.

\section{Oron 2018}

Oron G, Hiersch L, Rona S, Prag-Rosenberg R, Sapir O, Tuttnauer-Hamburger M, et al. Endometrial thickness of less than $7.5 \mathrm{~mm}$ is associated with obstetric complications in fresh IVF cycles: a retrospective cohort study. reproductive biomedicine online journal 2018;6483:30314-6.

\section{Orth 2011}

Orth TA, Shi SQ, Williamson K, Shi L, Chambliss L, Coonrod DV, et al. Additive inhibitory effects of progesterone and sodium nitroprusside on uterine contractility during pregnancy. Reproductive Sciences 2011;18(9):868-75. [PUBMED: 21421898]

\section{Pinborg 2011}

Pinborg A, Gaarslev C, Hougaard CO, Nyboe Andersen A, Andersen PK, Boivin J, et al. Influence of female bodyweight on IVF outcome: a longitudinal multicentre cohort study of 487 infertile couples. Reproductive BioMedicine Online 2011;23(4):490-9. [PUBMED: 21856228]

\section{Pouwer 2015}

Pouwer AW, Farquhar C, Kremer JA. Long-acting FSH versus daily FSH for women undergoing assisted reproduction. Cochrane Database of Systematic Reviews 2015;(7):CD009577:doi: 10.1002/14651858.CD009577.pub3.

\section{Raine-Fenning 2004}

Raine-Fenning NJ, Campbell BK, Kendall NR, Clewes JS, Johnson IR. Endometrial and subendometrial perfusion are impaired in women with unexplained subfertility. Human Reproduction 2004;19(11):2605-14. [PUBMED: 15465835]

\section{Revel 2012}

Revel A. Defective endometrial receptivity. Fertility and Sterility 2012;97(5):1028-32. [PUBMED: 22542142]

\section{Schmidt 2012}

Schmidt L, Sobotka T, Bentzen JG, Nyboe Andersen A. Demographic and medical consequences of the postponement of parenthood. Human Reproduction Update 2012;18(1):29-43. [PUBMED: 21989171]

\section{Senturk 2008}

Senturk LM, Erel CT. Thin endometrium in assisted reproductive technology. Current Opinion in Obstetrics \& Gynecology 2008;20(3):221-8. [PUBMED: 18460935]

\section{Sher 2002}

Sher G, Fisch JD. Effect of vaginal sildenafil on the outcome of in vitro fertilization (IVF) after multiple IVF failures attributed to poor endometrial development. Fertility and Sterility 2002;78(5):1073-6. [PUBMED: 12413996]

\section{Sullivan 2013}

Sullivan EA, Zegers-Hochschild F, Mansour R, Ishihara O, de Mouzon J, Nygren KG, et al. International Committee for Monitoring Assisted Reproductive Technologies (ICMART) world report: assisted reproductive technology 2004. Human Reproduction 2013;28(5):1375-90. [PUBMED: 23442757]

\section{Sunderam 2012}

Sunderam S, Kissin DM, Flowers L, Anderson JE, Folger SG, Jamieson DJ, et al. Assisted reproductive technology surveillance - United States, 2009. Morbidity and Mortality Weekly Report Surveillance Summaries/CDC 2012;61(7):1-23. [PUBMED: 23114281]

\section{Sunderam 2017}

Sunderam S, Kissin DM, Crawford SB, Folger SG, Jamieson DJ, Warner L, et al. Assisted reproductive technology surveillance - United States, 2014. Morbidity and Mortality Weekly Report Surveillance Summaries 2017;66(6):1-24.

\section{Takasaki 2010}

Takasaki A, Tamura H, Miwa I, Taketani T, Shimamura K, Sugino N. Endometrial growth and uterine blood flow: a pilot study for improving endometrial thickness in the patients with a thin endometrium. Fertility and Sterility 2010;93(6):1851-8. [PUBMED: 19200982]

\section{Torres 2005}

Torres RF, Habana AE, Tansengco LG. The effect of estrogen supplementation on the endometrium and pregnancy rate among infertile women treated with clomifene citrate: a metaanalysis. Fertility and Sterility 2005;84:S162-3.

\section{Weiss 2017}

Weiss NS, van Vliet MN, Limpens J, Hompes PGA, Lambalk CB, Mochtar $\mathrm{MH}$, et al. Endometrial thickness in women undergoing IUI with ovarian stimulation. How thick is too thin? A systematic review and meta-analysis. Human Reproduction 2017;32(5):1009-18.

\section{Wetzka 2001}

Wetzka B, Schafer WR, Stehmans A, Zahradnik HP. Effects of nitric oxide donors on the contractility and prostaglandin synthesis of myometrial strips from pregnant and non-pregnant women. Gynecological Endocrinology 2001;15(1):34-42. [PUBMED: 11293922]

\section{Wilson 1990}

Wilson AG, Kirby JD. Successful pregnancy in a woman with systemic sclerosis while taking nifedipine. Annals of the Rheumatic Diseases 1990;49(1):51-2. [PUBMED: 2310228]

\section{Yavas 2017}

Yavas Y. Curvilinear relationship between age and assisted reproduction technique success: retrospective analyses of US National ART Surveillance System data from 2010-2014. Reproductive BioMedicine Online 2017;35(6):657-68. 


\section{Zegers-Hochschild 2009}

Zegers-Hochschild F, Adamson GD, de Mouzon J, Ishihara O, Mansour R, Nygren K, et al. International Committee for Monitoring Assisted Reproductive Technology (ICMART) and the World Health Organization (WHO) revised glossary of ART terminology, 2009. Fertility and Sterility 2009; Vol. 92, issue 5:1520-4. [PUBMED: 19828144]

\section{Zegers-Hochschild 2017}

Zegers-Hochschild F, Adamson GD, Dyer S, Racowsky C, de Mouzon J, Sokol R, et al. The International Glossary on Infertility and Fertility Care, 2017. Fertility and Sterility 2017;108(3):393-406.

\section{Zhang 2004}

Zhang X, Sharma RK, Agarwal A, Falcone T. Antioxidant effect of pentoxifylline in reducing oxidative stress induced embryotoxicity. Fertility and Sterility 2004;82:324-5.

\section{Zinger 2006}

Zinger M, Liu JH, Thomas MA. Successful use of vaginal sildenafil citrate in two infertility patients with Asherman's

\section{CHARACTERISTICS OF STUDIES}

Characteristics of included studies [ordered by study ID] syndrome. Journal of Women's Health 2006;15(4):442-4. [PUBMED: 16724891]

\section{References to other published versions of this review Gutarra-Vilchez 2012 \\ Gutarra Vilchez RB, Bonfill Cosp X, Glujovsky D, Urrútia G. Vasodilators for women undergoing assisted reproduction. Cochrane Database of Systematic Reviews 2012, Issue 7. [DOI: 10.1002/14651858.CD010001]}

\section{Gutarra-Vilchez 2014}

Gutarra-Vilchez RB, Urrútia G, Glujovsky D, Coscia A, Bonfill Cosp X. Vasodilators for women undergoing fertility treatment. Cochrane Database of Systematic Reviews 2014, Issue 10. [DOI: 10.1002/14651858.CD010001.pub2]

* Indicates the major publication for the study

\section{Abdel 2017}

\begin{tabular}{ll}
\hline Methods & Blinded randomised controlled clinical trial \\
\hline Participants & Number of centres: 1 \\
Setting: hospital & Country: Egypt \\
Length of follow-up: not stated (at least 1 cycle) \\
Number of randomised participants: 120 (60 per group) \\
Age (mean and SD): $28.24 \pm 6.82$ years in experimental group, 26.80 \pm 4.11 years in control group \\
Inclusion criteria: housewives and non-smokers; diagnosis of Idiopathic or unexplained infertility due \\
to failure to achieve pregnancy after 12 months of unprotected regular intercourse; investigations re- \\
vealed (1) normal semen analysis according to WHO reference values, (2) normal regular ovulation with \\
a mid-cycle serum progesterone level of 410 ng/mL, (3) patent fallopian tubes and normal pelvic cavity \\
on ultrasound examination, hysterosalpingography, and hysteroscopy/laparoscopy when indicated
\end{tabular}

Exclusion criteria: women given hypertension drug treatment; refusal of intrauterine insemination

Interventions
- Experimental group: CC $100 \mathrm{mg}$ daily from cycle day 5 to 9 plus isosorbide mononitrate (IMN) $10 \mathrm{mg}$ vaginal tablets

- Control group: oral CC $100 \mathrm{mg}$ daily from cycle day 5 to 9 plus placebo vaginal tablets

Length of treatment: placebo and IMN were given until diagnosis of pregnancy or occurrence of menstruation

Outcomes
Primaries: endometrial thickness, uterine artery blood flow indices, endometrial blood flow indices

Secondaries: pregnancy (diagnosed by serum $\beta-h C G$ and vaginal ultrasound), twins 
Abdel 2017 (Continued)

Notes Funding: not reported

Conflict of interest: study authors declare no conflict of interest

Protocol registry: ACTRN 12613001124729

Sample size calculation: yes

\section{Risk of bias}

\begin{tabular}{lll}
\hline Bias & Authors' judgement & Support for judgement \\
\hline $\begin{array}{l}\text { Random sequence genera- } \\
\text { tion (selection bias) }\end{array}$ & Low risk & $\begin{array}{l}\text { Quote: "120 patients were randomly allocated by computer-generated table } \\
\text { in 1:1 ratio to a control group (60 cases)" }\end{array}$ \\
\hline $\begin{array}{l}\text { Allocation concealment } \\
\text { (selection bias) }\end{array}$ & Low risk & $\begin{array}{l}\text { Quote: "120 patients were randomly allocated by computer-generated table } \\
\text { in 1:1 ratio to a control group (60 cases)" }\end{array}$ \\
& $\begin{array}{l}\text { Comment: "however there is a sentence that makes confusion about alloca- } \\
\text { tion concealment" } \\
\text { The allocated treatment was put inside a sealed opaque envelope and was } \\
\text { chosen by the participant while all investigators were blind. }\end{array}$ \\
\hline
\end{tabular}

\begin{tabular}{|c|c|c|}
\hline $\begin{array}{l}\text { Blinding of participants } \\
\text { and personnel (perfor- } \\
\text { mance bias) } \\
\text { All outcomes }\end{array}$ & Low risk & $\begin{array}{l}\text { Quote: "placebo vaginal tablets" and "... all investigators were blind" } \\
\text { Comment: placebo vaginal tablets were used to blind the interventions }\end{array}$ \\
\hline $\begin{array}{l}\text { Blinding of outcome as- } \\
\text { sessment (detection bias) } \\
\text { All outcomes }\end{array}$ & Low risk & $\begin{array}{l}\text { Quote: "... all investigators were blind" } \\
\text { Comment: placebo vaginal tablets were used to blind the interventions. } \\
\text { Study authors report that pregnancy was diagnosed by serum } \beta-h C G \text { and vagi- } \\
\text { nal ultrasound. }\end{array}$ \\
\hline
\end{tabular}

Incomplete outcome data Low risk

(attrition bias)

Comment: no participant dropout was reported.

All outcomes

Study authors mention that all participants who were randomised were analysed.

\begin{tabular}{|c|c|c|}
\hline $\begin{array}{l}\text { Selective reporting (re- } \\
\text { porting bias) }\end{array}$ & Low risk & $\begin{array}{l}\text { Comment: study authors did report all outcomes that they proposed to mea- } \\
\text { sure in the methods }\end{array}$ \\
\hline Other bias & Low risk & $\begin{array}{l}\text { Comment: Table } 1 \text { shows no significant differences between groups with re- } \\
\text { gard to participant age, body mass index, duration of infertility, endometrial } \\
\text { thickness, uterine artery resistance index and pulsation index and endometrial } \\
\text { vascular index, and flow index and vascular flow index }\end{array}$ \\
\hline
\end{tabular}

\section{Aleyasin 2009}

\begin{tabular}{ll}
\hline Methods & Randomised clinical trial; not blinded \\
\hline Participants & Number of centres: 1 \\
& Setting: Hospital Infertility Department \\
Country: Iran
\end{tabular}


Length of follow-up: not stated (at least 1 cycle)

Number of randomised participants: 112 infertile women (56 intervention, 56 control)

Age (mean and SD): $29.96 \pm 4.62$ experimental group, $29.41 \pm 4.59$ control group

Inclusion criteria: infertile women planned for ZIFT (zygote intrafallopian transfer); younger than 39 years of age without a previous history of ZIFT or IVF failure

Exclusion criteria: hypothalamic amenorrhoea, drug reactions or complications, endometriosis and fibroids

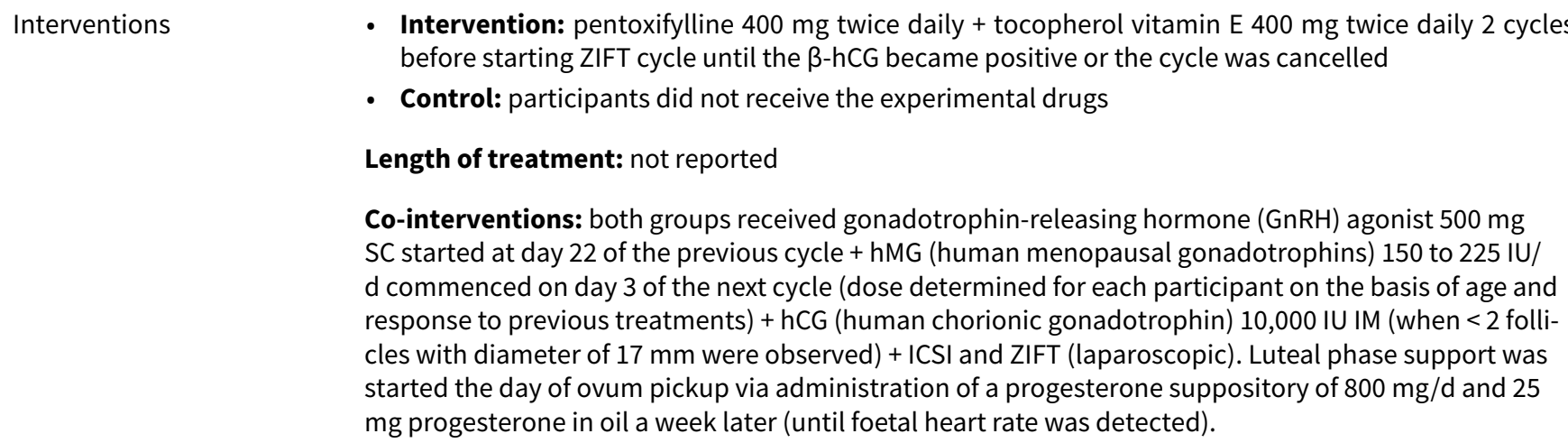

\begin{tabular}{ll}
\hline Outcomes & Primary: clinical pregnancy \\
& $\begin{array}{l}\text { Secondaries: term delivery (equivalent "live birth"), multiple ges } \\
\text { tion/miscarriage, ectopic pregnancy, preterm labour }\end{array}$ \\
\hline Notes & Funding: Infertility Department of Shariati Hospital \\
Conflict of interest: study authors declare no conflict of interest & Protocol registry: not reported \\
& Sample size calculation: not reported
\end{tabular}

\section{Risk of bias}

\begin{tabular}{lll}
\hline Bias & Authors' judgement & Support for judgement \\
\hline $\begin{array}{l}\text { Random sequence genera- } \\
\text { tion (selection bias) }\end{array}$ & Low risk & $\begin{array}{l}\text { Comment: study authors described the method used to generate the alloca- } \\
\text { tion sequence in sufficient detail to allow an assessment of whether it should } \\
\text { produce comparable groups. Computer-generated random number table was } \\
\text { used for randomisation. }\end{array}$
\end{tabular}

Allocation concealment Low risk
(selection bias)

Comment: study authors described the method used to conceal the allocation sequence in sufficient detail to reveal whether intervention allocations could have been determined in advance of, or during, enrolment. Group assignments were placed in sealed, opaque, sequentially numbered envelopes.

\begin{tabular}{|c|c|c|}
\hline $\begin{array}{l}\text { Blinding of participants } \\
\text { and personnel (perfor- } \\
\text { mance bias) } \\
\text { All outcomes }\end{array}$ & Low risk & $\begin{array}{l}\text { Comment: the intervention was not blinded, but surgeons who performed the } \\
\text { operations were blind to participant groups. However, this does not seem to } \\
\text { have affected study results. }\end{array}$ \\
\hline $\begin{array}{l}\text { Blinding of outcome as- } \\
\text { sessment (detection bias) } \\
\text { All outcomes }\end{array}$ & Low risk & $\begin{array}{l}\text { Comment: no blinding of outcome assessment was described, but the review } \\
\text { authors judge that outcome measurement is not likely to be influenced by lack } \\
\text { of blinding }\end{array}$ \\
\hline
\end{tabular}


Aleyasin 2009 (Continued)

Incomplete outcome data Low risk Comment: no participant dropout was reported (all participants were fol(attrition bias) lowed up)

All outcomes

\begin{tabular}{|c|c|c|}
\hline $\begin{array}{l}\text { Selective reporting (re- } \\
\text { porting bias) }\end{array}$ & Low risk & $\begin{array}{l}\text { Comment: study protocol not available, but it is clear that published reports } \\
\text { include all expected outcomes, including those that were prespecified }\end{array}$ \\
\hline
\end{tabular}

Other bias Low risk Comment: groups were comparable for the variables described (age, duration of infertility, type of infertility, cause of infertility, endometrial thickness, retrieved oocytes, metaphase II oocytes)

Alieva 2012

\begin{tabular}{ll}
\hline Methods & Randomised controlled trial \\
\hline Participants & Sumber of centres: 1 \\
& Country: Russia \\
& Length of follow-up: not reported \\
& Number of randomised participants: 91 (32 in experimental group I, 29 in experimental group II, and \\
& 30 in control or group III) \\
& Age (mean and SD): not reported \\
Inclusion criteria: women with tubal infertility who had undergone at least 2 unsuccessful IVF and \\
embryo transfer attempts when transferred embryos were of high quality and disturbances in uterine \\
haemodynamics were present \\
Exclusion criteria: not reported \\
Intervention \\
- Group I: magnetic therapy using intense low frequency in the cycle previous to IVF \\
• Group II: sildenafil citrate in the IVF cycle \\
Control/Group III: no additional treatment \\
\hline Interventions
\end{tabular}

Outcomes

Primaries: evidence of increasing end-diastolic flow velocity, decreased vascular resistance, increased blood flow to uterine vessels

Secondaries: thickness of the endometrium after intervention, pregnancy rate and reproductive loss that were not defined

Funding: not reported
Conflict of interest: not reported
Protocol registry: not reported
Sample size calculation: not reported
Published currently only as an abstract
We did not include this study in the meta-analysis owing to lack of definitions for pregnancy and repro-
ductive loss.


Alieva 2012 (Continued)

Risk of bias

\begin{tabular}{|c|c|c|}
\hline Bias & Authors' judgement & Support for judgement \\
\hline $\begin{array}{l}\text { Random sequence genera- } \\
\text { tion (selection bias) }\end{array}$ & Unclear risk & Comment: methods were not adequately described \\
\hline $\begin{array}{l}\text { Allocation concealment } \\
\text { (selection bias) }\end{array}$ & Unclear risk & Comment: methods were not adequately described \\
\hline $\begin{array}{l}\text { Blinding of participants } \\
\text { and personnel (perfor- } \\
\text { mance bias) } \\
\text { All outcomes }\end{array}$ & Unclear risk & Comment: methods were not adequately described \\
\hline $\begin{array}{l}\text { Blinding of outcome as- } \\
\text { sessment (detection bias) } \\
\text { All outcomes }\end{array}$ & Unclear risk & Comment: methods were not adequately described \\
\hline $\begin{array}{l}\text { Incomplete outcome data } \\
\text { (attrition bias) } \\
\text { All outcomes }\end{array}$ & Unclear risk & Comment: methods were not adequately described \\
\hline $\begin{array}{l}\text { Selective reporting (re- } \\
\text { porting bias) }\end{array}$ & Unclear risk & Comment: methods were not adequately described \\
\hline Other bias & Unclear risk & Comment: methods were not adequately described \\
\hline
\end{tabular}

Azmy 2016

\begin{tabular}{ll}
\hline Methods & Randomised controlled clinical trial \\
\hline Participants & Clinical trial design: randomised controlled trial \\
& Number of participant centres: 1 \\
& Setting: not reported \\
& Country: Egypt \\
& Length of follow-up: 2 cycles (56 days) \\
& Number of randomised participants: $65 ; 30$ in the experimental group, 35 in the control group \\
& Age (mean and SD): not reported \\
& Inclusion criteria: infertile women with diagnosis of polycystic ovarian syndrome \\
& Exclusion criteria: not reported \\
\hline Interventions & Experimental intervention: clomiphene citrate (CC) + amlodipine \\
Length of treatment: 2 cycles (56 days)
\end{tabular}

Outcomes

Primary: pregnancy rate 
Azmy 2016 (Continued)

Secondaries: endometrial thickness, pulsatility index of uterine artery, pulsatility index of ovarian artery, ultrasound indices, sonographically detectable mature follicle by cycle

Funding: not reported
Conflict of interest: not reported
Sample size calculation: not reported
Published currently only as an abstract

Risk of bias

\begin{tabular}{lll}
\hline Bias & Authors' judgement & Support for judgement \\
\hline $\begin{array}{l}\text { Random sequence genera- } \\
\text { tion (selection bias) }\end{array}$ & Unclear risk & Comment: methods were not described \\
\hline
\end{tabular}

Allocation concealment $\quad$ Unclear risk Comment: methods were not described
(selection bias)

Blinding of participants Unclear risk Comment: methods were not described
and personnel (performance bias)

All outcomes

\begin{tabular}{lll}
\hline $\begin{array}{l}\text { Blinding of outcome as- } \\
\text { sessment (detection bias) } \\
\text { All outcomes }\end{array}$ & Unclear risk & Comment: methods were not described \\
\hline $\begin{array}{l}\text { Incomplete outcome data } \\
\text { (attrition bias) }\end{array}$ & Unclear risk & Comment: methods were not described \\
All outcomes & &
\end{tabular}

\begin{tabular}{lll}
\hline $\begin{array}{l}\text { Selective reporting (re- } \\
\text { porting bias) }\end{array}$ & Low risk & $\begin{array}{l}\text { Comment: less than } 20 \% \text { of losses. Study authors describe that } 65 \text { women } \\
\text { were recruited but describe only } 60 \text { in the text. }\end{array}$ \\
\hline Other bias & Unclear risk & $\begin{array}{l}\text { Comment: we did not know the original outcomes to be measured; therefore } \\
\text { we cannot know if all of them were reported }\end{array}$ \\
\hline
\end{tabular}

Das 2009

\begin{tabular}{ll}
\hline Methods & Randomised controlled trial \\
\hline Participants & Number of centres: 1 \\
Setting: tertiary care hospital & Country: India \\
& Length of follow-up: not reported \\
& Number of randomised participants: 50 (25 per group) \\
& Age (mean and SD): $26.96 \pm 2.92$ years in experimental group, $26.08 \pm 3.83$ years in control group \\
& Inclusion criteria: infertile women with a thin endometrium $(<9$ mm) undergoing intrauterine insemi- \\
& nation on 2 occasions
\end{tabular}


Das 2009 (Continued)

Exclusion criteria: tubal block or severe tubal damage; ovarian failure; very poor egg quality and quantity; severe male factor infertility; known hypersensitivity to sildenafil; coronary heart disease and taking nitrates; liver or kidney disease; peptic ulcer; bleeding disorder; migraine; receiving erythromycin, ketoconazole, verapamil, or cimetidine treatment

Interventions $\begin{aligned} & \text { Intervention: sildenafil } 25 \mathrm{mg} \text { vaginally } 4 \text { times a day from day } 5 \text { of cycle until day of hCG adminis- } \\ & \text { tration }\end{aligned}$
- Control: no sildenafil
Co-interventions: both groups: ovulation induction was achieved with clomiphene citrate $100 \mathrm{mg}$
from days 2 through 6 . Follicular monitoring was conducted until the follicle reached 18 to $20 \mathrm{~mm}$, at
which time 5000 IU hCG injection was given and IUI was done on 2 occasions: after 24 hours and after
48 hours. Before IUI, couples were advised abstinence for 3 to 4 days. 200 mg micronised progesterone
was given orally as luteal phase support twice daily for 14 days after second IUI.

Length of treatment: not reported

\begin{tabular}{ll}
\hline Outcomes & Primary: pregnancy or conception rates (positive urine pregnancy test) \\
& Secondaries: endometrial thickness, uterine artery PI on day of hCG administration \\
\hline Notes & Funding: Research Cell CSMMU, Lucknow, India \\
& Conflict of interest: not reported \\
& Protocol registry: not reported \\
& Sample size calculation: not reported \\
\hline
\end{tabular}

\section{Risk of bias}

\begin{tabular}{lll}
\hline Bias & Authors' judgement & Support for judgement \\
\hline $\begin{array}{l}\text { Random sequence genera- } \\
\text { tion (selection bias) }\end{array}$ & Unclear risk & $\begin{array}{l}\text { Comment: methods were not adequately described (alternate participants } \\
\text { were taken as case and control). Patients received sildenafil } 25 \text { mg vaginal } \\
\text { suppositories, and controls received no treatment. }\end{array}$ \\
\hline $\begin{array}{l}\text { Allocation concealment } \\
\text { (selection bias) }\end{array}$ & Unclear risk & $\begin{array}{l}\text { Comment: } \text { methods were not adequately described (all cases were given tab } \\
\text { sildenafil } 25 \text { mg vaginally } 4 \text { times a day from day } 5 \text { of the cycle until day of hCG } \\
\text { administration) }\end{array}$ \\
\hline
\end{tabular}

Blinding of participants Unclear risk Comment: study did not use placebo
and personnel (perfor-
mance bias)
All outcomes

\begin{tabular}{|c|c|c|}
\hline $\begin{array}{l}\text { Blinding of outcome as- } \\
\text { sessment (detection bias) } \\
\text { All outcomes }\end{array}$ & Low risk & $\begin{array}{l}\text { Comment: no blinding of outcome assessment was described, but review au- } \\
\text { thors judged that measurement of pregnancy outcome is not likely to be influ- } \\
\text { enced by lack of blinding }\end{array}$ \\
\hline
\end{tabular}

\begin{tabular}{lll}
\hline $\begin{array}{l}\text { Incomplete outcome data } \\
\text { (attrition bias) } \\
\text { All outcomes }\end{array}$ & Low risk & Comment: investigators evaluated all randomly assigned women \\
\hline $\begin{array}{l}\text { Selective reporting (re- } \\
\text { porting bias) }\end{array}$ & Unclear risk & $\begin{array}{l}\text { Comment: study protocol was not available, and published reports do not in- } \\
\text { clude all expected outcomes - only those that were prespecified }\end{array}$ \\
\hline Other bias & Low risk & $\begin{array}{l}\text { Comment: } \text { no statistically significant differences in age or BMI were noted be- } \\
\text { tween the 2 groups }\end{array}$ \\
\hline
\end{tabular}




\begin{tabular}{ll}
\hline Methods & Randomised clinical controlled trial, not blinded \\
\hline Participants & Number of centres: 1 \\
Setting: Centre for Infertility - University Hospital \\
Country: Iran \\
Length of follow-up: not reported \\
Number of randomised participants: 80 (40 per group) \\
Age (mean and SD): 29 years in experimental group, 28 years in control group \\
Inclusion criteria: women with an antecedent of poor endometrial response and frozen embryos were \\
included in this study. Inclusion criteria required participants to be younger than 40 years of age and to \\
have high-quality frozen embryos.
\end{tabular}

Exclusion criteria: history of endocrine disease; hysteroscopic surgery; cardiovascular, renal, and liver disease; hypotension (blood pressure $<90 / 50 \mathrm{mmHg}$ ); history of stroke or myocardial infarction

- Intervention: sildenafil citrate tablets $(50 \mathrm{mg}$ ) daily (from first day of cycle until day progesterone was
started)
- Control: no sildenafil
Co-interventions: in both groups on the 13 th day of the menstrual cycle, endometrial thickness was
measured by transvaginal ultrasonography. If endometrial thickness was
$>8 \mathrm{~mm}, 100 \mathrm{mg}$ progesterone was injected IM
Oral oestradiol valerate (first to fourth day of menstrual cycle, 2 mg oestradiol valerate tablets; fifth to
eighth day of menstrual cycle, $4 \mathrm{mg}$ oestradiol valerate tablets; ninth to 12 th day of menstrual cycle, 6
mg oestradiol valerate tablets) was given daily.
Administering oestradiol valerate and progesterone continued until 2 weeks after embryos were trans-
ferred.

Outcomes Primary outcome: endometrial thickness

Other outcome: implantation rate, chemical pregnancy rate (we used implantation rate as the clinical pregnancy rate)

Notes

Funding: Shahid Sadoughi University of Medical Sciences and Health Services, Yazd, Iran

Conflict of interest: study authors reported no conflicts of interest

Protocol registry: no registry reported

Sample size calculation: not reported

\section{Risk of bias}

\begin{tabular}{lll}
\hline Bias & Authors' judgement & Support for judgement \\
\hline $\begin{array}{l}\text { Random sequence genera- } \\
\text { tion (selection bias) }\end{array}$ & Low risk & $\begin{array}{l}\text { Comment: participants were divided into 2 groups on the basis of randomised } \\
\text { tables }\end{array}$ \\
\hline $\begin{array}{l}\text { Allocation concealment } \\
\text { (selection bias) }\end{array}$ & Unclear risk & $\begin{array}{l}\text { Comment: information was insufficient to permit judgement of 'low risk' or } \\
\text { 'high risk'. Allocation was not described. }\end{array}$ \\
\hline
\end{tabular}


Dehghani Firouzabadi 2013 (Continued)
Blinding of participants
Unclear risk
Comment: study did not use placebo and personnel (perfor- mance bias)
All outcomes

\begin{tabular}{lll}
\hline $\begin{array}{l}\text { Blinding of outcome as- } \\
\text { sessment (detection bias) }\end{array}$ & Low risk & $\begin{array}{l}\text { Comment: no blinding of outcome assessment, but review authors judge that } \\
\text { measurement of pregnancy outcome is not likely to be influenced by lack of } \\
\text { All outcomes }\end{array}$ \\
\hline
\end{tabular}

\begin{tabular}{lll}
\hline $\begin{array}{l}\text { Incomplete outcome data } \\
\text { (attrition bias) } \\
\text { All outcomes }\end{array}$ & Low risk & Comment: investigators evaluated all randomly assigned women \\
\hline $\begin{array}{l}\text { Selective reporting (re- } \\
\text { porting bias) }\end{array}$ & Low risk & $\begin{array}{l}\text { Comment: study protocol is available, and published reports include those } \\
\text { that were prespecified. Investigators did not include all expected outcomes. }\end{array}$ \\
\hline Other bias & Low risk & $\begin{array}{l}\text { Comment: groups were comparable for the variables described (duration of } \\
\text { infertility, age, basal FSH, basal LH, basal oestrogen, basal progesterone, basal } \\
\text { FSH/LH) }\end{array}$ \\
\hline
\end{tabular}

\section{El-Berry 2010}

\begin{tabular}{ll}
\hline Methods & Randomised controlled study \\
\hline Participants & Number of centres: 1 \\
& Setting: University Hospital \\
& Country: Egypt \\
& Length of follow-up: not reported \\
& Number of randomised participants: 30 (15 per group) \\
& Age (mean and SD): $27.13 \pm 4.32$ years in experimental group, $28.40 \pm 3.62$ years in control group \\
& Inclusion criteria: polycystic ovary infertile women diagnosed according to American Society of Re- \\
productive Medicine and European Society of Human Reproductive and Embryology who underwent \\
ovulation induction \\
Exclusion criteria: not reported \\
- Intervention: nitric oxide donors (isosorbide mononitrate (ISMN)) 20 mg vaginally until diagnosis of \\
ovulation and pregnancy \\
Control: did not receive experimental drug \\
Co-intervention: both groups received 100 mg clomiphene citrate (CC) for 5 days from fifth day of cycle \\
Length of treatment: 3 cycles \\
\hline Interventions
\end{tabular}

Outcomes

Primaries: ovulation and pregnancy rates (diagnosed by serum $\beta-h C G$ )

Secondaries: number of mature follicles, cervical mucus score, endometrial thickness

Funding: not reported
Conflict of interest: not reported
Protocol registry: not reported


El-Berry 2010 (Continued)

Sample size calculation: not reported

\section{Risk of bias}

\begin{tabular}{lll}
\hline Bias & Authors' judgement & Support for judgement \\
\hline $\begin{array}{l}\text { Random sequence genera- } \\
\text { tion (selection bias) }\end{array}$ & Unclear risk & $\begin{array}{l}\text { Comment: insufficient information about the sequence generation process to } \\
\text { allow judgement }\end{array}$ \\
\hline
\end{tabular}

\begin{tabular}{lll}
\hline $\begin{array}{l}\text { Allocation concealment } \\
\text { (selection bias) }\end{array}$ & Unclear risk & $\begin{array}{l}\text { Comment: } \text { method of concealment not described to allow a definitive judge- } \\
\text { ment }\end{array}$ \\
\hline $\begin{array}{l}\text { Blinding of participants } \\
\text { and personnel (perfor- } \\
\text { mance bias) } \\
\text { All outcomes }\end{array}$ & Unclear risk & Comment: methods used in this study not adequately described \\
\hline $\begin{array}{l}\text { Blinding of outcome as- } \\
\text { sessment (detection bias) }\end{array}$ & Low risk & $\begin{array}{l}\text { Comment: no blinding of outcome assessment, but review authors judge that } \\
\text { measurement of pregnancy outcome is not likely to be influenced by lack of } \\
\text { blinding }\end{array}$ \\
\hline $\begin{array}{l}\text { Incomplete outcome data } \\
\text { (attrition bias) }\end{array}$ & Unclear risk & $\begin{array}{l}\text { Comment: } \text { no loss of participants, but unclear how many cycles each partic- } \\
\text { ipant received and reasons for interrupting treatment. } 37 \text { cycles in the inter- } \\
\text { vention group and } 40 \text { in the control group, but we used number of women (15 } \\
\text { in each group) }\end{array}$ \\
\hline $\begin{array}{l}\text { Selective reporting (re- } \\
\text { porting bias) }\end{array}$ & Unclear risk & $\begin{array}{l}\text { Comment: study protocol is not available, and published reports do not in- } \\
\text { clude all expected outcomes - only those that were prespecified }\end{array}$ \\
\hline $\begin{array}{l}\text { Other bias } \\
\text { Comment: groups were comparable for variables described (age, body mass }\end{array}$ \\
\hline
\end{tabular}

Fahmy 2015

Methods Prospective randomised clinical trial

Participants

\section{Number of centres: 1}

Setting: clinic at a University Hospital

Country: Egypt

Length of follow-up: not stated (at least 1 cycle)

Number of randomised participants: 70 (35 women per group)

Age (mean and SD): $28.34 \pm 4.13$ years in experimental group, $28.40 \pm 3.15$ years in control group

Inclusion criteria: infertile women between 18 and 40 years of age with primary or secondary infertility and with regular menstrual cycles

Exclusion criteria: ovarian cysts; abnormal hormonal profile (e.g. hyperprolactinaemia); significant cardiovascular liver or renal disease; history of any pelvic pathology

\footnotetext{
Interventions

- Experimental group: sildenafil citrate $25 \mathrm{mg}$ (Viagra, Pfizer) orally 3 times/d from seventh to 11 th day of cycle

- Control group: placebo (not described)
} 
Fahmy 2015 (Continued)

Co-interventions: induction of ovulation in both groups with clomiphene citrate (CC) $50 \mathrm{mg}$ (clomid, Glopa) orally 3 times/d from third to seventh day of the cycle along with intramuscular injection of 5000 IU of human chorionic gonadotrophin (hCG), which was used to trigger ovulation

Length of treatment: not reported

\begin{tabular}{ll}
\hline Outcomes & Primary: pregnancy rate (chemical ( $\beta$-hCG positive)) \\
Secondaries: endometrial thickness, total follicles, side effects of vasodilator (headache, flushing, \\
blurring of vision)
\end{tabular}

Notes
Conflict of interest: study authors declare no conflict of interest
Protocol registry: not reported
Sample size calculation: not reported

\section{Risk of bias}

\begin{tabular}{lll}
\hline Bias & Authors' judgement & Support for judgement \\
\hline $\begin{array}{l}\text { Random sequence genera- } \\
\text { tion (selection bias) }\end{array}$ & Unclear risk & $\begin{array}{l}\text { Quote: "The patients in this study were divided into two groups by random al- } \\
\text { location using sealed envelope: the treatment group (Sildenafil group) and the } \\
\text { control group (placebo group) with 35 patients in each group" }\end{array}$ \\
& $\begin{array}{l}\text { Comment: the method used to generate the random sequence was not speci- } \\
\text { fied }\end{array}$ \\
\hline $\begin{array}{l}\text { Allocation concealment } \\
\text { (selection bias) }\end{array}$ & Low risk & $\begin{array}{l}\text { Quote: "The patients in this study were divided into two groups by random al- } \\
\text { location using sealed envelope: the treatment group (Sildenafil group) and the } \\
\text { control group (placebo group) with 35 patients in each group" }\end{array}$
\end{tabular}

Blinding of participants Unclear risk Comment: methods were not adequately described
and personnel (performance bias)

All outcomes

\begin{tabular}{lll}
\hline $\begin{array}{l}\text { Blinding of outcome as- } \\
\text { sessment (detection bias) } \\
\text { All outcomes }\end{array}$ & Unclear risk & Comment: methods were not adequately described \\
\hline $\begin{array}{l}\text { Incomplete outcome data } \\
\text { (attrition bias) } \\
\text { All outcomes }\end{array}$ & Low risk & $\begin{array}{l}\text { Comment: no participant dropout was reported (all participants were fol- } \\
\text { lowed up). Study flow chart shows that all randomised participants were } \\
\text { analysed. }\end{array}$ \\
\hline $\begin{array}{l}\text { Selective reporting (re- } \\
\text { porting bias) }\end{array}$ & Low risk & $\begin{array}{l}\text { Comment: we defined a PICO question for the article from the abstract and } \\
\text { the methods section; study authors did report all outcomes that they pro- } \\
\text { posed to measure }\end{array}$ \\
\hline
\end{tabular}

Other bias Low risk Comment: differences in demographic characteristics of participants between treatment and control groups were non-significant, except for endometrial thickness

\begin{tabular}{ll}
\hline Methods $\quad$ Prospective randomised double-blinded placebo-controlled clinical trial \\
\hline
\end{tabular}


Farzi 2005 (Continued)

\section{Participants}

\section{Number of centres: 1}

Setting: clinic of infertility

Country: Iran

Length of follow-up: not reported

Number of randomised participants: 100 (50 per group)

Age (mean and SD): $31 \pm 5.5$ years in experimental group, $30.1 \pm 5.1$ in control group

Inclusion criteria: participants underwent ICSI regardless of male or female infertility when both were present, or when causes were unknown

Exclusion criteria: not reported

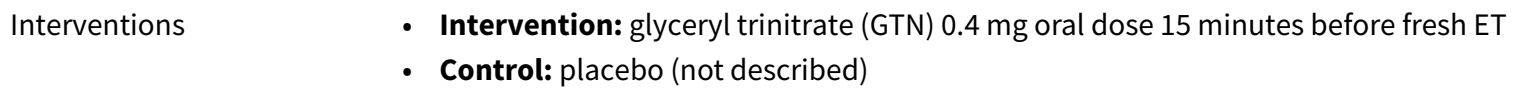

Co-interventions: both groups were initially stimulated with a long protocol. Then, on the third day of of the next menstrual cycle, hMG 150 to $225 \mathrm{IU}$ was injected and was adjusted with follicular development monitoring by vaginal ultrasound. In addition, 10,000 IU hCG was given IM when at least 3 follicular diameters of $18 \mathrm{~mm} 38$ hours later led to ovarian puncture

Length of treatment: 1 cycle was performed for each participant

\begin{tabular}{ll}
\hline Outcomes & Primaries: implantation rate, clinical pregnancy rate \\
& Secondaries: taking baby home (equivalent "live birth"), spontaneous abortion/miscarriage, biochem- \\
ical pregnancy
\end{tabular}

Notes

Funding: not reported

Conflict of interest: not reported

Protocol registry: not reported

Sample size calculation: not reported

\section{Risk of bias}

\begin{tabular}{lll}
\hline Bias & Authors' judgement & Support for judgement \\
\hline $\begin{array}{l}\text { Random sequence genera- } \\
\text { tion (selection bias) }\end{array}$ & Unclear risk & $\begin{array}{l}\text { Comment: information about the sequence generation process was insuffi- } \\
\text { cient to allow judgement }\end{array}$ \\
\hline $\begin{array}{l}\text { Allocation concealment } \\
\text { (selection bias) }\end{array}$ & Unclear risk & Comment: method of concealment not described \\
\hline $\begin{array}{l}\text { Blinding of participants } \\
\text { and personnel (perfor- } \\
\text { mance bias) }\end{array}$ & Low risk & Comment: double-blinded with use of placebo \\
All outcomes & & \\
\hline
\end{tabular}

\begin{tabular}{|c|c|c|}
\hline $\begin{array}{l}\text { Blinding of outcome as- } \\
\text { sessment (detection bias) }\end{array}$ & Low risk & $\begin{array}{l}\text { Comment: not described, but main outcome not subjective. Outcome mea- } \\
\text { surement is not likely to be influenced by lack of blinding. }\end{array}$ \\
\hline
\end{tabular}

All outcomes

Incomplete outcome data Low risk Comment: study described 100 randomly assigned cycles
(attrition bias)


Farzi 2005 (Continued)

All outcomes
Additional information from study authors: 100 participants entered and completed this randomisation study; 1 cycle was performed for each participant

\begin{tabular}{lll}
\hline $\begin{array}{l}\text { Selective reporting (re- } \\
\text { porting bias) }\end{array}$ & Low risk & $\begin{array}{l}\text { Comment: study protocol is not available, but it is clear that published reports } \\
\text { include all expected outcomes, including those that were prespecified }\end{array}$ \\
\hline Other bias & Low risk & $\begin{array}{l}\text { Comment: groups were comparable for variables described: age of the father } \\
\text { and age of the mother, duration of infertility, oocyte retrieved, oocyte injected, } \\
2 \text { pronuclei, cleaved embryos, embryos transferred, causes of infertility, em- } \\
\text { bryo quality }\end{array}$ \\
\hline
\end{tabular}

Kim 2010

\begin{tabular}{|c|c|}
\hline Methods & Pilot randomised clinical trial \\
\hline \multirow[t]{8}{*}{ Participants } & Number of centres: 1 \\
\hline & Setting: MizMedi Hospital \\
\hline & Country: Korea \\
\hline & Length of follow-up: not reported \\
\hline & $\begin{array}{l}\text { Number of randomised participants: } 48 \text { women ( } 21 \text { intervention, } 27 \text { control) among } 170 \text { patients with } \\
\text { a thin endometrium }\end{array}$ \\
\hline & Age (mean and SD): $36.4 \pm 4.6$ years in experimental group, $36.3 \pm 4.3$ years in control group \\
\hline & $\begin{array}{l}\text { Inclusion criteria: women with a thin endometrium ( }<8 \mathrm{~mm} \text { : range } 5 \text { to } 7.9 \mathrm{~mm} \text { ) at the time of embryo } \\
\text { transfer undergoing IVF }\end{array}$ \\
\hline & Exclusion criteria: not reported \\
\hline \multirow[t]{4}{*}{ Interventions } & $\begin{array}{l}\text { - Intervention: vaginal sildenafil } 25 \mathrm{mg} / \mathrm{d}+\text { oral oestradiol valerate } 4 \mathrm{mg} / \mathrm{d} \text { from day of embryo transfer } \\
\text { until pregnancy test (11 days) }\end{array}$ \\
\hline & - Control: did not receive the above drugs \\
\hline & $\begin{array}{l}\text { Co-interventions: both groups received recombinant FSH beginning on } 3 \mathrm{CD}+\text { multiple-dose proto- } \\
\text { col of } \mathrm{GnRH} \text { antagonist }+250 \mu \mathrm{g} \text { recombinant } \mathrm{hCG} \text { (when dominant follicles averaged } 19 \mathrm{~mm} \text { in diame- } \\
\text { ter to trigger ovulation). For all participants, luteal phase was supported by vaginal micronised proges- } \\
\text { terone } 600 \mathrm{mg} / \mathrm{d} \text {, starting on the day of oocyte retrieval and continued for another } 6 \text { to } 8 \text { weeks when } \\
\text { pregnancy was achieved. }\end{array}$ \\
\hline & Length of treatment: not reported \\
\hline \multirow[t]{2}{*}{ Outcomes } & Primary: clinical pregnancy \\
\hline & Secondary: fertilisation rate \\
\hline \multirow[t]{4}{*}{ Notes } & Funding: not reported \\
\hline & Conflict of interest: not reported \\
\hline & Protocol registry: not reported \\
\hline & Sample size calculation: not reported \\
\hline
\end{tabular}

\section{Risk of bias}


Kim 2010 (Continued)

\begin{tabular}{lll} 
Bias & Authors' judgement & Support for judgement \\
\hline $\begin{array}{l}\text { Random sequence genera- } \\
\text { tion (selection bias) }\end{array}$ & Unclear risk & $\begin{array}{l}\text { Comment: information about sequence generation process insufficient to al- } \\
\text { low judgement }\end{array}$ \\
\hline $\begin{array}{l}\text { Allocation concealment } \\
\text { (selection bias) }\end{array}$ & Unclear risk & $\begin{array}{l}\text { Comment: } \text { method of concealment not described to allow a definitive judge- } \\
\text { ment }\end{array}$ \\
\hline $\begin{array}{l}\text { Blinding of participants } \\
\text { and personnel (perfor- } \\
\text { mance bias) }\end{array}$ & Unclear risk & Comment: study did not use placebo \\
All outcomes & &
\end{tabular}

Blinding of outcome as- Low risk sessment (detection bias) All outcomes
Comment: not described, but outcome measurement not likely to be influenced by lack of blinding

Incomplete outcome data Low risk Comment: investigators evaluated all randomly assigned women
(attrition bias)

All outcomes

\begin{tabular}{|c|c|c|}
\hline $\begin{array}{l}\text { Selective reporting (re- } \\
\text { porting bias) }\end{array}$ & Unclear risk & $\begin{array}{l}\text { Comment: study protocol not available; no published reports describe all ex- } \\
\text { pected outcomes }\end{array}$ \\
\hline
\end{tabular}

Selective reporting (re- Unclear risk

Other bias Low risk

Comment: groups were comparable for the variables described (female age, duration of infertility, cause of infertility, total dose of gonadotrophin, day of triggering, endometrial thickness at triggering, number of ICSI cycles, number of embryos transferred)

Magdi Ammar 2017

Methods Randomised controlled trial

Participants

\author{
Number of centres: 1 \\ Setting: infertility clinic of the Cytogenetic and Endoscopy Unit, Zagazig University Hospital \\ Country: Egypt \\ Length of follow-up: 15 months
}

Number of participants: 236 patients who underwent a single cycle of ovulation induction and timed intercourse

Age: 18 to 35 years

Inclusion criteria: primary infertility due to unexplained infertility or PCOS; both tubes and uterine cavity normal as assessed by hysterosalpingography (HSG); neither history of previous endometrial surgery nor history of smoking; willingness to participate in the study; body mass index (BMI) ranging between 18 and $25 \mathrm{~kg} / \mathrm{m}^{2}$

Exclusion criteria: endometriosis; history of ovarian hyperstimulation syndrome (OHSS); abnormal HSG/laparoscopy suggestive of pelvic adhesions with altered tubo-ovarian relationship (like pelvic endometriosis, chronic PID, and postoperative adhesions); Mullerian malformations; hypogonadotropic hypogonadism; primary amenorrhoea; premature ovarian failure; secondary infertility; failed IUI or IVF; abnormal husband semen parameters

Interventions

- Group A: clomiphene citrate (Clomid $50 \mathrm{mg}$ ) as $100 \mathrm{mg}$ (2 tablets) daily for 5 days (from second day until sixth day of the cycle)

- Group B: clomiphene citrate (Clomid $50 \mathrm{mg}$ ) as $100 \mathrm{mg}$ (2 tablets) daily for 5 days (from second day until sixth day of the cycle) and tadalafil (CIALIS-tadalafil) oral $5 \mathrm{mg} / \mathrm{d}$ for 7 days (from fourth day until 10 th day of the cycle) 
- Group C: human menopausal gonadotropin (hMG) (Menogon) IM was given from second day of the cycle until 1 to 3 follicles reach a size $\geq 18 \mathrm{~mm}$. Dose of hMG ranged from 75 to $225 \mathrm{IU} / \mathrm{mL}$ according to the patient's response.

Co-interventions: all participants in the 3 studied groups received luteal phase support by vaginal progesterone suppositories $200 \mathrm{mg}$ (Prontogest, GMP Marcyrl) twice daily, which was started on the day of timed intercourse for 2 weeks until pregnancy test and was continued for 2 weeks longer if positive

Primary
- Endometrial thickness on the day of hCG triggering
- Total pregnancy rate (cases with a positive pregnancy test defined as a finding of plasma $\beta$-hCG con-
centration $>10 \mathrm{mU} / \mathrm{mL} 2$ weeks after timed intercourse). All cases with positive serum pregnancy test
(chemical pregnancy) were followed up by transabdominal ultrasound 6 weeks from the first day of
the last menstrual period for detection of intrauterine gestational sac (clinical pregnancy).

Notes

Funding: not reported

Conflict of interest: not reported

Protocol registry: not reported

Sample size calculation: not reported

\section{Risk of bias}

\begin{tabular}{lll}
\hline Bias & Authors' judgement & Support for judgement \\
\hline $\begin{array}{l}\text { Random sequence genera- } \\
\text { tion (selection bias) }\end{array}$ & Low risk & $\begin{array}{l}\text { Quote: "Patients were divided randomly by using random number table (com- } \\
\text { puter), software Open Epi version 3.21, into three groups (A, B, and C). Patients } \\
\text { were assigned to either group by the randomization known while allocation } \\
\text { concealment concentrated on preventing selection and confusing biases" }\end{array}$ \\
\hline
\end{tabular}

Allocation concealment Unclear risk Comment: not reported

(selection bias)

Blinding of participants Unclear risk Comment: not reported
and personnel (perfor-
mance bias)
All outcomes

\begin{tabular}{|c|c|c|}
\hline $\begin{array}{l}\text { Blinding of outcome as- } \\
\text { sessment (detection bias) } \\
\text { All outcomes }\end{array}$ & Unclear risk & Comment: not reported \\
\hline $\begin{array}{l}\text { Incomplete outcome data } \\
\text { (attrition bias) } \\
\text { All outcomes }\end{array}$ & High risk & $\begin{array}{l}\text { Comment: } 102 \text { (30\%) participants were dropped from follow-up - those who } \\
\text { failed to respond to the administered ovulation induction drug }\end{array}$ \\
\hline $\begin{array}{l}\text { Selective reporting (re- } \\
\text { porting bias) }\end{array}$ & Low risk & Comment: results of all outcomes described in methods are reported \\
\hline Other bias & Low risk & Basal characteristics are similar between groups. \\
\hline
\end{tabular}


Mahran 2016

\begin{tabular}{|c|c|}
\hline Methods & Randomised open controlled clinical trial \\
\hline \multirow[t]{8}{*}{ Participants } & Number of centres: 2 \\
\hline & Setting: fertility units of hospitals \\
\hline & Country: Egypt \\
\hline & Length of follow-up: not reported \\
\hline & $\begin{array}{l}\text { Number of participants: } 95 \text { women; } 30 \text { ( } 74 \text { cycles) women in experimental group } 1 ; 30 \text { ( } 72 \text { cycles) in ex } \\
\text { perimental group } 2 ; 35 \text { ( } 81 \text { cycles) in the control group }\end{array}$ \\
\hline & $\begin{array}{l}\text { Age (mean and SD): } 27.5 \pm 4.3 \text { years in experimental group } 1 ; 26 \pm 5.4 \text { years in experimental group } 2 \text {; } \\
26.1 \pm 4 \text { years in control group }\end{array}$ \\
\hline & $\begin{array}{l}\text { Inclusion criteria: women } 20 \text { to } 39 \text { years old with diagnosis of polycystic ovarian syndrome (based on } \\
\text { the Rotterdam criteria); meeting at least } 2 \text { of the following } 3 \text { criteria: oligo or anovulation; clinical or } \\
\text { biochemical hyperandrogenaemia; and polycystic ovaries ( }>12 \text { follicles }<10 \mathrm{~mm} \text { and/or ovarian vol- } \\
\text { ume }>10 \mathrm{~mL} \text { per ovary by vaginal ultrasound) }\end{array}$ \\
\hline & $\begin{array}{l}\text { Exclusion criteria: women with uterine pathology as fibroids; tubal factor of infertility (diagnosed } \\
\text { by hysterosalpingography (HSG) or laparoscopy); male factor infertility; any contraindications for } \\
\text { clomiphene citrate (CC) and nitric oxide (chronic liver and renal disease, known cardiac disease, and } \\
\text { migraine); hyperprolactinaemia; thyroid dysfunction; Cushing's syndrome; congenital adrenal hyper- } \\
\text { plasia; an adrenal or ovarian tumour }\end{array}$ \\
\hline
\end{tabular}

- Group B: treated with CC $100 \mathrm{mg}$ for 5 days starting from cycle day 5 in addition to $10 \mathrm{mg}$ isosorbide mononitrate (ISMN) tablets applied vaginally from day 2 to day 15 of the cycle

- Group C: treated with CC $100 \mathrm{mg}$ for 5 days starting from fifth day of cycle in addition to $20 \mathrm{mg}$ ISMN tablets applied vaginally from day 2 to day 15 of the cycle

- Control group (group A): treated with CC $100 \mathrm{mg}$ for 5 days starting from cycle day 5

Length of treatment: not reported

$\begin{array}{ll}\text { Outcomes } & \text { Primaries: ovulation rate per treatment cycle; pregnancy rate per treatment cycle (pregnancy diag- } \\ \text { nosed by serum } \beta-\mathrm{hCG})\end{array}$

Secondaries: number of mature follicles; endometrial thickness; side effects recorded with treatment

Notes

Funding: Department of Obstetrics and Gynecology, Minia University, Minia, Egypt

Conflict of interest: study authors declare that there is no conflict of interest in this paper

Protocol registry: not reported

Sample size calculation: not reported

\section{Risk of bias}

\begin{tabular}{lll}
\hline Bias & Authors' judgement & Support for judgement \\
\hline $\begin{array}{l}\text { Random sequence genera- } \\
\text { tion (selection bias) }\end{array}$ & Unclear risk & $\begin{array}{l}\text { Quote: "Patients were randomized into three groups" - "Randomization was } \\
\text { done simply using sealed envelopes" } \\
\text { Comment: study authors did not specify how the randomisation list was gen- } \\
\text { erated }\end{array}$ \\
\hline
\end{tabular}

\begin{tabular}{l}
$\begin{array}{l}\text { Allocation concealment } \\
\text { (selection bias) }\end{array}$ \\
\hline
\end{tabular}


Mahran 2016 (Continued)

Blinding of participants Unclear risk Quote: "The subject allocation was neither blinded to the patients nor to the and personnel (perforphysicians and investigators" mance bias)

All outcomes

Comment: pregnancy outcome measurement not likely to be influenced by lack of blinding, but yes in the case of side effects

\section{Blinding of outcome as- Unclear risk} sessment (detection bias)

All outcomes

Quote: "The subject allocation was neither blinded to the patients nor to the physicians and investigators"

Comment: pregnancy outcome measurement not likely to be influenced by lack of blinding, but yes in the case of side effects; reported that pregnancy was diagnosed by serum $\beta$-hCG

\begin{tabular}{|c|c|c|}
\hline $\begin{array}{l}\text { Incomplete outcome data } \\
\text { (attrition bias) }\end{array}$ & Unclear risk & $\begin{array}{l}\text { Comment: no participant dropout was reported (all participants were fol- } \\
\text { lowed up). }\end{array}$ \\
\hline
\end{tabular}

All outcomes

\begin{tabular}{lll}
\hline $\begin{array}{l}\text { Selective reporting (re- } \\
\text { porting bias) }\end{array}$ & Low risk & $\begin{array}{l}\text { Comment: study authors did report all outcomes that they proposed to mea- } \\
\text { sure in methods }\end{array}$ \\
\hline Other bias & Low risk & $\begin{array}{l}\text { No significant differences between the 3 groups in demographic, hormonal, or } \\
\text { sonographic features }\end{array}$ \\
\hline
\end{tabular}

Mostafa 2003

Methods $\quad$ Randomised controlled trial

\section{Participants}

\section{Number of centres: 1}

Setting: Department of Obstetrics and Gynecology, Ain Shams University, Nasr City, Cairo

Country: Egypt

Length of follow-up: not reported

Number of randomised participants: 60 (30 per group)

Age (range): 25 to 35 years

Inclusion criteria: women who underwent IVF/ICSI indicated for infertility associated with a male factor

Exclusion criteria: not reported

\begin{tabular}{ll}
\hline Interventions & Intervention: glyceryl trinitrate skin patches 5 mg daily for 2 weeks \\
- Control: participants did not receive the aforementioned drug
\end{tabular}

\section{Outcomes}

Primaries: pregnancy (we do not know the method used to establish pregnancy), implantation rate (number of implantations and pregnancies is equal, so we used this as the clinical pregnancy rate)

Secondary outcome: pulsatility index

Co-interventions: participants received the long protocol of controlled ovarian hyperstimulation. Luteal phase support was undertaken with progesterone suppositories (Cyclogest $400 \mathrm{mg}$ daily) starting on the day of oocyte retrieval and for 2 weeks after embryo transfer. Two to three good quality embryos were transferred for each woman.

$\begin{array}{ll}\text { Notes } & \text { Funding: not reported } \\ \text { Conflict of interest: not reported }\end{array}$


Protocol registry: not reported

Sample size calculation: not reported

Published currently only as an abstract

\section{Risk of bias}

\begin{tabular}{lll}
\hline Bias & Authors' judgement & Support for judgement \\
\hline $\begin{array}{ll}\text { Random sequence genera- } \\
\text { tion (selection bias) }\end{array}$ & Unclear risk & $\begin{array}{l}\text { Quote: "The subjects were divided randomly into two groups after embryo } \\
\text { transfer" }\end{array}$ \\
& & Comment: methods not adequately described
\end{tabular}

\begin{tabular}{|c|c|c|}
\hline $\begin{array}{l}\text { Allocation concealment } \\
\text { (selection bias) }\end{array}$ & Unclear risk & $\begin{array}{l}\text { Quote: "The subjects were divided randomly into two groups after embryo } \\
\text { transfer" }\end{array}$ \\
\hline & & Comment: methods not adequately described \\
\hline
\end{tabular}

Blinding of participants Unclear risk Comment: methods not adequately described
and personnel (perfor-
mance bias)
All outcomes

Blinding of outcome as- Unclear risk Comment: methods not adequately described
sessment (detection bias)

All outcomes

Incomplete outcome data Unclear risk Comment: methods not adequately described
(attrition bias)

All outcomes

Selective reporting (re- Unclear risk Comment: methods not adequately described
porting bias)
porting bias)

Other bias Unclear risk Comment: methods not adequately described

Ohl 2002

\begin{tabular}{ll}
\hline Methods $\quad$ Randomised multi-centre double-blinded placebo-controlled trial \\
\hline
\end{tabular}

Participants Number of centres: 3

Setting: Hospital Gynecology and Obstetric Services

Country: France

Length of follow-up: not reported

Number of randomised participants: 138 (70 in intervention group, 68 in control group)

Age (mean and SD): 25 to 35 years

Inclusion criteria: women with a history of 2 or more previous implantation failures

Exclusion criteria: hypersensitivity to nitric oxide donors; heart failure; severe anaemia; high intracranial blood pressure; high intraocular blood pressure 
Ohl 2002 (Continued)

Interventions

- Intervention: $5 \mathrm{mg}$ glyceryl trinitrate (GTN) patch applied once daily, beginning the morning of the day before transfer, just after transvaginal ultrasonography and colour doppler were performed

- Control: placebo

Outcomes

Primary outcome: clinical pregnancy

Secondary outcomes: newborn (equivalent "live birth"), multiple gestation or birth, spontaneous abortion/miscarriage, ectopic pregnancy, vasodilator side effects

Co-interventions: both groups received GnRH agonist long protocol daily SC (continued up to the day when hCG was administered) + recombinant FSH + 5000 IU hCG + ICSI or conventional in vitro fertilisation + embryo transfer (embryos were transferred 2 or 3 days after oocyte retrieval)

\section{Funding: not reported}

\section{Conflict of interest: not reported}

Protocol registry: not reported

Sample size calculation: yes. A total sample of 288 patients was calculated (144 placebo and 144 NTG) in a unilateral test at the 5\% significance level with $80 \%$ power. In January 2000, whereas 164 out of 288 patients were enrolled in the study, placebo as well as NTG patches became out of date. New patches were not affordable. A new power calculation showed $53 \%$ in a unilateral test at the $5 \%$ significance level.

\section{Risk of bias}

\begin{tabular}{lll}
\hline Bias & Authors' judgement & Support for judgement \\
\hline $\begin{array}{l}\text { Random sequence genera- } \\
\text { tion (selection bias) }\end{array}$ & Low risk & $\begin{array}{l}\text { Comment: investigators describe a random component in the sequence gen- } \\
\text { eration process. Randomisation was performed with the use of } 4 \text { randomly } \\
\text { permuted blocks and was stratified by centre. }\end{array}$ \\
\hline
\end{tabular}

\begin{tabular}{ll}
\hline $\begin{array}{l}\text { Allocation concealment } \\
\text { (selection bias) }\end{array}$ & Low risk
\end{tabular}

\begin{tabular}{|c|c|c|}
\hline $\begin{array}{l}\text { Blinding of participants } \\
\text { and personnel (perfor- } \\
\text { mance bias) } \\
\text { All outcomes }\end{array}$ & Low risk & Comment: double-blinded with the use of placebo \\
\hline $\begin{array}{l}\text { Blinding of outcome as- } \\
\text { sessment (detection bias) } \\
\text { All outcomes }\end{array}$ & Low risk & $\begin{array}{l}\text { Comment: not described, but main outcome measurement is not likely to be } \\
\text { influenced by lack of blinding }\end{array}$ \\
\hline $\begin{array}{l}\text { Incomplete outcome data } \\
\text { (attrition bias) } \\
\text { All outcomes }\end{array}$ & Low risk & $\begin{array}{l}\text { Comment: intention-to-treat analysis was performed in this study, but study } \\
\text { authors reported losses for transvaginal ultrasonography }\end{array}$ \\
\hline $\begin{array}{l}\text { Selective reporting (re- } \\
\text { porting bias) }\end{array}$ & Low risk & $\begin{array}{l}\text { Comment: study protocol is not available, but it is clear that published reports } \\
\text { include all expected outcomes, including those that were prespecified }\end{array}$ \\
\hline Other bias & Low risk & $\begin{array}{l}\text { Comment: groups were comparable for the variables described (age, body } \\
\text { mass index, years of infertility, causes of infertility, number of previous preg- } \\
\text { nancy failures, basal FSH level, number of ICSI cycles, duration of stimulation, } \\
\text { oestradiol level on day of hCG, endometrial thickness, secretory change be- } \\
\text { tween day before and day of embryo transfer, pulsatility index) }\end{array}$ \\
\hline
\end{tabular}


Shaker 1993

Methods Double-blind study with random allocation

\section{Participants}

\section{Number of centres: 1}

Setting: University Department of Obstretics Gynecology, Glasgow

Country: UK

Length of follow-up: not reported

Number of randomised participants: 120 (intervention 60, placebo 60)

Age (mean and SD): not reported

Inclusion criteria: women having their first IVF/embryo transfer and accepted to participate

Exclusion criteria: not reported

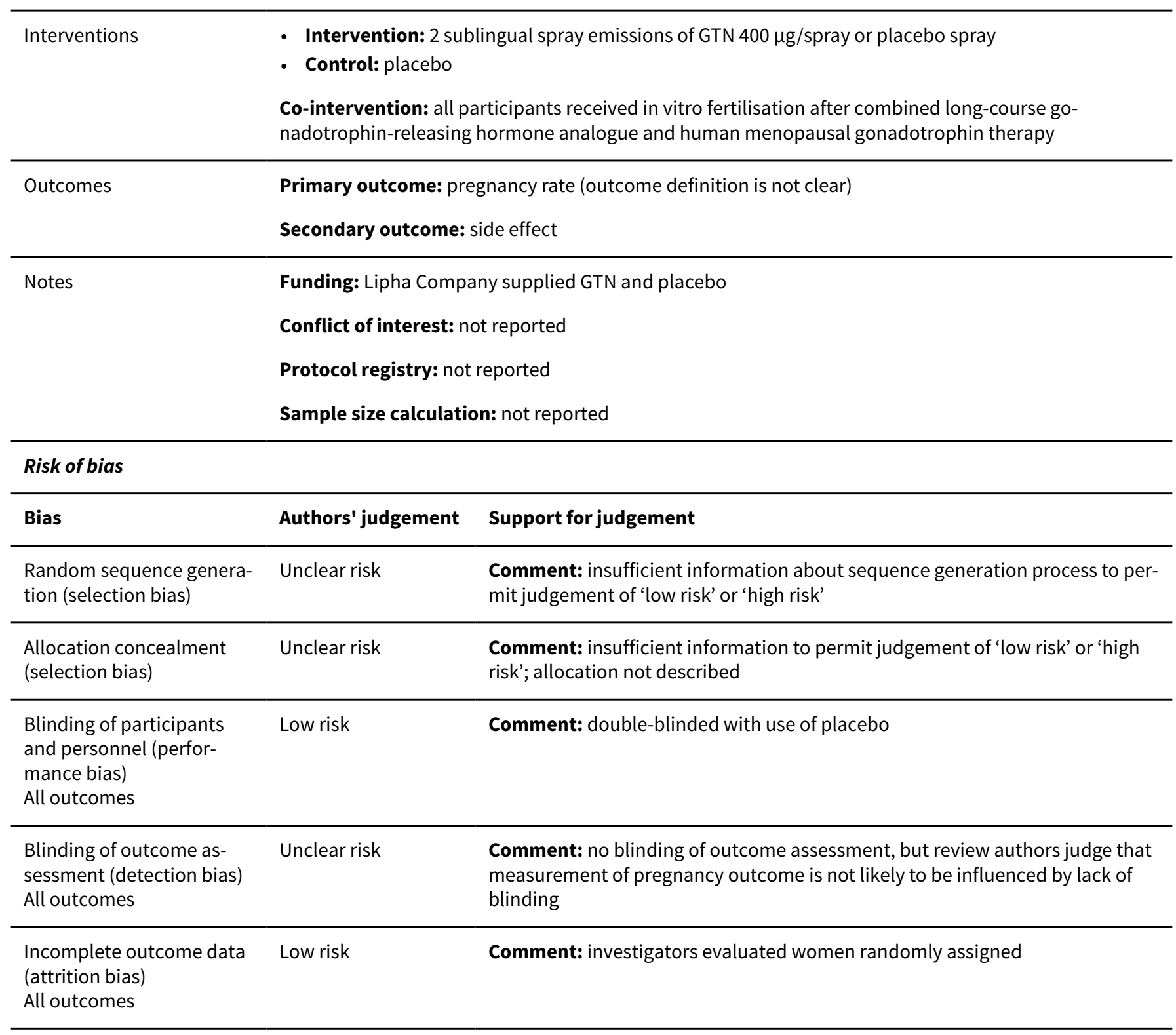


Shaker 1993 (Continued)

Selective reporting (reporting bias)

Low risk

Comment: study protocol is not available, but it is clear that published reports include all prespecified outcomes and some expected outcomes

Other bias

Low risk

Comment: 2 participant groups were comparable with respect to age, duration of infertility, and parity

Abbreviations:

BMI: body mass index.

CC: clomiphene citrate.

CD: cycle day.

ET: embryo transfer.

FSH: follicle-stimulating hormone.

$\mathrm{GnRH}$ : gonadotrophin-releasing hormone.

GTN: glyceryl trinitrate.

hCG: human chorionic gonadotrophin.

hMG: human menopausal gonadotrophin.

HSG: hysterosalpingography.

ICSI: intracytoplasmic sperm injection.

ICSI-ET: intracytoplasmic sperm injection - embryo transfer.

IMN: isosorbide mononitrate.

ISMN: isosorbide mononitrate.

IUI: intrauterine insemination.

IVF: in vitro fertilisation.

LH: luteinising hormone.

OHSS: ovarian hyperstimulation syndrome.

PCOS: polycystic ovary syndrome.

PI: pulsatility index.

PICO: population-intervention-comparison-outcome format.

PID: pelvic inflammatory disease.

SC: subcutaneous.

SD: standard deviation.

WHO: World Health Organization.

ZIFT: zygote intrafallopian transfer.

Characteristics of excluded studies [ordered by study ID]

Study Reason for exclusion

Alborzi 2007

Study used pentoxifylline as an immunomodulator for controlling endometriosis. As participants did not undergo AR, they were not of interest for this review.

Quote: "Randomization was carried out by asking each patient to choose a number from 1 to 60 . One of our nursing staff then put the even numbers in group I and the odd numbers in group II. After informed consent, patients in group I were allocated to receive sildenafil $50 \mathrm{mg} /$ day orally and those in group II were allocated to receive placebo"

Comment: allocation was done on the basis of a pseudo-random sequence

Balasch 1997

This study did not report participants of interest for this review. Not all underwent AR (the study description is that only 13/29 corrected additional infertility factors in PTX group and 11/27 corrected additional infertility factors in placebo group); pentoxifylline was used as an immunomodulator for controlling endometriosis.

Check 2004

Eliminated because this is not a parallel randomised controlled trial. In this study, some participants do cross over. Nine women were randomly assigned to vaginal sildenafil vs protocol in their first cycle, and 7 to vaginal oestradiol. Only 3 women in the vaginal sildenafil group completed both study arms. 


\begin{tabular}{ll}
\hline Study & Reason for exclusion \\
\hline Creus 2008 & $\begin{array}{l}\text { This study did not report participants of interest for this review. Only some participants un- } \\
\text { derwent insemination or ovulation induction, and investigators used pentoxifylline as an im- } \\
\text { munomodulator to control endometriosis. }\end{array}$ \\
\hline Kamencic 2008 & Study did not report participants or outcomes of interest for this review. \\
\hline Malinova 2013 & $\begin{array}{l}\text { Study did not report outcomes of interest for this review. Time frame was too short for investiga- } \\
\text { tor to evaluate outcomes. }\end{array}$ \\
\hline Raine-Fenning 2009 & Eliminated because it is not a parallel randomised controlled trial but is rather a cross-over study \\
\hline Rosen 1987 & $\begin{array}{l}\text { Study reported no comparisons of interest for this review. Study compared 0.7\% isoflurane + ni- } \\
\text { trous oxide vs } 1.4 \% \text { isoflurane + nitrous oxide. }\end{array}$ \\
\hline Sher 2000 & $\begin{array}{l}\text { Eliminated because this is not a parallel randomised controlled trial but is rather anobservational } \\
\text { study including 4 participants }\end{array}$ \\
\hline Shin 2002 & $\begin{array}{l}\text { Eliminated because this isnot a parallel randomised controlled trial but is rather a controlled clin- } \\
\text { ical trial }\end{array}$ \\
\hline
\end{tabular}

AR: assisted reproduction.

PTX: pentoxifylline.

Characteristics of studies awaiting assessment [ordered by study ID]

Casper 2013

\begin{tabular}{ll}
\hline Methods & Randomised parallel double-blind controlled trial \\
\hline Participants & Women 21 to 40 years of age with intact normal ovaries, early follicular phase (2 days)
\end{tabular}

\begin{tabular}{ll}
\hline Interventions & Experimental group: nimodipine $30 \mathrm{mg}$ tablets will be self-administered by participants every 6 \\
hours starting on the day that the ultrasound criterion for $\mathrm{hCG}$ triggering is met
\end{tabular}

Outcomes Primary outcome measures: delay in LH surge by at least 2 days

Secondary outcome measures: side effect profile of nimodipine or placebo

Notes Starting date: July 2012

Penzias 2012

\begin{tabular}{ll}
\hline Methods & Randomised parallel double-blind controlled trial \\
\hline Participants & $\begin{array}{l}\text { Women } 25 \text { to } 40 \text { years of age at time of enrolment, with both ovaries intact by history and ultra- } \\
\text { sound assessment early follicular phase }\end{array}$ \\
\hline Interventions & $\begin{array}{l}\text { Experimental group: nimodipine } 30 \mathrm{mg} \text { liquid oral, } 4 \text { times a day for } 8 \text { total doses in prefilled sy- } \\
\text { ringes }\end{array}$
\end{tabular}

Outcomes Primary outcome measures: delay in LH surge


Penzias 2012 (Continued)

Secondary outcome measures: side effect profile of nimodipine, clinical pregnancy (positive pregnancy test and ultrasound evidence of foetal heart rate)

Notes

Starting date: September 2012

hCG: human chorionic gonadotrophin.

LH: luteinising hormone.

Characteristics of ongoing studies [ordered by study ID]

\section{NCT02072291}

\begin{tabular}{ll}
\hline Trial name or title & Nifedipine treatment on uterine contractility in in vitro fertilisation \\
\hline Methods & Randomised parallel double-blind controlled trial \\
\hline Participants & Women 18 to 45 years of age undergoing frozen embryo transfer \\
\hline Interventions & Experimental group: nifedipine $5 \mathrm{mg}$ single dose \\
& Control group: placebo \\
\hline
\end{tabular}

Outcomes Primary outcome measures: uterine contractility after treatment (time frame 30 minutes after treatment) (designated as safety issue: no)

Secondary outcome measures: implantation and pregnancy rates (time frame 4 weeks) (designated as safety issue: no)

\begin{tabular}{ll}
\hline Starting date & 24 February 2014 \\
\hline Contact information & Assaf Ben-Meir, MD; 972-2-6776425; assaf.benmeir@gmail.com \\
\hline Notes & $\begin{array}{l}\text { We wrote to the study author, and he mentioned: "The study is still under recruitment so I don't } \\
\text { have final results. Hopefully soon". }\end{array}$ \\
\hline
\end{tabular}

DATA AND ANALYSES

Comparison 1. Vasodilator vs placebo or no treatment

\begin{tabular}{lllll}
\hline Outcome or subgroup title & No. of studies & $\begin{array}{l}\text { No. of partici- } \\
\text { pants }\end{array}$ & Statistical method & Effect size \\
\hline 1 Live birth & 3 & 350 & Risk Ratio (M-H, Fixed, 95\% Cl) & $1.18[0.83,1.69]$ \\
\hline $\begin{array}{l}1.1 \text { Glyceryl trinitrate (GTN) vs } \\
\text { placebo }\end{array}$ & 2 & 238 & Risk Ratio (M-H, Fixed, 95\% Cl) & $1.09[0.69,1.72]$ \\
\hline $\begin{array}{lllll}1.2 \text { PTX vitamin E vs no treatment } \\
2 \text { Vasodilator side effects }\end{array}$ & 1 & 112 & Risk Ratio (M-H, Fixed, 95\% Cl) & $1.36[0.76,2.43]$ \\
\hline $\begin{array}{l}2.1 \text { Glyceryl trinitrate (GTN) vs } \\
\text { placebo }\end{array}$ & 2 & 418 & Risk Ratio (M-H, Fixed, 95\% Cl) & $2.35[1.51,3.66]$ \\
\hline
\end{tabular}




\begin{tabular}{|c|c|c|c|c|}
\hline Outcome or subgroup title & No. of studies & $\begin{array}{l}\text { No. of partici- } \\
\text { pants }\end{array}$ & Statistical method & Effect size \\
\hline $\begin{array}{l}2.2 \text { Sildenafil vs placebo or no } \\
\text { treatment }\end{array}$ & 1 & 70 & Risk Ratio (M-H, Fixed, 95\% Cl) & $1.88[0.91,3.85]$ \\
\hline $\begin{array}{l}2.3 \text { Isosorbid mononitrate vs } \\
\text { placebo }\end{array}$ & 1 & 90 & Risk Ratio (M-H, Fixed, 95\% Cl) & $3.3[1.44,7.58]$ \\
\hline 3 Specific vasodilator side effects & 2 & & Risk Ratio (M-H, Fixed, 95\% Cl) & Subtotals only \\
\hline 3.1 Hypotension & 1 & 90 & Risk Ratio (M-H, Fixed, 95\% Cl) & $1.11[0.58,2.14]$ \\
\hline 3.2 Headache & 2 & 160 & Risk Ratio (M-H, Fixed, 95\% Cl) & $4.12[1.87,9.06]$ \\
\hline 3.3 Tachycardia & 1 & 90 & Risk Ratio (M-H, Fixed, 95\% Cl) & $3.83[1.25,11.75]$ \\
\hline 3.4 Dizziness & 1 & 90 & Risk Ratio (M-H, Fixed, 95\% Cl) & $1.57[0.76,3.26]$ \\
\hline 3.5 Hot flushes & 2 & 160 & Risk Ratio (M-H, Fixed, 95\% Cl) & $2.40[0.96,5.99]$ \\
\hline 4 Clinical pregnancy & 11 & 1054 & Risk Ratio (M-H, Fixed, 95\% Cl) & $1.45[1.19,1.77]$ \\
\hline $\begin{array}{l}\text { 4.1 Glyceryl trinitrate (GTN) vs } \\
\text { placebo or no treatment }\end{array}$ & 4 & 418 & Risk Ratio (M-H, Fixed, 95\% Cl) & $1.07[0.80,1.43]$ \\
\hline $\begin{array}{l}4.2 \text { Sildenafil vs placebo or no } \\
\text { treatment }\end{array}$ & 2 & 139 & Risk Ratio (M-H, Fixed, 95\% Cl) & $1.47[0.68,3.20]$ \\
\hline $\begin{array}{l}4.3 \text { Sildenafil + oestrogen vs no } \\
\text { treatment }\end{array}$ & 1 & 48 & Risk Ratio (M-H, Fixed, 95\% Cl) & $1.84[0.84,4.01]$ \\
\hline $\begin{array}{l}\text { 4.4 PTX + vitamin E vs no treat- } \\
\text { ment }\end{array}$ & 1 & 112 & Risk Ratio (M-H, Fixed, 95\% Cl) & $1.45[0.98,2.16]$ \\
\hline 4.5 Amlodipine vs placebo & 1 & 60 & Risk Ratio (M-H, Fixed, 95\% Cl) & $3.67[1.14,11.84]$ \\
\hline $\begin{array}{l}4.6 \text { Isosorbide mononitrate vs } \\
\text { placebo }\end{array}$ & 1 & 120 & Risk Ratio (M-H, Fixed, 95\% Cl) & $2.8[1.08,7.29]$ \\
\hline 4.7 Tadalafil vs no treatment & 1 & 157 & Risk Ratio (M-H, Fixed, 95\% Cl) & $2.08[1.12,3.86]$ \\
\hline 5 Thickened endometrium & 5 & 477 & $\begin{array}{l}\text { Mean Difference (IV, Random, } \\
95 \% \mathrm{CI} \text { ) }\end{array}$ & $2.11[1.16,3.07]$ \\
\hline $\begin{array}{l}5.1 \text { Isosorbid mononitrate vs } \\
\text { placebo }\end{array}$ & 2 & 210 & $\begin{array}{l}\text { Mean Difference (IV, Random, } \\
95 \% \mathrm{CI} \text { ) }\end{array}$ & $1.26[0.38,2.14]$ \\
\hline 5.2 Amlodipine vs placebo & 1 & 60 & $\begin{array}{l}\text { Mean Difference (IV, Random, } \\
95 \% \mathrm{CI} \text { ) }\end{array}$ & $1.80[0.66,2.94]$ \\
\hline $\begin{array}{l}5.3 \text { Sildenafil vs placebo or no } \\
\text { treatment }\end{array}$ & 1 & 50 & $\begin{array}{l}\text { Mean Difference (IV, Random, } \\
95 \% \mathrm{CI} \text { ) }\end{array}$ & $2.61[2.13,3.09]$ \\
\hline 5.4 Tadalafil vs no treatment & 1 & 157 & $\begin{array}{l}\text { Mean Difference (IV, Random, } \\
95 \% \mathrm{Cl} \text { ) }\end{array}$ & $3.57[3.01,4.13]$ \\
\hline 6 Other adverse effects & 4 & & Risk Ratio (M-H, Fixed, 95\% Cl) & Subtotals only \\
\hline
\end{tabular}




\begin{tabular}{lllll}
\hline Outcome or subgroup title & No. of studies & $\begin{array}{l}\text { No. of partici- } \\
\text { pants }\end{array}$ & Statistical method & Effect size \\
\hline $\begin{array}{l}\text { 6.1 Multiple gestation or birth: } \\
\text { NTG or isosorbide mononitrate vs } \\
\text { placebo and PTX + tocopherol vs } \\
\text { no treatment }\end{array}$ & 3 & 370 & Risk Ratio (M-H, Fixed, 95\% Cl) & $1.15[0.55,2.42]$ \\
\hline $\begin{array}{l}\text { 6.2 Spontaneous abortion/miscar- } \\
\text { riage NTG vs placebo and PTX+ to- } \\
\text { copherol vs no treatment }\end{array}$ & 3 & 350 & Risk Ratio (M-H, Fixed, 95\% Cl) & $0.83[0.37,1.86]$ \\
\hline $\begin{array}{l}\text { 6.3 Ectopic pregnancy: NTG vs } \\
\text { placebo and PTX + tocopherol vs } \\
\text { no treatment }\end{array}$ & 2 & 250 & Risk Ratio (M-H, Fixed, 95\% Cl) & $1.48[0.25,8.69]$ \\
\hline
\end{tabular}

Analysis 1.1. Comparison 1 Vasodilator vs placebo or no treatment, Outcome 1 Live birth.

\begin{tabular}{|c|c|c|c|c|c|}
\hline \multirow[t]{2}{*}{ Study or subgroup } & \multirow{2}{*}{$\begin{array}{c}\text { Vasodilator } \\
n / N\end{array}$} & $\begin{array}{c}\text { Placebo or } \\
\text { no treatment }\end{array}$ & \multirow{2}{*}{$\begin{array}{c}\text { Risk Ratio } \\
\text { M-H, Fixed, } 95 \% \mathrm{Cl} \\
\end{array}$} & \multirow[t]{2}{*}{ Weight } & \multirow{2}{*}{$\begin{array}{c}\text { Risk Ratio } \\
\text { M-H, Fixed, 95\% Cl }\end{array}$} \\
\hline & & $n / N$ & & & \\
\hline \multicolumn{3}{|c|}{ 1.1.1 Glyceryl trinitrate (GTN) vs placebo } & & & \\
\hline Farzi 2005 & $13 / 50$ & $9 / 50$ & & $21.81 \%$ & $1.44[0.68,3.07]$ \\
\hline Ohl 2002 & $17 / 70$ & $18 / 68$ & - & $44.26 \%$ & $0.92[0.52,1.63]$ \\
\hline Subtotal $(95 \% \mathrm{Cl})$ & 120 & 118 & & $66.07 \%$ & $1.09[0.69,1.72]$ \\
\hline \multicolumn{3}{|c|}{ Heterogeneity: $\operatorname{Tau}^{2}=0 ; \mathrm{Chi}^{2}=0.88, \mathrm{df}=1(\mathrm{P}=0.35) ; \mathrm{I}^{2}=0 \%$} & & & \\
\hline \multicolumn{3}{|c|}{ Test for overall effect: $Z=0.38(P=0.71)$} & & & \\
\hline \multicolumn{3}{|c|}{ 1.1.2 PTX vitamin E vs no treatment } & & & \\
\hline Aleyasin 2009 & $19 / 56$ & $14 / 56$ & & $33.93 \%$ & $1.36[0.76,2.43]$ \\
\hline Subtotal $(95 \% \mathrm{Cl})$ & 56 & 56 & & $33.93 \%$ & $1.36[0.76,2.43]$ \\
\hline \multicolumn{3}{|c|}{ Heterogeneity: Not applicable } & & & \\
\hline \multicolumn{3}{|c|}{ Test for overall effect: $Z=1.03(P=0.3)$} & & & \\
\hline Total $(95 \% \mathrm{Cl})$ & 176 & 174 & & $100 \%$ & $1.18[0.83,1.69]$ \\
\hline \multicolumn{4}{|c|}{ Total events: 49 (Vasodilator), 41 (Placebo or no treatment) } & & \\
\hline \multicolumn{4}{|c|}{ Heterogeneity: $\operatorname{Tau}^{2}=0 ; \mathrm{Chi}^{2}=1.24, \mathrm{df}=2(\mathrm{P}=0.54) ; \mathrm{I}^{2}=0 \%$} & & \\
\hline \multicolumn{3}{|c|}{ Test for overall effect: $Z=0.91(P=0.36)$} & & & \\
\hline \multicolumn{3}{|c|}{ Test for subgroup differences: $\mathrm{Chi}^{2}=0.33, \mathrm{df}=1(\mathrm{P}=0.56), \mathrm{I}^{2}=0 \%$} & & & \\
\hline
\end{tabular}

\section{Analysis 1.2. Comparison 1 Vasodilator vs placebo or no treatment, Outcome 2 Vasodilator side effects.}

\begin{tabular}{|c|c|c|c|c|c|}
\hline Study or subgroup & $\begin{array}{c}\text { Vasodilator } \\
\mathrm{n} / \mathrm{N} \\
\end{array}$ & $\begin{array}{c}\text { Placebo } \\
n / N\end{array}$ & $\begin{array}{c}\text { Risk Ratio } \\
\text { M-H, Fixed, 95\% CI }\end{array}$ & Weight & $\begin{array}{c}\text { Risk Ratio } \\
\text { M-H, Fixed, } 95 \% \mathrm{CI}\end{array}$ \\
\hline \multicolumn{6}{|c|}{ 1.2.1 Glyceryl trinitrate (GTN) vs placebo } \\
\hline Ohl 2002 & $0 / 70$ & $1 / 68$ & & $6.56 \%$ & $0.32[0.01,7.82]$ \\
\hline Shaker 1993 & $17 / 60$ & $7 / 60$ & & $30.19 \%$ & $2.43[1.09,5.43]$ \\
\hline
\end{tabular}




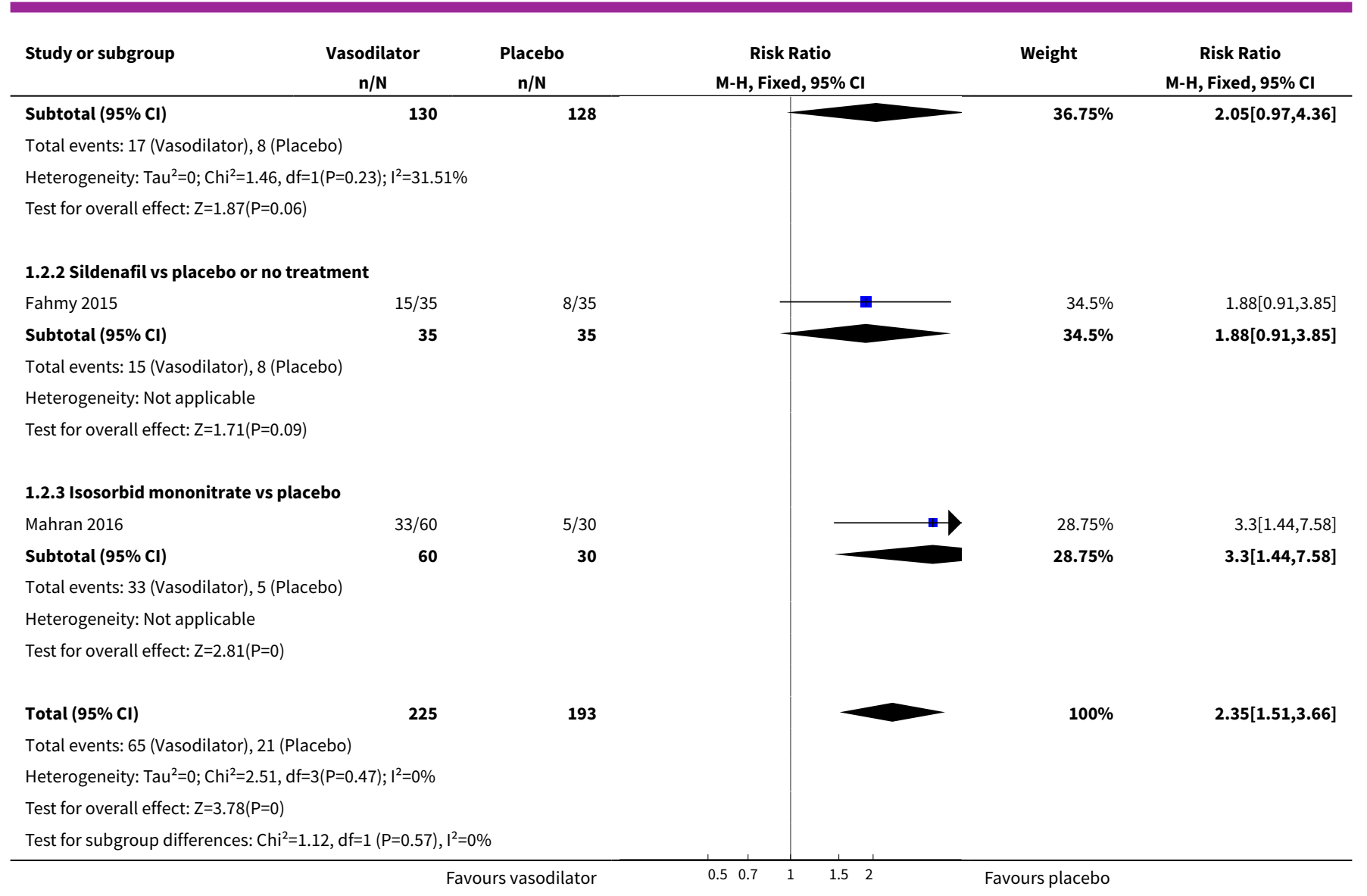

\section{Analysis 1.3. Comparison 1 Vasodilator vs placebo or no treatment, Outcome 3 Specific vasodilator side effects.}

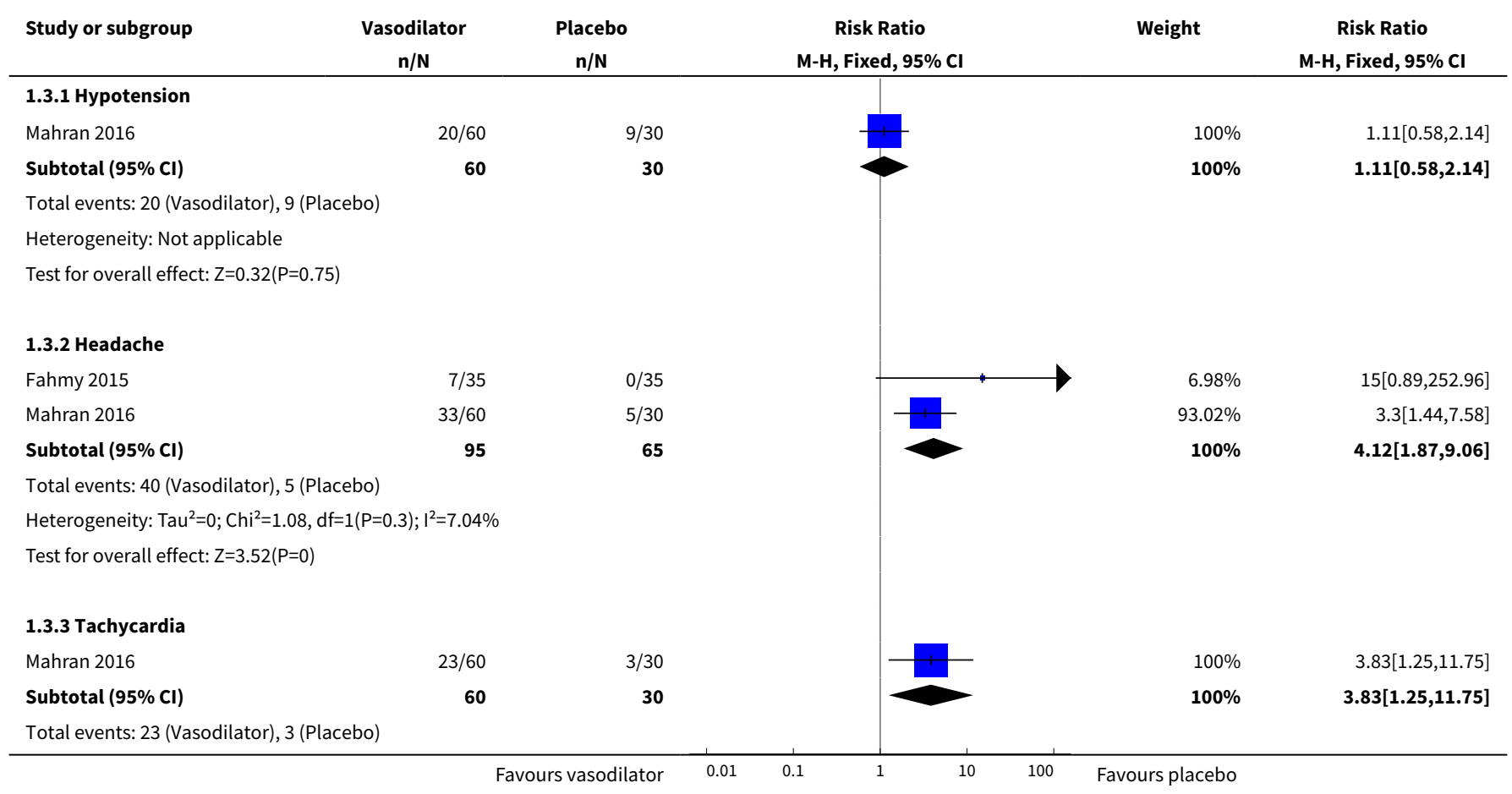




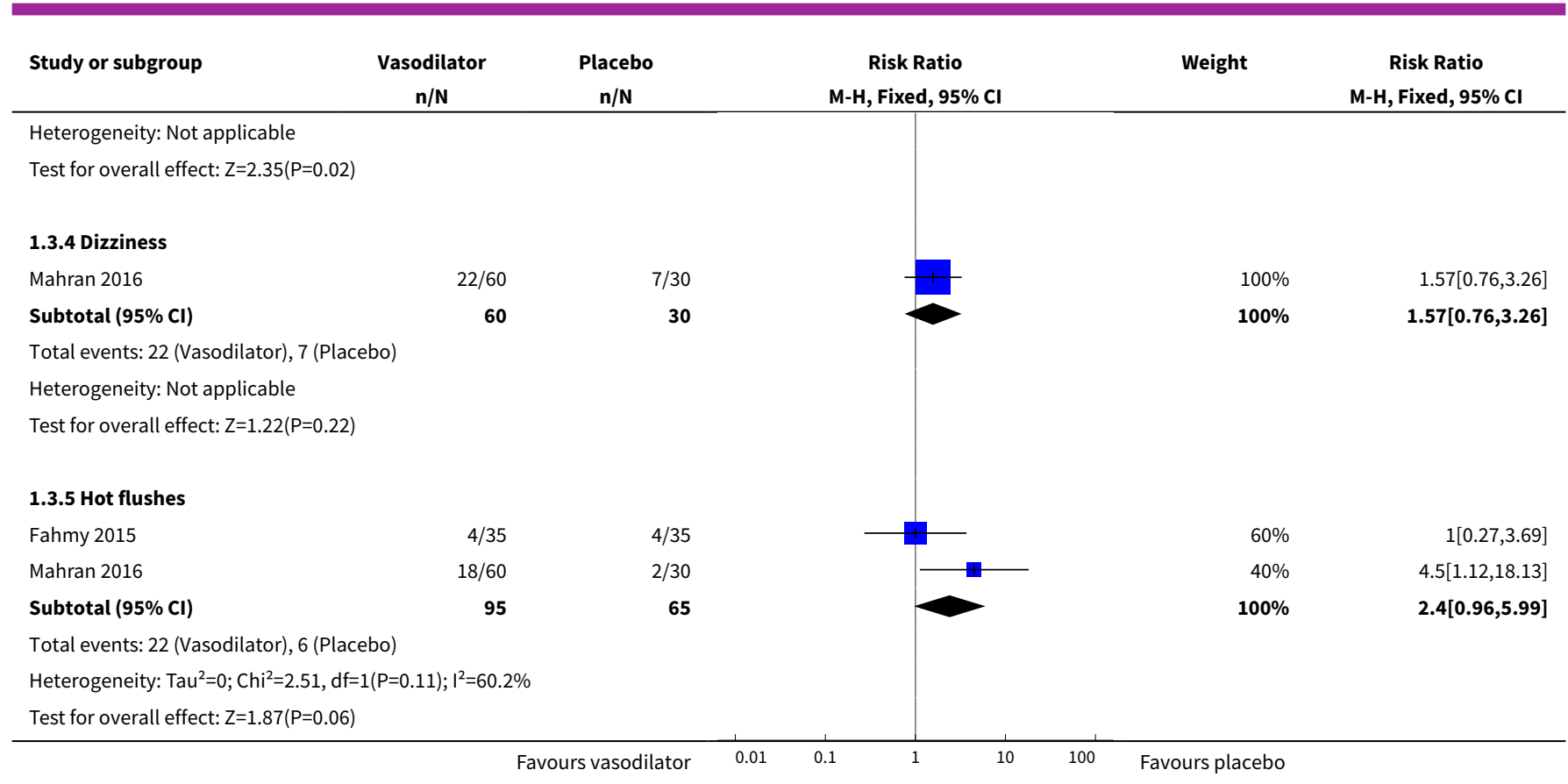

Analysis 1.4. Comparison 1 Vasodilator vs placebo or no treatment, Outcome 4 Clinical pregnancy.

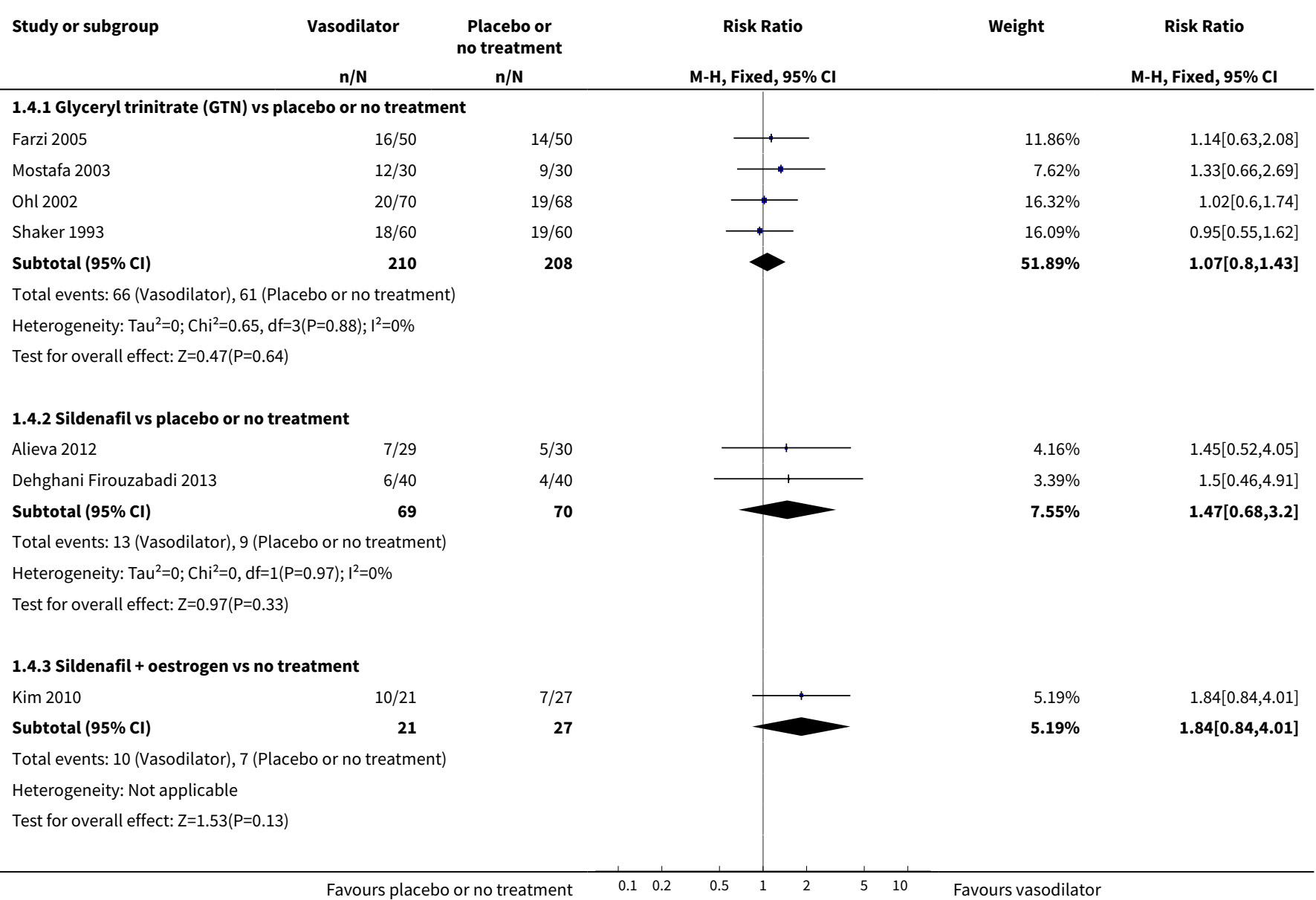




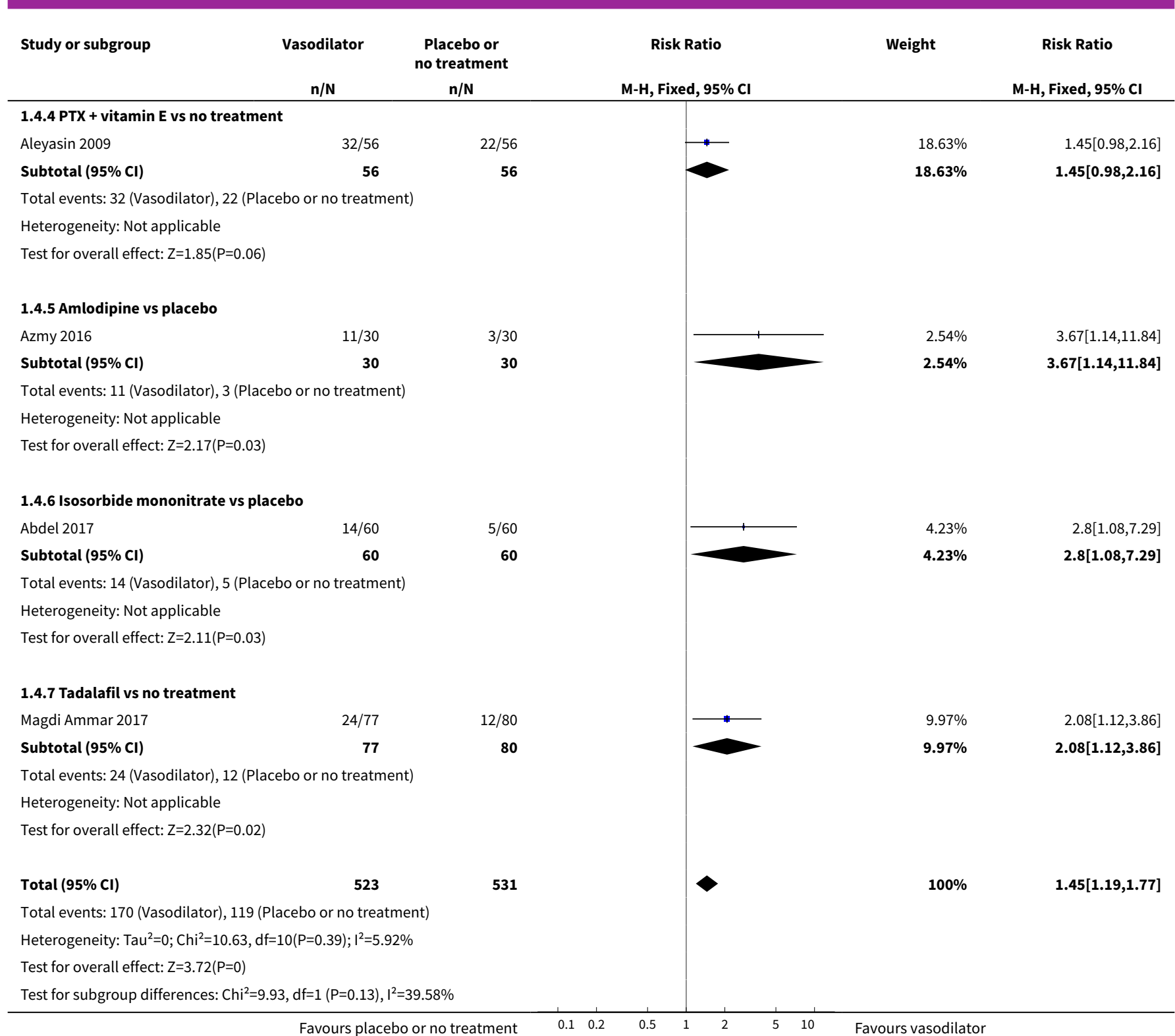

\section{Analysis 1.5. Comparison 1 Vasodilator vs placebo or no treatment, Outcome 5 Thickened endometrium.}

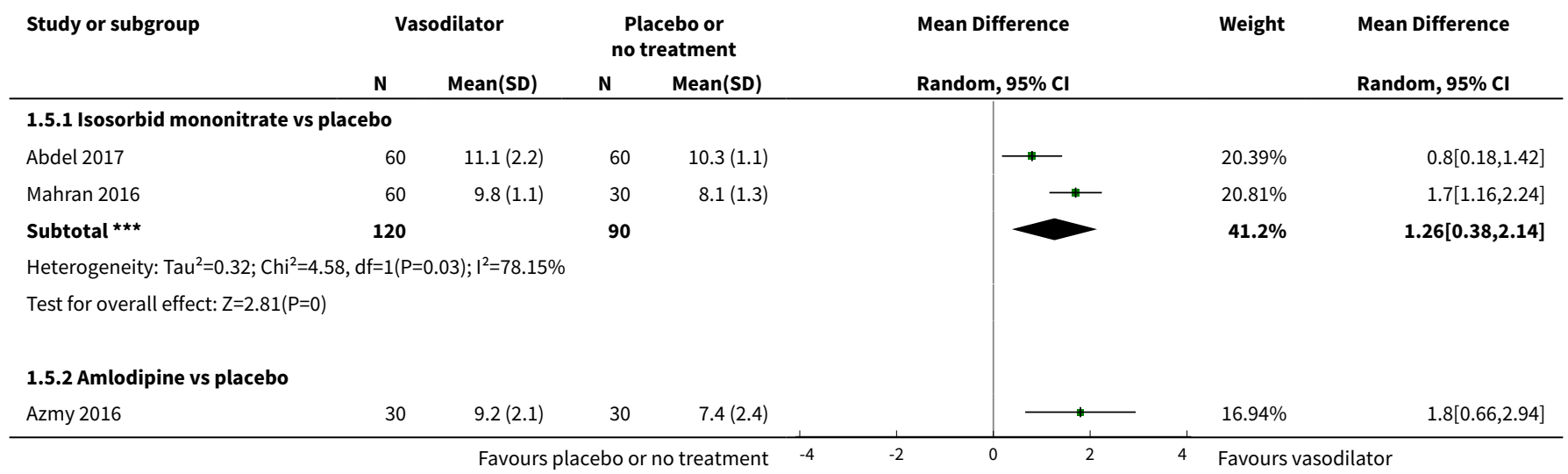




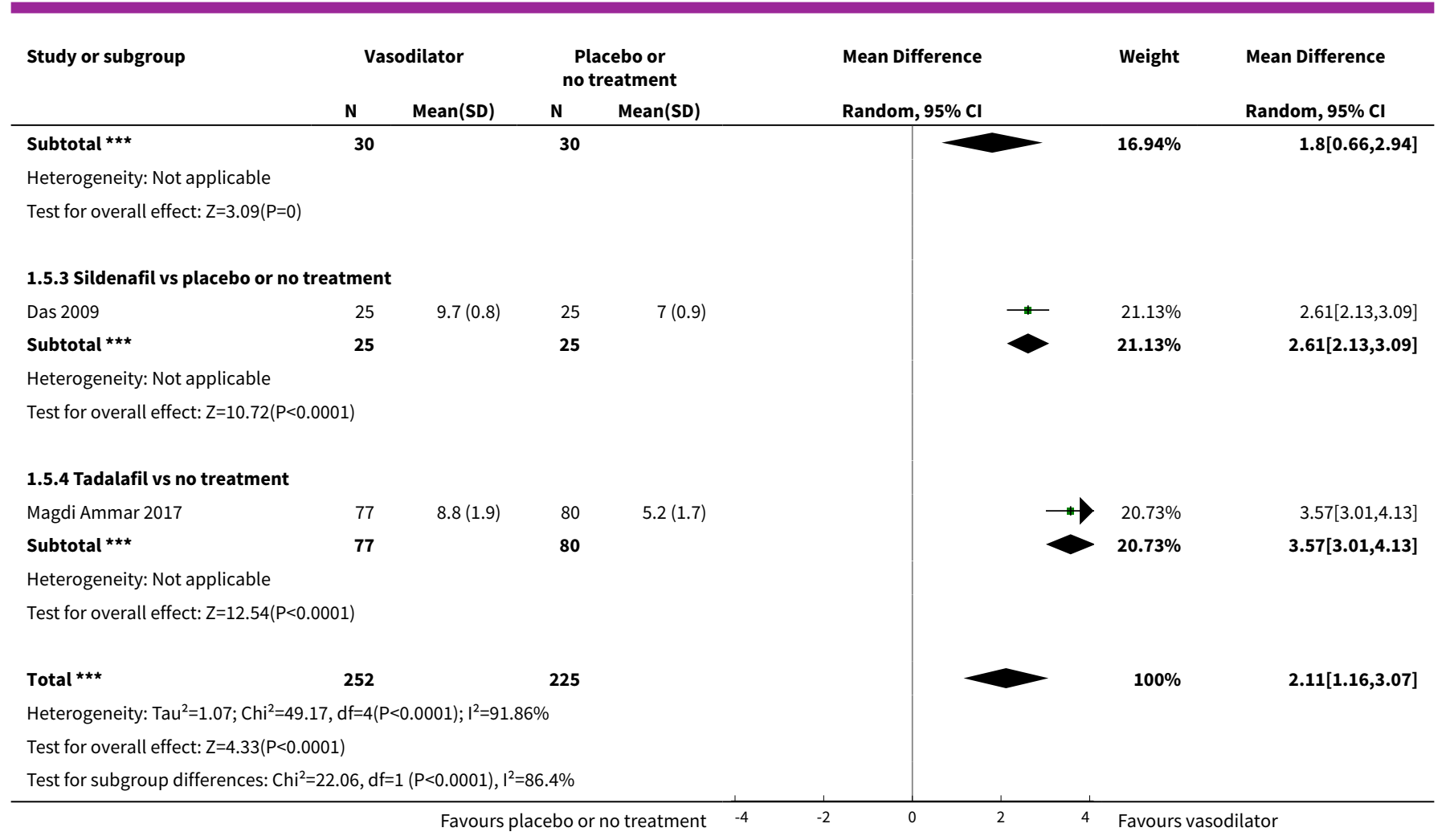

\section{Analysis 1.6. Comparison 1 Vasodilator vs placebo or no treatment, Outcome 6 Other adverse effects.}

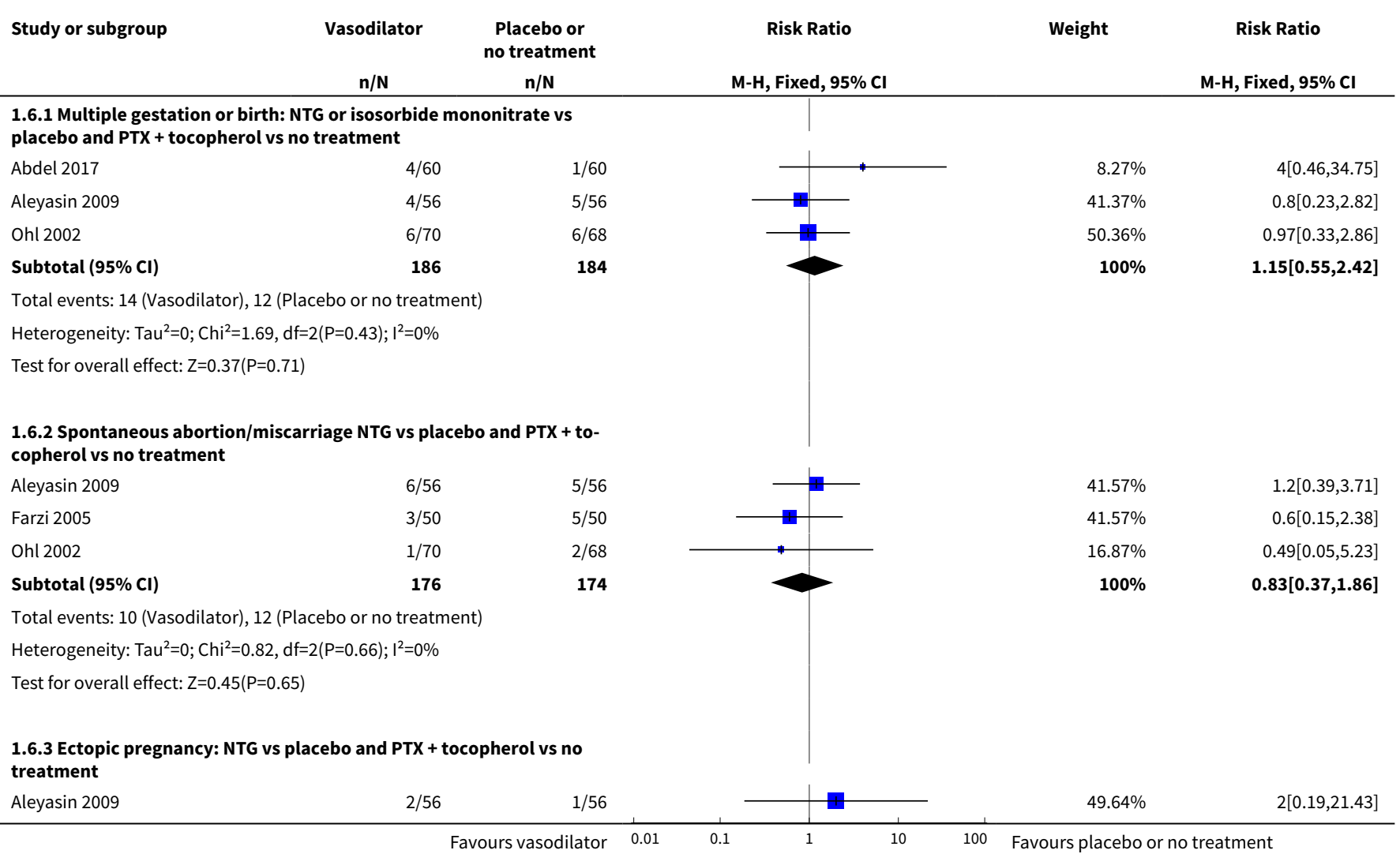




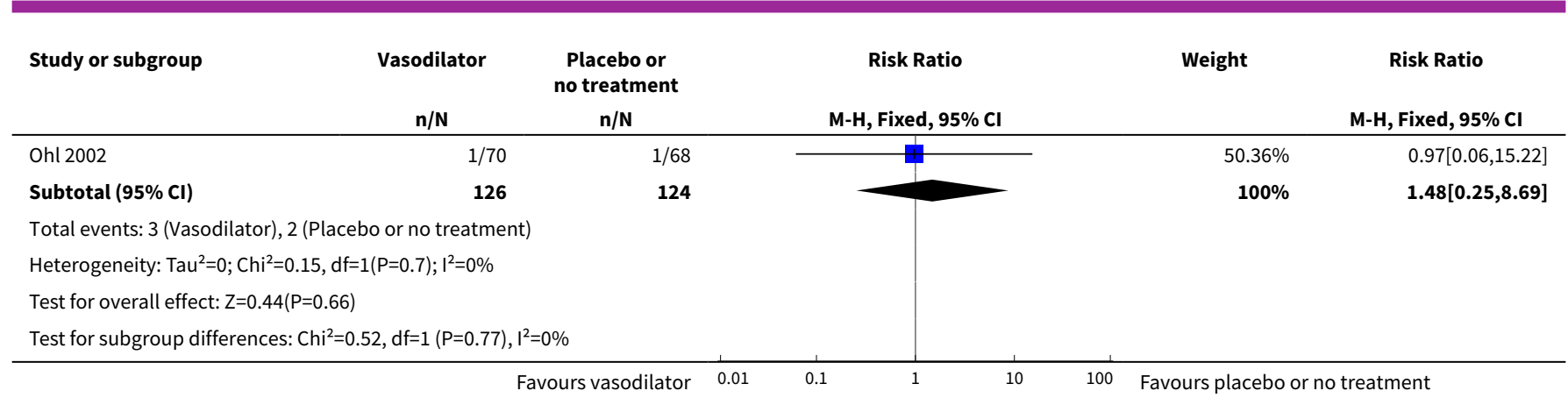

\section{APPENDICES}

\section{Appendix 1. Cochrane Gynaecology and Fertility Group (CGFG) specialised register search}

Searched 24 October 2017

PROCITE platform

Keywords CONTAINS "ART" or "assisted reproduction" or "assisted reproduction techniques" or "IVF" or "ICSI" or "in vitro fertilisation" or "in-vitro fertilisation techniques" or "in vitro fertilization" or "in vitro maturation" or "intracytoplasmic sperm injection" or "subfertility" or "Infertility" or "IUI" or "Intrauterine Insemination" or "^Embryo Transfer" or "ET" or "endometrial" or "endometrial vascularity" or "Endometrium" or "endometrium profile" or Title CONTAINS"ART" or "assisted reproduction" or "assisted reproduction techniques" or "IVF" or "ICSI" or "in vitro fertilisation" or "in-vitro fertilisation techniques" or "in vitro fertilization" or "in vitro maturation" or "intracytoplasmic sperm injection" or "subfertility" or "Infertility" or "IUI" or "Intrauterine Insemination" or "^Embryo Transfer" or "ET" or "endometrial" or "endometrial vascularity" or "Endometrium" or "endometrium profile "

AND

Keywords CONTAINS "vasodilation" or "Vasodilator Agents" or "Nifedipine" or"*Nitric Oxide" or "nitroglyceril" or "nitroglycerin" or "glycerine trinitrate" or "glyceryl trinitrate" or "Sildenafil" or "viagra" or "pentoxifylline" or "GTN" or Title CONTAINS "vasodilation" or "Vasodilator Agents" or "Nifedipine" or"*Nitric Oxide" or "nitroglyceril" or "nitroglycerin" or "glycerine trinitrate" or "glyceryl trinitrate" or "Sildenafil" or "viagra" or "pentoxifylline" or "GTN" (121 hits)

\section{Appendix 2. CENTRAL search strategy}

Searched 24 October 2017

Web platform

\#1 MESH DESCRIPTOR Embryo Transfer EXPLODE ALL TREES 967

\#2 MESH DESCRIPTOR Fertilization in Vitro EXPLODE ALL TREES 1861

\#3 MESH DESCRIPTOR Sperm Injections, Intracytoplasmic EXPLODE ALL TREES 481

\#4 (embryo* adj2 transfer*):TI,AB,KY 2454

\#5 (vitro fertili?ation):TI,AB,KY 2149

\#6 ivf:TI,AB,KY 3521

\#7 icsi:TI,AB,KY 1628

\#8 (intracytoplasmic sperm injection*):TI,AB,KY 1315

\#9 (blastocyst ${ }^{\star}$ adj2 transfer ${ }^{\star}$ ):TI,AB,KY 253

\#10 MESH DESCRIPTOR Reproductive Techniques, Assisted EXPLODE ALL TREES 2848

$\# 11$ (assisted reproduct $\left.{ }^{\star}\right): T I, A B, K Y 829$ 
\#12 (artificial insemination):TI,AB,KY 182

\#13 MESH DESCRIPTOR Insemination, Artificial EXPLODE ALL TREES 345

\#14 IUI:TI,AB,KY 550

\#15 (intrauterine insemination*):TI,AB,KY 714

\#16 (ovulation induc*):TI,AB,KY 1915

\#17 (ovar* adj2 stimulat ${ }^{\star}$ ):TI,AB,KY 1373

\#18 superovulat*:TI,AB,KY 176

\#19 (ovarian hyperstimulation):TI,AB,KY 950

\#20 COH:TI,AB,KY 247

\#21 infertil*:TI,AB,KY 4472

\#22 subfertil*:TI,AB,KY 598

\#23 (ovar* adj2 induction):TI,AB,KY 178

\#24 \#1 OR \#2 OR \#3 OR \#4 OR \#5 OR \#6 OR \#7 OR \#8 OR \#9 OR \#10 OR \#11 OR \#12 OR \#13 OR \#14 OR \#15 OR \#16 OR \#17 OR \#18 OR \#19 OR \#20 OR \#21 OR \#22 OR\#23 9284

\#25 endometrium:TI,AB,KY 2554

\#26 endometrial:TI,AB,KY 3556

\#27 \#25 OR \#26 4212

\#28 \#24 OR \#27 12417

\#29 MESH DESCRIPTOR Vasodilator Agents EXPLODE ALL TREES 21709

\#30 MESH DESCRIPTOR Nifedipine EXPLODE ALL TREES 1982

\#31 MESH DESCRIPTOR nitroglycerin EXPLODE ALL TREES 1713

\#32 MESH DESCRIPTOR Endothelium-Dependent Relaxing Factors EXPLODE ALL TREES 1711

\#33 MESH DESCRIPTOR Nitric Oxide EXPLODE ALL TREES 1705

\#34 MESH DESCRIPTOR Pentoxifylline EXPLODE ALL TREES 440

\#35 MESH DESCRIPTOR Nimodipine EXPLODE ALL TREES 216

\#36 vasodilator*:TI,AB,KY 6128

\#37 nifedipine:TI,AB,KY 3462

\#38 (glyceryl trinitrate or glyceryltrinitrate):TI,AB,KY 1504

\#39 (GTN or NTG):TI,AB,KY 876

\#40 nitroglycerin:TI,AB,KY 2754

\#41 (nitric oxide):TI,AB,KY 5189

\#42 nimodipine:TI,AB,KY 653

\#43 (isosorbide monohydrate or Isosorbide Mononitrate):TI,AB,KY 279

\#44 pentoxifylline:TI,AB,KY 926

\#45 sildenafil:TI,AB,KY 1182 
\#46 Viagra:TI,AB,KY 136

\#47 \#29 OR \#30 OR \#31 OR \#32 OR \#33 OR \#34 OR \#35 OR \#36 OR \#37 OR \#38 OR \#39 OR \#40 OR \#41 OR \#42 OR \#43 OR \#44 OR \#45 OR \#4630879

\#48 \#28 AND \#47 101

\section{Appendix 3. MEDLINE search strategy}

Searched from 1946 to 24 October 2017

Ovid platform

1 exp embryo transfer/ or exp fertilization in vitro/ or exp sperm injections, intracytoplasmic/ (40351)

2 embryo transfer\$.tw. (10959)

3 vitro fertili?ation.tw. (22214)

4 ivf-et.tw. (2469)

5 ivf.tw. (22183)

6 icsi.tw. (7351)

7 intracytoplasmic sperm injection\$.tw. (6445)

8 (blastocyst adj2 transfer\$).tw. (822)

9 exp reproductive techniques, assisted/ or exp insemination, artificial/ or exp ovulation induction/ (66621)

10 assisted reproduct\$.tw. (12915)

11 artificial insemination.tw. (6214)

12 iui.tw. (1657)

13 intrauterine insemination\$.tw. (2383)

14 ovulation induc\$.tw. (4249)

15 (ovari\$ adj2 stimulat\$).tw. (6492)

16 superovulat\$.tw. (3385)

17 ovarian hyperstimulation.tw. (4997)

18 COH.tw. (1563)

19 infertil\$.tw. (57074)

20 subfertil\$.tw. (4807)

21 (ovari\$ adj2 induction).tw. (280)

22 endometrium.tw. (26929)

23 endometrial.tw. (55007)

24 or/1-23 (189642)

25 exp vasodilator agents/ or exp nifedipine/ or exp nitroglycerin/ or exp endothelium-dependent relaxing factors/ or exp nitric oxide/ (430137)

26 exp Pentoxifylline/ (4260)

27 exp Nimodipine/ (2758)

28 vasodilator\$.tw. (36048)

29 nifedipine.tw. (20421)

30 (glyceryl trinitrate or glyceryltrinitrate).tw. (2532)

31 (GTN or NTG).tw. (4958)

32 nitroglycerin.tw. (10595)

33 nitric oxide.tw. (136969)

34 nimodipine.tw. (3970)

35 (isosorbide monohydrate or Isosorbide Mononitrate).tw. (380)

36 pentoxifylline.tw. (4417)

37 sildenafil.tw. (6158)

38 Viagra.tw. (1091)

39 or/25-38 (519322)

4024 and 39 (1497)

41 randomized controlled trial.pt. (497429)

42 controlled clinical trial.pt. (99269)

43 randomized.ab. (434012)

44 placebo.tw. (208217)

45 clinical trials as topic.sh. (195636)

46 randomly.ab. (299126)

47 trial.ti. (195999)

48 (crossover or cross-over or cross over).tw. (80875)

49 or/41-48 (1240559) 
50 exp animals/ not humans.sh. (4680511)

5149 not 50 (1143253)

5240 and 51 (115)

\section{Appendix 4. Embase search strategy}

Searched from 1980 to 24 October 2017

Ovid platform

1 exp embryo transfer/ or exp fertilization in vitro/ or exp intracytoplasmic sperm injection/ (58902)

2 embryo $\$$ transfer $\$$.tw. (18051)

3 in vitro fertili?ation.tw. (26605)

4 icsi.tw. (13920)

5 intracytoplasmic sperm injection\$.tw. (8391)

6 (blastocyst adj2 transfer\$).tw. (1933)

7 ivf.tw. (34828)

8 exp infertility therapy/ or exp artificial insemination/ or exp intrauterine insemination/ or exp ovulation induction/ (86522)

9 assisted reproduct\$.tw. (19022)

10 artificial insemination.tw. (5557)

11 iui.tw. (2804)

12 intrauterine insemination\$.tw. (3306)

13 ovulation induc $\$$.tw. (5219)

14 (ovari\$ adj2 stimulat\$).tw. (9678)

15 superovulat\$.tw. (3524)

16 ovarian hyperstimulation.tw. (6759)

17 COH.tw. (2126)

18 infertil\$.tw. (73043)

19 subfertil\$.tw. (6033)

20 (endometrium or endometrial).tw. (82219)

21 (ovari\$ adj2 induction).tw. (335)

22 or/1-21 (239111)

23 exp vasodilator agent/ (544768)

24 exp nifedipine/ (46662)

25 exp glyceryl trinitrate/ (35843)

26 exp Pentoxifylline/ (12593)

27 exp Nimodipine/ (9635)

28 nitroglycerin.tw. (11414)

29 exp nitric oxide/ (142551)

30 exp endothelium derived relaxing factor/ (4005)

31 vasodilator\$.tw. (41034)

32 nifedipine.tw. (22609)

33 (GTN or NTG).tw. (6429)

34 (glyceryl trinitrate\$ or glyceryltrinitrate\$).tw. (2869)

35 nitric oxide.tw. (162284)

36 nimodipine.tw. (4775)

37 (isosorbide monohydrate or Isosorbide Mononitrate).tw. (540)

38 pentoxifylline.tw. (5071)

39 sildenafil.tw. (8858)

40 Viagra.tw. (4223)

41 exp sildenafil/ (19077)

42 or/23-41 (626118)

4322 and 42 (2495)

44 Clinical Trial/ (953339)

45 Randomized Controlled Trial/ (475152)

46 exp randomization/ (76149)

47 Single Blind Procedure/ (29912)

48 Double Blind Procedure/ (141466)

49 Crossover Procedure/ (53656)

50 Placebo/ (301908)

51 Randomi?ed controlled trial\$.tw. (169788)

52 Rct.tw. (26090)

53 random allocation.tw. (1708) 
54 randomly allocated.tw. (28609)

55 allocated randomly.tw. (2279)

56 (allocated adj2 random).tw. (787)

57 Single blind\$.tw. (19980)

58 Double blind\$.tw. (176576)

59 ((treble or triple) adj blind\$).tw. (725)

60 placebo\$.tw. (257756)

61 prospective study/ (410882)

62 or/44-61 (1824183)

63 case study/ (50599)

64 case report.tw. (341442)

65 abstract report/ or letter/ (1014796)

66 or/63-65 (1398612)

6762 not 66 (1777862)

6843 and 67 (396)

\section{Appendix 5. PsycINFO search strategy}

Searched from 1806 to 24 October 2017

Ovid platform

1 exp reproductive technology/ (1654)

2 in vitro fertili?ation.tw. (672)

3 ivf-et.tw. (17)

4 (ivf or et).tw. (123274)

5 icsi.tw. (67)

6 intracytoplasmic sperm injection\$.tw. (50)

7 (blastocyst adj2 transfer\$).tw. (4)

8 assisted reproduct\$.tw. (819)

9 artificial insemination.tw. (243)

10 iui.tw. (31)

11 intrauterine insemination\$.tw. (23)

12 ovulation induc\$.tw. (27)

13 (ovari\$ adj2 stimulat\$).tw. (55)

14 ovarian hyperstimulation.tw. (11)

$15 \mathrm{COH} . t w$. (97)

16 superovulat\$.tw. (6)

17 infertil\$.tw. (3149)

18 subfertil\$.tw. (82)

19 (ovari\$ adj2 induction).tw. (7)

20 (endometrial or endometrium).tw. (353)

21 or/1-20 (127886)

22 exp vasodilator drugs/ (513)

23 (isosorbide monohydrate or Isosorbide Mononitrate).tw. (8)

24 pentoxifylline.tw. (74)

25 nifedipine.tw. (490)

26 nimodipine.tw. (449)

27 nitroglycerin.tw. (162)

28 exp Nitric Oxide/ (3354)

29 nitric oxide.tw. (5340)

30 vasodilator\$.tw. (620)

31 (GTN or NTG).tw. (164)

32 (glyceryl trinitrate or glyceryltrinitrate).tw. (93)

33 exp Sildenafil/ (305)

34 sildenafil.tw. (574)

35 Viagra.tw. (243)

36 or/22-35 (8088)

3721 and 36 (310)

38 random.tw. (51200)

39 control.tw. (395909)

40 double-blind.tw. (21045)

41 clinical trials/ (10626) 
42 placebo/ (4994)

43 exp Treatment/ (697142)

44 or/38-43 (1081717)

4537 and $44(122)$

\section{Appendix 6. CINAHL search strategy}

Searched from 1961 to 24 October 2017

Ebsco platform

\begin{tabular}{|c|c|c|}
\hline$\#$ & Query & Results \\
\hline S60 & S47 AND S59 & 41 \\
\hline S59 & $\begin{array}{l}\text { S48 OR S } 49 \text { OR S50 OR S51 OR S52 OR S53 OR S54 OR S55 OR S56 OR S57 OR } \\
\text { S58 }\end{array}$ & $1,170,446$ \\
\hline S58 & TX allocat ${ }^{\star}$ random* & 7,342 \\
\hline S57 & (MH "Quantitative Studies") & 16,570 \\
\hline S56 & (MH "Placebos") & 10,412 \\
\hline S55 & TX placebo* & 47,780 \\
\hline S54 & TX random* allocat* & 7,342 \\
\hline S53 & (MH "Random Assignment") & 44,365 \\
\hline S52 & $\mathrm{TX}$ randomi ${ }^{\star}$ control $^{\star}$ trial $^{\star}$ & 133,408 \\
\hline S51 & 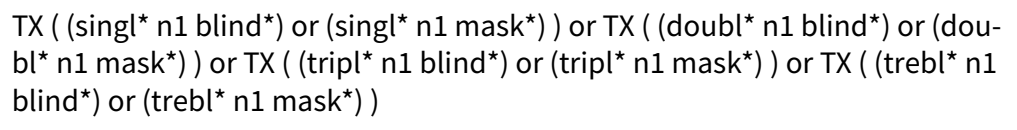 & 913,662 \\
\hline S50 & TX clinic $^{\star} \mathrm{n} 1$ trial $^{*}$ & 212,726 \\
\hline S49 & PT Clinical trial & 80,060 \\
\hline S48 & (MH "Clinical Trials+") & 223,465 \\
\hline S47 & S27 AND S46 & 113 \\
\hline S46 & $\begin{array}{l}\text { S28 OR S29 OR S } 30 \text { OR S } 31 \text { OR S } 32 \text { OR S } 33 \text { OR S } 34 \text { OR S35 OR S } 36 \text { OR S } 37 \text { OR } \\
\text { S38 OR S39 OR S40 OR S41 OR S42 OR S43 OR S44 OR S45 }\end{array}$ & 20,949 \\
\hline S45 & TX (isosorbide monohydrate or Isosorbide Mononitrate) & Display \\
\hline S44 & TX GTN or TX NTG & 440 \\
\hline S43 & TX glyceryltrinitrate & Display \\
\hline S42 & TX Nimodipine & 366 \\
\hline S41 & (MM "Nimodipine") & 136 \\
\hline
\end{tabular}


(Continued)

\begin{tabular}{lll} 
S40 & TX Pentoxifylline & Display \\
\hline S39 & (MM "Pentoxifylline") & 214 \\
\hline S38 & TX Viagra & 395 \\
\hline S36 & TX sildenafil & Display \\
\hline S35 & TX nitric oxide & 11,740 \\
\hline S34 & TX nitroglycerin & 1,599 \\
\hline S33 & TX glyceryl trinitrate & Display \\
\hline S32 & TX nifedipine & 1,027 \\
\hline S31 & TX vasodilator* & 5,440 \\
\hline S30 & (MM "Nitric Oxide") & Display \\
\hline S29 & (MM "Nitroglycerin") & 540 \\
\hline S28 & (MM "Nifedipine") & 350 \\
\hline S27 & (MM "Vasodilator Agents") & 1,817 \\
\hline S26 & S1 OR S2 OR S3 OR S4 OR S5 OR S6 OR S7 OR S8 OR S9 OR S10 OR S11 OR S12 & Display \\
\hline & OR S13 OR S14 OR S15 OR S16 OR S17 OR S18 OR S19 OR S20 OR S21 OR S22 & \\
\hline
\end{tabular}

WHAT'S NEW

\begin{tabular}{lll}
\hline Date & Event & Description \\
\hline 20 March 2018 & New search has been performed & $\begin{array}{l}\text { In this version, we have added 5 studies (Abdel 2017; Azmy 2016; } \\
\text { Fahmy 2015; Magdi Ammar 2017; Mahran 2016). }\end{array}$ \\
\hline 20 March 2018 & $\begin{array}{l}\text { New citation required but conclusions } \\
\text { have not changed }\end{array}$ & $\begin{array}{l}\text { The addition of } 5 \text { new studies has not led to a change in the con- } \\
\text { clusions of this review. }\end{array}$ \\
\hline
\end{tabular}

\section{CONTRIBUTIONS OFAUTHORS}

For the 2018 update:

RBG conceived of and designed the study; co-ordinated the whole review process; and participated in the search and in selection and assessment of studies. She completed data extraction activities; conducted the analysis; wrote the review; and approved the final version of the review.

XB conceived of the study; co-ordinated the whole review process; provided general advice on all processes; solved discrepancies; and approved the final version of the review. 
DG participated in study selection; provided general advice on study design; collaborated in the writing process of the review; and approved the final version of the review.

AV participated in study selection and assessment and data extraction; and approved the final version of the review.

FR participated in assessment and extraction of data; and approved the final version of the review actualisation.

MJM participated in assessment of potentially eligible studies; performed data analysis; collaborated in the writing process of the review; and approved the final version of the review.

\section{DECLARATIONS OF INTEREST}

The review authors declare that they have no conflicts of interest to report.

\section{SOURCES OF SUPPORT}

\section{Internal sources}

- CIBER de Epidemiología y Salud Pública (CIBERESP), Spain.

\section{External sources}

- Ford Foundation International Fellowships Program, USA.

RBG received a fellowship from the Ford Foundation International Fellowships Program

- Instituto de Salud Carlos III, Spain.

Dr. Ma José Martinez Zapata is funded by a Miguel Servet research contract from the Instituto de Salud Carlos III and European Social Fund (investing in Your Future) (CP15/00116)

\section{DIFFERENCES BETWEEN PROTOCOLANDREVIEW}

In this version, we added the word "safety" to the objectives.

In the previous version, review authors performed the analysis while applying a random-effects model; however for this update, review authors used a fixed-effect model because clinical and statistical heterogeneity between studies was minimal.

We did not perform a sensitivity analysis by calculating the odds ratio (OR), as the rate of events were common (>20\%) and in this case, the OR may overestimate the intervention effect.

We added a post hoc subgroup analysis to evaluate studies that used only vasodilators versus no co-intervention.

\section{INDEX TERMS}

\section{Medical Subject Headings (MeSH)}

*Pregnancy Rate; Embryo Implantation [ ${ }^{\star}$ drug effects]; Infertility, Female [^therapy]; Live Birth; Randomized Controlled Trials as Topic; Vasodilator Agents [ ${ }^{\star}$ therapeutic use]

\section{MeSH check words}

Female; Humans; Pregnancy 